\title{
Characterising the benthic Phormidium autumnale- dominated biofilm community and anatoxin production throughout biofilm succession
}

\author{
A thesis \\ submitted in partial fulfilment \\ of the requirements of the degree \\ of \\ Masters of Science in Ecology and Biodiversity \\ At \\ Victoria University of Wellington \\ By
}

\section{Katie Anne Brasell}

School of Biological Science

Victoria University of Wellington

New Zealand

2014 


\section{Abstract}

There has been an increase in the prevalence and intensity of Phormidium autumnale-dominated benthic blooms in New Zealand over the last decade. This species produces the potent neurotoxins Anatoxin-a, Homoanatoxin-a and their derivatives, and consumption of $P$. autumnale biofilms has led to over 70 dog deaths since 2005 . The mechanisms regulating the dominance and toxicity of P. autumnale are still unclear, as these blooms can reach high biomass in low nutrient conditions. Benthic biofilms are composed of multiple taxa and usually harbor a complex community of bacteria and other microbes, which can change over time and interact to facilitate biofilm development and metabolic processing. Prior to this thesis, the microbial composition of $P$. autumnale-dominated biofilms was unknown. This study provides insights into the relationships of this neurotoxic cyanobacterium with microbial components of the biofilm community.

Benthic biofilms were sampled every two to four days for 32 days from three sites in the Hutt River (Wellington) following a high flow event. A combination of microscopy and molecular techniques (bacterial ARISA and Illumina ${ }^{\mathrm{TM}}$ sequencing) were used to identify the micro-algal and bacterial components of the biofilm throughout its development. Variation in total anatoxin production was measured using LC-MS and changes in toxic $P$. autumnale cell numbers were quantified using QPCR. A suite of environmental variables (point velocity, depth, flow, conductivity, temperature and nutrients) were also monitored throughout the study period.

Three distinct phases of microbial succession were identified (early, mid and late) using nonmetric multidimensional cluster analyses. The micro-algal community composition (including $P$. autumnale) shifted from early to mid-phase ca. 16 days after the flushing flow and from mid to late phase at ca. day 30 . The ARISA and Illumina ${ }^{\mathrm{TM}}$ sequencing showed the bacterial community 
shifts occurred ca. 4 and 9 days before the respective micro-algal community shifts. These analyses indicate a close coupling of the micro-algal and bacterial communities and may suggest bacterial driven succession. However, bacteria are likely to depend on micro-algal by-products for nutrition from the mid-phases onward and assessment of the metabolic processes occurring within the biofilms is needed to clarify this.

Phormidium autumnale was dominant in the biofilm from an early stage in development and grew exponentially despite an influx of diatoms at day 20. None of the environmental parameters measured could explain the temporal variation in micro-algal and bacterial communities, which suggested that intrinsic rather than extrinsic factors were more important in regulating succession. This further supports the hypothesis that biofilm microbes may facilitate $P$. autumnale dominance.

There was a significant variation in anatoxins per cell over time $(p=0.034)$. Production of anatoxins was greatest in the mid-phase of succession $\left(208 \mathrm{fg} \mathrm{cell}^{-1}\right)$, coinciding with an increase in diatom biomass, which could implicate anatoxins as allelopathic chemicals that alleviate the effects of competition on $P$. autumnale. Changes in proportions of the different anatoxin variants produced over time also aligned with the three successional phases in both the micro-algal and bacterial communities, providing further evidence of a relationship between anatoxin production and microbial biofilm components.

Bacterial taxa of the Alphaproteobacteria were dominant within the early bacterial community, but were surpassed by the Betaproteobacteria and Flavobacteria in mid and late phases. Bacterial genera involved in exopolysaccharide production, alkaline phosphatase activity and biopolymer degradation were identified. These attributes are important in the formation, maintenance and break-down of biofilms and therefore strengthen the likelihood of linkages between the micro- 
algal and bacterial community. Further investigations into functional roles of the biofilm components are needed to infer relationships between $P$. autumnale and the bacterial community.

A clear pattern of microbial succession is described here and linkages between the micro-algal and bacterial communities are evident. Future work should focus on the functional attributes of microbes occurring at different stages of succession to further understand how $P$. autumnale dominates these benthic communities. 


\section{Acknowledgements}

This research project was possible thanks to the guidance and encouragement of many people and was conducted in collaboration with the Cawthron Institute.

First and foremost I would like to thank my supervisors, Dr. Ken Ryan (VUW) and Dr. Susie Wood (Cawthron), for their ongoing enthusiasm and support for this project. Thank you both for the helpful discussions, the proof reading and all the fantastic opportunities that have come out of this cyanobacteria work. I have thoroughly enjoyed being involved in the downstream applications of this research in freshwater management, as well as the opportunities to travel and meet some wonderful people. Special thanks also goes to Mark Heath for introducing and growing this area of research at Victoria University with the help of Susie and Ken, his work on Phormidium that began as an MSc project was what sparked my interest in this area - thanks for sharing your time and knowledge with me in the field, the lab and over many cups of coffee.

Collecting the immense amount of data for this project would not have been possible without the help of the many field assistants that accompanied me out to the Hutt River over the 32 days of field work. Mark Heath, Susie Wood, Ken Ryan, Ryan Hughes, Andrew Martin, Isidora Echenique-Subiabre, Jean-Françios Humbert, Catherine Quiblier, Mieke Walveart, Mum and Dad - thank you for your time and efforts no matter how big or small!

For statistical and IT assistance, I thank Dalice Simm (Dept. of Mathematics, Statistics and Computing, VUW), Stephen Hartley (Dept. of Biological Sciences, VUW), Eric Botts (Waikato University) and Craig Allen (Cawthron). 
I would also like to thank the network of technical support at from staff at Victoria University: Lesley Milicich, Sushila Pillai, Shaun Graham, Dez Tessler and Daniel McNaughtan for supply and maintenance of field and laboratory equipment. Additionally, I want to thank the Cawthron Institute and their ever-enthusiastic, helpful and inspirational team of scientist. I spent several week-long stints in Nelson using their facilities for most of my molecular laboratory work and joined their group at two Freshwater Science Society Conferences - they have always made me feel welcome and readily offered help when I needed it.

I would like to thank Victoria University for the support I received through the Master's by Thesis Scholarship, as well as the Masterton District Council for the Murray King Memorial Scholarship I received during the first year of my MSc. The Greater Wellington Regional Council has also provided support to my work through providing long term data from the Hutt River and involving me in focus group meetings and public forums on the issue of toxic cyanobacteria in the region.

Thank you to my parents, Joss and Vern, and my partner Ryan Hughes for all their love and support throughout my studies. Your unfading belief in me has been truly amazing.

Lastly, thanks to the many friends and colleagues that have been a part of my undergraduate and post-graduate journey for all the ways they have supported and inspired me. 


\section{Table of Contents}

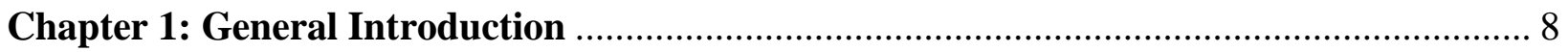

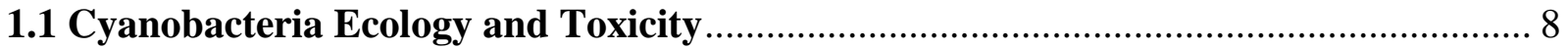

1.2 New Zealand Benthic Freshwater Cyanobacterial Blooms ........................................ 9

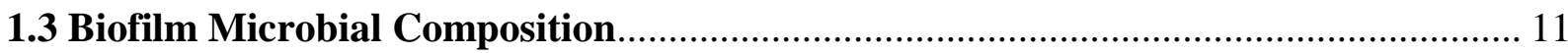

1.4 Characterising Microbial Communities.................................................................... 13

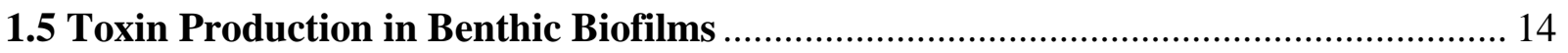

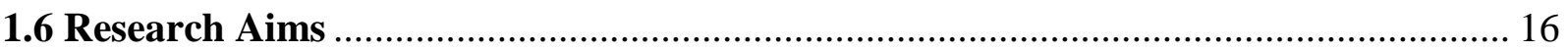

Chapter 2: Successional changes in microbial community composition of benthic

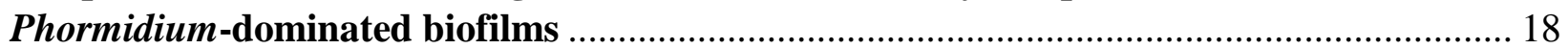

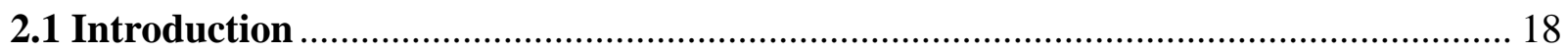

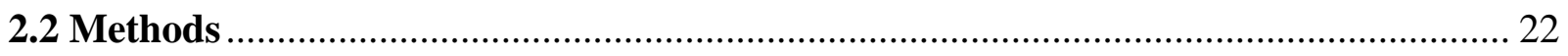

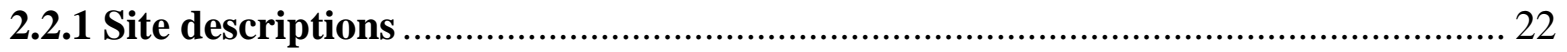

2.2.2 Experimental design and sampling ............................................................... 22

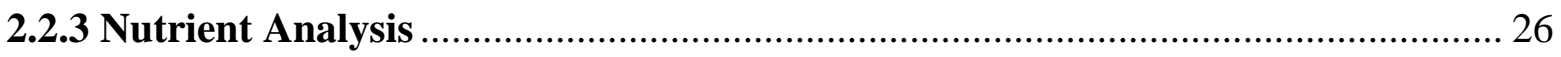

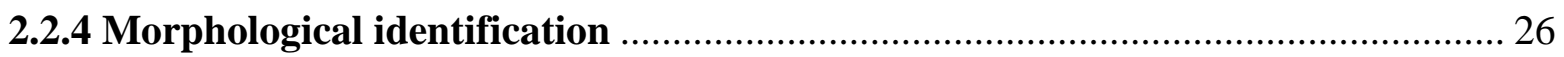

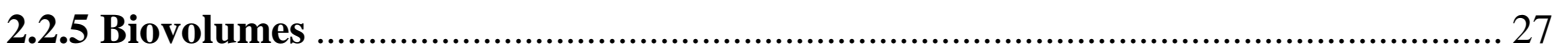

2.2.6 DNA extraction and Automated Ribosomal Intergenic Spacer Analysis (ARISA)

(A)

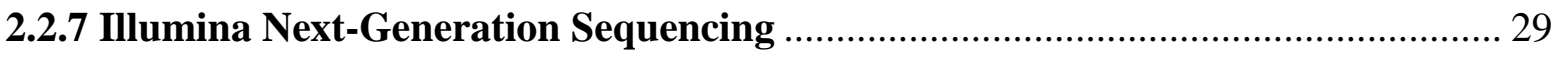

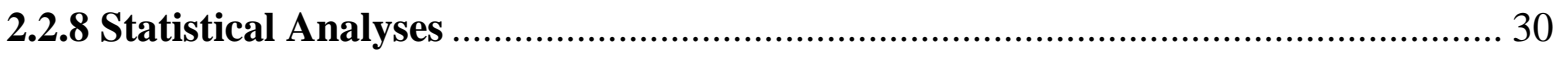

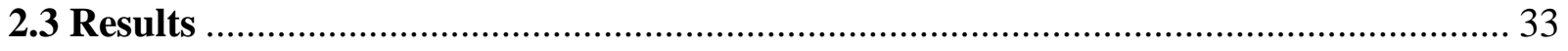

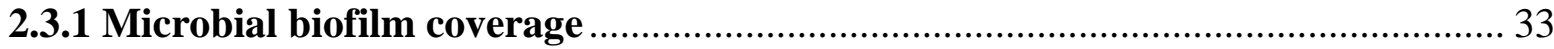

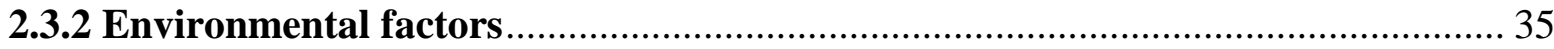

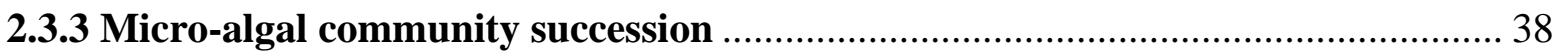

2.3.4 Automated Ribosomal Intergenic Spacer Analysis (ARISA) of bacterial community succession ..................................................................................................... 43

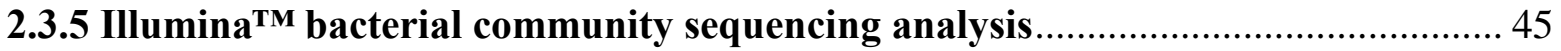

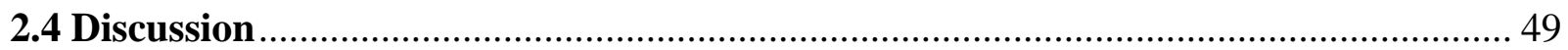

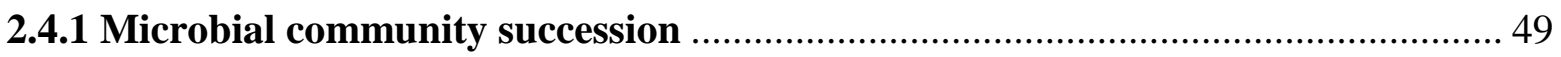

2.4.2 Environmental parameters ................................................................................... 52

2.4.3 Biofilm coverage …………………………..................................................... 56 


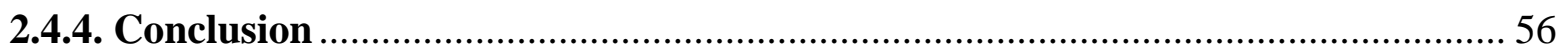

Chapter 3: Anatoxin production and variability during biofilm succession...................... 58

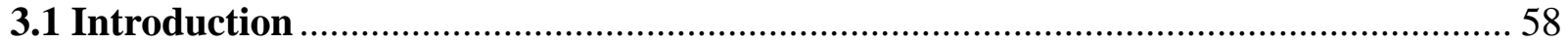

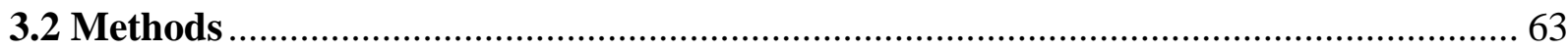

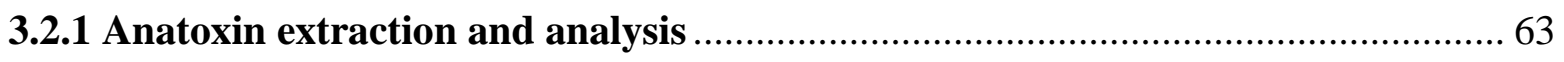

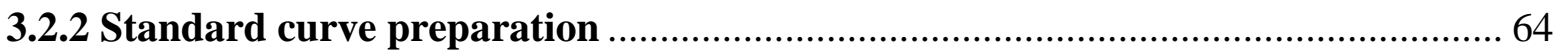

3.2.3 Quantitative Polymerase Chain Reaction (QPCR) Analysis ................................. 64

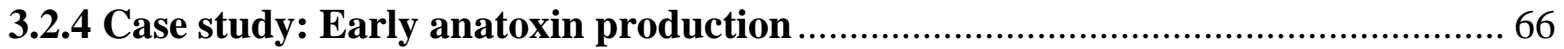

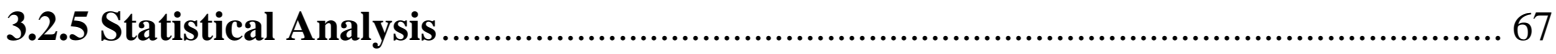

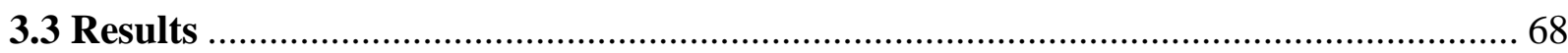

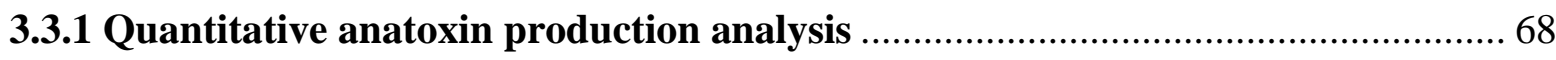

3.3.2 Early anatoxin production .................................................................................. 71

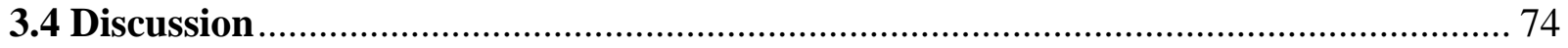

3.4.1 Anatoxin variability throughout Phormidium biofilm succession......................... 74

3.4.2 Quantitative analysis of anatoxin production ....................................................... 75

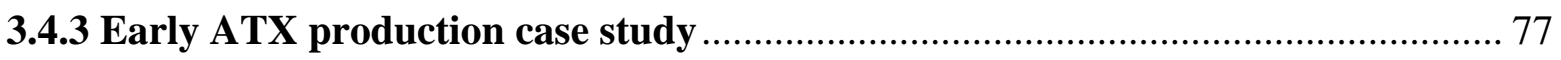

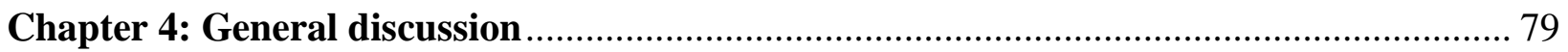

4.1 Microbial succession and relationships among biofilm components .......................... 80

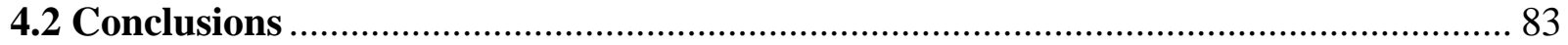

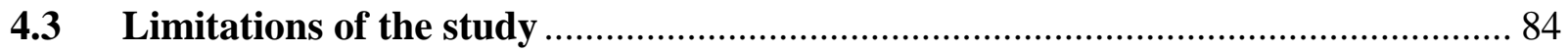

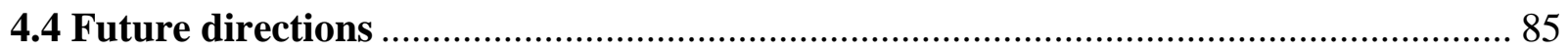

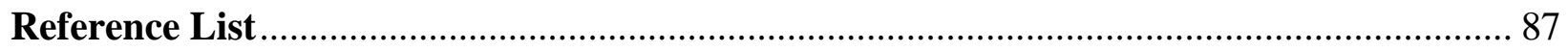

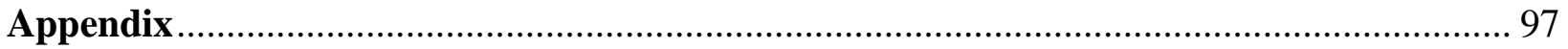




\section{Chapter 1: General Introduction}

\subsection{Cyanobacteria Ecology and Toxicity}

Cyanobacteria are prokaryotic organisms that can be uni- or multicellular. Most are aerobic photoautotrophs although some cyanobacteria may utilise heterotrophic nutrition (Chorus and Bartram, 1999). They are found worldwide in a range of environments, from extremely hot thermal pools to the dry valleys of Antarctica (Ward and Castenholz, 2002, Wood et al., 2008). Their ability to survive in extreme environments is testament to their evolutionary history. Cyanobacteria are believed to be the first photosynthetic organism on Earth, surviving in the volcanically heated oceans and hot springs of Earths' primitive environment (Chorus and Bartram, 1999).

Cyanobacteria produce a range of secondary metabolites, many of which are toxic to humans and other animals. Collectively these are known as cyanotoxins and they can be produced by both planktonic and benthic species. The health risks posed to humans and animals by toxic cyanobacteria are now recognised worldwide (Chorus and Bartram, 1999). When conditions are favourable (e.g., high temperatures and abundant nutrients), cyanobacterial blooms can form, and the toxins produced during these events can have severe impacts for aquatic organisms and human and animal users of these ecosystems. One of the most severe cases of human poisoning from cyanotoxins occurred in Brazil in 1996 when a hospital's water supply was contaminated with cyanotoxins, leading to the death of 52 renal dialysis patients (Azevedo et al., 2002). There have also been multiple cases of death or poisoning of domestic and wild animals after consumption of cyanobacteria. For example: In a Japanese lake, 20 ducks died of hepatotoxicity after a bloom of microcystin-producing Microcystis auriginosa. In an extreme case, 10,000 livestock died after a massive bloom of neurotoxic Anabeana circinalis occurred in the Darling river, Australia (Falconer, 1998). 
In contrast to the planktonic cyanobacteria, benthic species and their associated toxins are poorly studied, despite being linked to numerous animal deaths globally (Hamill, 2001, Mez et al., 1998, Gugger et al., 2005, Milne and Watts, 2007, Heath et al., 2011, Cadel-Six et al., 2007). Benthic cyanobacteria grow on bottom sediments and can form biofilms in both marine and freshwater environments. Biofilms can form on a range of substrate types, including sand, cobbles, bedrock, and submerged structures such as wharf piers. Globally, common genera that dominate benthic biofilms include Oscillatoria, Phormidium, Leptolyngbya and Tychonema (Quiblier et al., 2013). Toxin production and/or toxicosis from benthic cyanobacteria has been reported from France (Gugger et al., 2005), Spain (Hurtado et al., 2008), the Netherlands (Fiore et al., 2009), Switzerland (Mez et al., 1998), Scotland (Edwards et al., 1992), Ireland (James et al., 1997), USA (Izaguirre et al., 2007), Canada (Lajeunesse et al., 2012), Australia (Seifert et al., 2007), New Zealand (Wood et al., 2012a), Kenya (Krienitz et al., 2003), Egypt (Mohamed et al., 2006) and the Baltic sea (Surakka et al., 2005).

\subsection{New Zealand Benthic Freshwater Cyanobacterial Blooms}

In New Zealand, the occurrence of planktonic blooms has been recorded for many decades (Pridmore and Etheredge, 1987) and animal deaths linked to planktonic blooms have been reported from numerous water bodies across the country, including Lake Forsyth and Lake Ellesmere since the 1970's (Wood, 2004). The most common cyanobacteria found in New Zealand planktonic blooms are Microcystis spp. and Anabeana spp. (Wood et al., 2006). Microcystins (MC) are the most common cyanotoxin produced by the cyanobacteria forming these blooms, although other cyanotoxins, such as nodularin, cylindrospermopsin, anatoxin and saxitoxin, have also been detected from New Zealand planktonic blooms (Wood et al., 2006). Over the last decade there has been an apparent increase in the prevalence and intensity of benthic cyanobacterial blooms in New 
Zealand rivers (Milne and Watts, 2007, Wood and Young, 2012). This has largely been identified due to increased reports of dog deaths after consumption of benthic cyanobacterial material (Hamill, 2001, Wood et al., 2007). As a result, New Zealand is one of the first nations to undertake detailed research on the ecology of toxic benthic cyanobacteria.

The first report of dog neurotoxicosis in New Zealand after ingestion of benthic cyanobacteria was in 1998 (Hamill, 2001). The cyanobacteria responsible were identified as from the order Oscillatoriales. Subsequently, in 2005, five dogs died rapidly after visiting the Hutt River (Wellington, New Zealand). Analysis of stomach contents and cyanobacteria biofilms confirmed the presence of the potent neurotoxins anatoxin-a (ATX) and homoanatoxin-a (HTX). Phormidium autumnale (Oscillatoriales) was identified as the causative species (Wood et al., 2007). Further studies have shown $P$. autumnale is the dominant cyanobacteria comprising benthic biofilms in New Zealand rivers (Heath et al., 2010). Phormidium autumnale blooms have predominantly been observed in stable flow conditions and sites with the greatest $P$. autumnale coverage generally have low levels of Dissolved Reactive Phosphorus (DRP; ca. $<0.01 \mathrm{mg} \mathrm{L}^{-1}$ ) and elevated Dissolved Inorganic Nitrogen (DIN; ca. $>0.1 \mathrm{mg} \mathrm{L}^{-1}$ ) (Wood and Young, 2012). Growth is optimal in water velocities between 0.6 and $1.1 \mathrm{~m}^{3} \mathrm{~s}^{-1}$, although substrate cover $>25 \%$ has been observed at high velocity $\left(2.1 \mathrm{~m}^{3} \mathrm{~s}^{-1}\right)$ (Heath et al., 2013). Unlike many cyanobacterial species, P. autumnale does not have the ability to fix atmospheric nitrogen - analysis of New Zealand cultures of P. autumnale did not detect genes responsible for nitrogen fixation (Heath and Wood, unpublished). These findings indicate an ability of $P$. autumnale to out-compete other periphyton in low $\mathrm{P}$ conditions and support the observed need for elevated DIN for bloom formation. However, these studies are limited to regions around New Zealand and may not truly represent the range of conditions in which $P$. autumnale can grow. Furthermore, little is currently known of the conditions within the 
biofilm matrix and how they differ to those of the surrounding water. $P$. autumnale biofilms form a dense matrix that may restrict movement of solutes and may alter local physio- or biochemical conditions (e.g. pH, nutrients and enzyme activity) and hence alter the available nutrients.

\subsection{Biofilm Microbial Composition}

Benthic cyanobacterial biofilms usually contain many different species of cyanobacteria, green algae, bacteria and diatoms with one or few species dominating. For example, $P$. autumnale is the dominant species comprising benthic biofilms that proliferate in many New Zealand rivers (Heath et al., 2010), but several other species of cyanobacteria, such as Oscillatoria, Pseudoanabeana and Tychonema, may also be present (Heath et al., 2011).

Environmental factors can influence the microbial composition of benthic biofilms. Water velocity is the main environmental factor that affects biofilm composition and architecture, as it controls other factors such as delivery of nutrients to the biofilm (Besemer et al., 2007). In general, biofilm biomass accumulation is greater in low water velocities, as opposed to high velocities that can impose stress on biofilm development (Lau and Liu, 1993), although high and low velocity is relative to the river system under study. Lau and Liu (1993) indicated that stress caused by high velocity reduced biomass accumulation, although high velocities deliver nutrients at a higher rate. Besemer et al. (2007) controlled flow conditions in a microcosm experiment and found that biofilm accumulation was greatest under low flow $\left(0.065 \mathrm{~m}^{3} \mathrm{~s}^{-1}\right)$ and diversity of biofilm communities

varied with low, medium $\left(0.162 \mathrm{~m}^{3} \mathrm{~s}^{-1}\right)$ and high $\left(0.39 \mathrm{~m}^{3} \mathrm{~s}^{-1}\right)$ velocities. They also demonstrated that biofilms formed distinct ridges and streamers under the highest flow, which allowed other microbes to colonise and increased microbial biomass as well as the bio-reactive surface area. The effect of velocity on Phormidium-dominated biofilm community composition is not yet known. 
Other environmental factors, such as light and nutrients supply, are also important in determining biofilm community composition (Wood et al., 2012a, Sekar et al., 2002, Barranguet et al., 2005). Additionally, biological factors can also contribute to shaping the biofilm community. For example, grazing of algal-bacterial biofilms by the snail, Potamopyrgus antipodarum, during development encouraged extracellular polymeric substances (EPS) production, and allowed filamentous cyanobacteria to dominate in the mature stages (Barranguet et al., 2005).

Benthic biofilms have successional stages of development much like a terrestrial forest ecosystem (Sekar et al., 2002, Jackson, 2003). Typically, biofilms start with a conditioning bacterial film that allows settlement of other microorganisms, followed by growth, stabilisation and eventual senescence as biofilms slough off (Barranguet et al., 2005). Jackson (2003) suggested that in the early successional stages, heterotrophic bacteria rely on dissolved organic carbon from the overlaying water, and their growth alters the substrate surface for colonisation by other microbes; later successional stages generally function as a closed system, where the bacteria rely on autotrophic production from algae and cyanobacteria (Barranguet et al., 2005, Roeselers et al., 2007). In general, biofilms are initially dominated by bacteria and diatoms, followed by green algae and finally dominance by cyanobacteria in late succession (Besemer et al., 2007, Roeselers et al., 2007, Barranguet et al., 2005, Leflaive et al., 2008).

Bacterial species within the biofilms appear to be an important component of biofilm development (Lear et al., 2008); however, few studies have investigated the relationship of these potentially symbiotic bacteria with other taxa in benthic biofilms. Espeland and Wetzel, (2001) undertook an experimental study that measured the extracellular phosphatase expression by biofilm bacteria exposed to different algal photosynthetic activities and phosphate levels. Bacterial phosphatase activity increased under photosynthetic inhibition (and subsequent reduction of extracellular 
organic carbon from photosynthesis) in phosphate deprived conditions. This association between bacterial phosphatase activity and photosynthetic inhibition was viewed as a mutualistic relationship between the bacteria and biofilm algae. The role of EPS in multispecies algal-bacterial biofilms has rarely been examined, despite its importance in biofilm-forming heterotrophic bacteria and cyanobacteria (Barranguet et al., 2005). It is likely that bacteria assist with attachment of inocula to the substrate and could potentially facilitate dominance of specific algae, such as $P$. autumnale. The existence of such a relationship in New Zealand Phormidium-dominated biofilms is yet to be identified and further study of the fine-scale mechanisms involved in biofilm development is needed.

\subsection{Characterising Microbial Communities}

Characterisation of microbial communities in many areas, including freshwater ecology, have previously been restricted to culturable organisms, which represents very little of the true diversity (Hill et al., 2000, Degnan and Ochman, 2011). The application of molecular methods over the last decade, particularly those targeting the $16 \mathrm{~S}$ and $18 \mathrm{~S}$ ribosomal RNA (rRNA) genes, has greatly improved the ability to detect microbial diversity (Hill et al., 2000). rDNA (which encodes the rRNA) is present in all forms of life and has multiple hypervariable regions interspersed among conserved regions. Those regions can easily be amplified by polymerase chain reaction (PCR) for nucleotide sequencing (Roh et al., 2010). Genetic studies of environmental material had typically used vector cloning and Sanger sequencing methods (Cardenas and Tiedje, 2008, Degnan and Ochman, 2011). Terminal-Restriction Fragment Length Polymorphism analysis (T-RFLP) and Automated Ribosomal Intergenic Spacer Analysis (ARISA) are two methods that utilise the 16S rRNA region or intergenic spacer region and fluorescent tagging technology; both have been successfully used to characterise benthic stream periphyton communities (Lear et al., 2008, Vinten 
et al., 2011). But new sequencing technologies, such as 454 and Illumina ${ }^{\mathrm{TM}}$ platforms, now allow genetic identification of these communities. Illumina ${ }^{\mathrm{TM}}$ GAIIx platform sequencing has been used to effectively recapture the microbial diversity of a known mock community of 65 isolates (Caporaso et al., 2011). Similarly, they examined 25 environmental samples from 8 different environments (ranging from freshwater to the human gut) that reproduced levels of diversity previously obtained from extensive and time-consuming meta-analyses. Application of molecular tools such as these could provide a rapid and cost effective way to study the microbial composition of benthic $P$. autumnale biofilms to identify potential microbial symbionts or facilitators.

\subsection{Toxin Production in Benthic Biofilms}

The function of toxins in both planktonic and benthic cyanobacteria is still unclear. A large body of research is available on the regulation of toxin production and ecological functions of toxins in planktonic groups (especially for microcystins). However, there are a limited number of studies investigating the same questions in benthic cyanobacteria. The majority of known cyanotoxins have been identified from benthic blooms, including hepatotoxins (microcystins, nodularins and cylindrospermopsins) and neurotoxins (ATX, HTX and saxitoxins; STX) (Quiblier et al., 2013). Globally, microcystins and ATX are the most common cyanotoxins associated with benthic blooms (Edwards et al., 1992, Gugger et al., 2005, Quiblier et al., 2013, Wood et al., 2007). However, this may be due to sampling biases and the availability of routine tests for these toxins. In New Zealand benthic blooms, ATX and HTX are the most commonly detected cyanotoxins (Heath et al., 2011, Milne and Watts, 2007, Wood et al., 2012b).

Co-occurrence of toxic and non-toxic genotypes within the same bloom is well documented in planktonic species. However, investigations of toxic and non-toxic genotypes in benthic blooms are scarce. A study by Heath et al. (2010) found that only five of the seven $P$. autumnale strains 
isolated from environmental samples, which had tested positive for anatoxins via Liquid Chromatography-Mass Spectrometry (LC-MS), produced anatoxins in culture. Additionally, Cadel-Six et al. (2007) found that a strain of Phormidium, isolated from the Tarn River in France, produced anatoxin although it was sampled from a 'non-toxic' biofilm. Toxic and non-toxic $P$. autumnale genotypes can occur in the same biofilm within a $1 \mathrm{~m}^{2}$ area of river substrate and different toxic genotypes may vary dramatically in their ability to produce toxins (Wood et al., 2012b). Quantitative molecular techniques may help determine variables that cause toxic and nontoxic $P$. autumnale genotypes to dominate, and establish how the relative abundances of genotypes relates to actual toxin concentrations within a biofilm. Recent studies suggest anatoxin production is variable under different nutrient culturing conditions (Smith, 2012) and also among localities over time (Heath et al., 2011).

Quantitative Polymerase Chain Reaction (QPCR), also called Real-Time PCR, is a method to simultaneously amplify and quantify specific target DNA sequences, which is useful for quantifying metabolite production, such as toxins. This method differs from standard PCR in that amplified DNA is quantified during the reaction process, rather than at the end of the amplification process, hence QPCR is faster and more accurate than other methods such as Gel Electrophoresis, Northern Blots and Southern Blots. Target DNA is quantified by the addition of fluorescent dyes; either a non-specific intercalating dye that binds to any double stranded DNA or a sequencespecific DNA probe with a fluorescent reporter sequence. Fluorescence peaks are produced as more target DNA is amplified, this can be compared with a standard curve to obtain a relative quantity of the target sequence per sample. A sequence coding for a polyketide synthase (now known as the ana gene cluster) was found to occur only in ATX-and HTX-producing strains of Oscillatoria sp. (Cadel-Six et al., 2009), and has subsequently been identified in other ATX 
producing cyanobacteria (Rantala-Ylinen et al., 2011), indicating its putative role in anatoxin biosynthesis. Phormidium autumnale cells possess a single copy of the ana gene cluster (Méjean et al., 2010), making it possible to PCR amplify sections of this cluster (anaA-anaG) to determine the proportion of toxin producing cells in a sample. Wood et al. (2010) successfully screened $P$. autumnale cultures and environmental samples for ATX-producing ability using the anaF segment of the ana gene cluster.

The exact causes of toxic/non-toxic strain variation are still unknown. The proportion of toxic and non-toxic $P$. autumnale strains does not appear to vary with water velocity, $\mathrm{pH}$, light intensity, depth and biofilm cover, while some correlations have been found where increased toxic strains occur with water temperatures above $15^{\circ} \mathrm{C}$ (Heath et al., 2010) this is not consistent with other studies (Wood and Young, 2012). Secondary metabolites are often produced for the purposes of cell-cell signalling or as anti-herbivore defences. Other than comparisons with $P$. autumnale biofilm cover, no study has yet investigated variation in toxic and non-toxic strains with biological variables, such as other algae associated with the biofilms.

\subsection{Research Aims}

The overarching goal of this thesis is to investigate the successional development and withinbiofilm relationships of $P$. autumnale-dominated biofilms in the Hutt River, Wellington, New Zealand - a river with yearly summer blooms and numerous dog poisoning cases. The goals of this study are:

1. To characterise the successional development of microalgae in the P. autumnale dominated biofilms of the Hutt River via microscopy. 
2. To investigate how the bacterial community varies through biofilm succession using ARISA and Next-generation sequencing and to identify potential bacterial symbionts or facilitators of $P$. autumnale dominance.

3. To explore the variation in anatoxin production and anatoxin-producing variants throughout biofilm succession to help identify the biological function(s) of anatoxin production.

Note: Chapters 2 and 3 have been written as self-contained research papers for publication. As a consequence there is some repetition in the introductions and discussions. 


\section{Chapter 2: Successional changes in microbial community composition of benthic Phormidium-dominated biofilms}

\subsection{Introduction}

Problematic cyanobacterial blooms are a common occurrence in many freshwater bodies around New Zealand and animal deaths resulting from planktonic blooms have been reported for decades (Pridmore and Etheredge, 1987). In contrast, the prevalence and intensity of benthic cyanobacterial blooms (defined as $>30 \%$ coverage of the substrate) dominated by the genus Phormidium appear to only have increased throughout New Zealand in the last decade (Wood and Young, 2012). The health risks posed by these blooms were highlighted following reports of dog deaths after consumption of benthic cyanobacteria material (Hamill, 2001, Wood et al., 2007). As a result, New Zealand became one of the first nations to undertake detailed research on the ecology of toxic Phormidium blooms.

The first report of dog neurotoxicosis in New Zealand after ingestion of benthic cyanobacteria was in 1998 (Hamill, 2001). Further dog deaths occurred in 2005 when they consumed material from Phormidium blooms in the Hutt River (Wellington). The potent neurotoxins anatoxin-a (ATX) and homoanatoxin-a (HTX) were detected in the cyanobacterial material and in the dogs' stomachs. Wood et al. (2007) confirmed that the dominant cyanobacteria comprising these biofilms was Phormidium autumnale (Oscillatoriales; Wood et al., 2007). Further research by Heath et al. (2010) confirmed that $P$. autumnale is the dominant bloom forming/toxin producing species responsible for blooms throughout New Zealand rivers. Phormidium autumnale blooms are usually observed in stable flow conditions and sites with the greatest coverage generally have low levels of dissolved reactive phosphorus (DRP; ca. $<0.01 \mathrm{mg} \mathrm{L}^{-1}$ ) and elevated dissolved inorganic nitrogen (DIN; ca. $>0.1 \mathrm{mg} \mathrm{L}^{-1}$; Wood and Young, 2012). Analysis of P. autumnale cultures from 
across New Zealand showed that, unlike many cyanobacterial species, they lacked the genes responsible for nitrogen fixation and this may explain why elevated DIN is normally required for bloom formation. Growth is optimal in water velocities between 0.6 and $1.1 \mathrm{~m}^{3} \mathrm{~s}^{-1}$, although growth (> 25\% coverage) has been observed at high velocity $\left(2.1 \mathrm{~m}^{3} \mathrm{~s}^{-1}\right.$; Heath et al., 2010). These findings indicate an ability of $P$. autumnale to out-compete other periphyton in low phosphorus (P) conditions. However, these studies are limited to locations within New Zealand and may not truly represent the range of conditions in which $P$. autumnale can grow. Furthermore, little is currently known of the conditions within the biofilm matrix and how they differ from those of the surrounding water. Phormidium autumnale biofilms form a dense matrix that could restrict movement of solutes from the water column, and may alter local physiochemical conditions (e.g. $\mathrm{pH}$, dissolved oxygen and nutrients) and hence alter available nutrients.

Phormidium autumnale occurs in biofilms with other microbial taxa, such as bacteria, diatoms and green algae (Wood et al., 2012a), but the relative proportions of these within the P. autumnaledominated biofilms and how they change temporally is currently unknown. Factors that influence the microbial composition of benthic biofilms are typically environmental factors, such as water velocity, temperature and nutrients. Water velocity is usually the most prominent of these - as high velocities can reduce the water temperature and control delivery of nutrients to biofilms (Lau and Liu, 1993). Light intensity can influence the composition of microbial biofilms, often increasing the proportion of photoautotrophs (such as cyanobacteria) in high light conditions (Barranguet et al., 2005); although bacterial numbers in a microcosm experiment were found to reduce under high light intensities (Lear et al., 2009). Additionally, biological factors can also contribute to shaping the biofilm community. For example, grazing of algal-bacterial biofilms by the snail, Potamopyrgus antipodarum, during development encouraged Extracellular Polymeric Substances 
(EPS) production, and allowed filamentous cyanobacteria to dominate in mature biofilms (Barranguet et al., 2005).

Biofilms are major sources of lotic primary production and the bacterial components of these are essential in the break-down of organic matter and consequent nutrient cycling (Roman and Sabater, 1999). However, there is a limited understanding of the relationship of these potentially symbiotic bacteria with other microbes in benthic biofilms. The increase of photoautotrophs, such as algae and cyanobacteria, within biofilms can increase the organic substrate available for bacterial metabolism but also slow the response of bacteria to changes in the microbial community (Roman and Sabater, 1999). Biofilm bacteria are a food source for protozoans and macroinvertebrate grazers, forming important trophic interactions (Dopheide et al., 2011). Grazing by ciliates can also effect the structure of the biofilm matrix, with some species forming holes and channels in the biofilm and others causing a more homogenous distribution of cells (Dopheide et al., 2011).

Benthic biofilms have successional stages of development much like a terrestrial forest ecosystem (Sekar et al., 2002, Jackson, 2003). Typically biofilms start with a conditioning bacterial film that allows settlement of other microorganisms, followed by growth, stabilisation and eventual senescence as biofilms slough off (Barranguet et al., 2005). Jackson (2003) suggested that in the early successional stages, heterotrophic bacteria rely on dissolved organic carbon from the overlaying water, and their growth alters the substrate surface for colonisation by other microbes. Later successional stages generally function as a closed system, where the bacteria rely on autotrophic production from algae and cyanobacteria (Barranguet et al., 2005, Roeselers et al., 2007). In general, the biofilms are initially dominated by bacteria and diatoms, followed by green algae and finally dominance by cyanobacteria in late succession (Besemer et al., 2007, Roeselers et al., 2007, Barranguet et al., 2005). 
Currently, there is limited knowledge of how the microbial community within the $P$. autumnaledominated biofilms changes temporally following clearance of the substrate by a flushing flow. The aim of this chapter was to characterise the successional changes of $P$. autumnale biofilms from the earliest phase through to the mature "sloughing" phase, using both microscope and molecular identification methods. This fine scale investigation of community change will provide evidence for possible micro-algal-bacterial associations that could be facilitating bloom formation by $P$. autumnale in New Zealand rivers. 


\subsection{Methods}

\subsubsection{Site descriptions}

Three study sites on the Hutt River (Wellington, New Zealand) were selected - Te Marua (Site 1), Mangaroa (Site 2) and Silverstream (Site 3; Figure 2.1). The sites were chosen based on previous occurrences of $P$. autumnale blooms (Heath et al., 2011, Milne and Watts, 2007), their accessibility, and varied water chemistries (Heath et al., 2011). The study was conducted over a 32 day period between the 9 February and 13 March 2013.

Site $1\left(41^{\circ} 04^{\prime} 48^{\prime \prime} \mathrm{S}, 175^{\circ} 08^{`} 30^{\prime \prime} \mathrm{E}\right)$ was located in the upper reaches of the Hutt River, adjacent to the Kiatoke municipal water storage ponds. The majority of the surrounding catchment is native forest with some small areas of residential and agricultural use. Site $2\left(41^{\circ} 5^{\circ} 40^{\prime \prime} \mathrm{S}, 175^{\circ} 7^{\circ} 25^{\prime \prime} \mathrm{E}\right)$ is ca. $500 \mathrm{~m}$ below the confluence of the Mangaroa River, a tributary of the Hutt River. The surrounding landscape is mostly residential and agricultural, and includes a local golf course. Site $3\left(41^{\circ} 8^{\prime} 23^{\prime \prime} \mathrm{S}, 175^{\circ} 0^{\prime} 23^{\prime \prime} \mathrm{E}\right)$ was located $14 \mathrm{~km}$ downstream from Site 2, where the river runs through residential areas, with a golf course to the east and a motorway to the west.

\subsubsection{Experimental design and sampling}

On 5 February 2013 there was a high rainfall event causing a 'flushing flow' (flow greater than three times the median; Hudson, 2010), in the Hutt River which removed existing P. autumnale growth. Flows at the three Greater Wellington Regional Council (GWRC) river gauging sites (Te Marua, Birchville and Taita Gorge; Figure 2.1) reached over 200, 500 and $580 \mathrm{~m}^{3} \mathrm{~s}^{-1}$ respectively, well over the long term median flow values $\left(5.8,12.4\right.$ and $14.2 \mathrm{~m}^{3} \mathrm{~s}^{-1}$; Hudson, 2010). On the 9 February the flow had reduced to $4 \mathrm{~m}^{3} \mathrm{~s}^{-1}$ and it was deemed safe to work in the river. Thereafter, the sites were visited every two days for the first 24 days and every third day up to day 36 . The experiment ceased on 13 March 2013 due to an imminent flushing flow $\left(190 \mathrm{~m}^{3} \mathrm{~s}^{-1}\right.$ at Taita Gorge; 
GWRC 3) on the 18 March 2013. The temporal sampling points refer to number of days since the flushing flow occurred (day 0) as a measure of the biofilm accrual period, with sampling beginning on day 4 and ran for 32 days, until day 36.

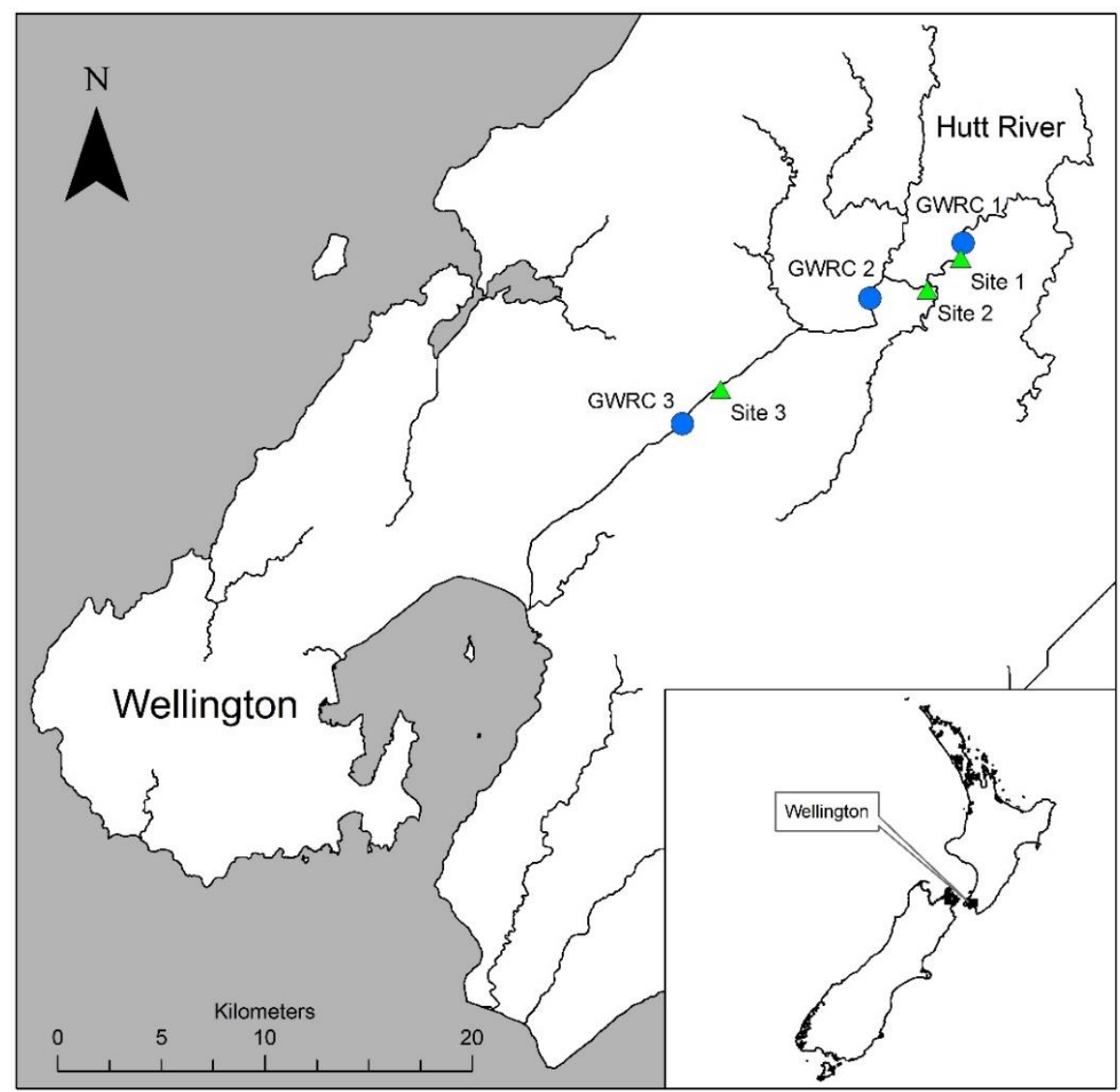

Figure 2.1 Map of study sites on the Hutt River and Greater Wellington Regional Council permanent monitoring stations (GWRC 1,2 and 3) from which flow and temperature data were obtained.

At each site, ten rocks $(20-30 \mathrm{~cm})$ that were completely submerged in the river prior to the start of the experiment, were randomly selected and arranged into two rows across the river (A and B, Figure 2.2). Small rocks numbered 1-10 with waterproof varnish were positioned next to the study 
rocks for identification purposes. The first row of five rocks were used for re-sampling of biofilm material, the remaining rocks were undisturbed controls.

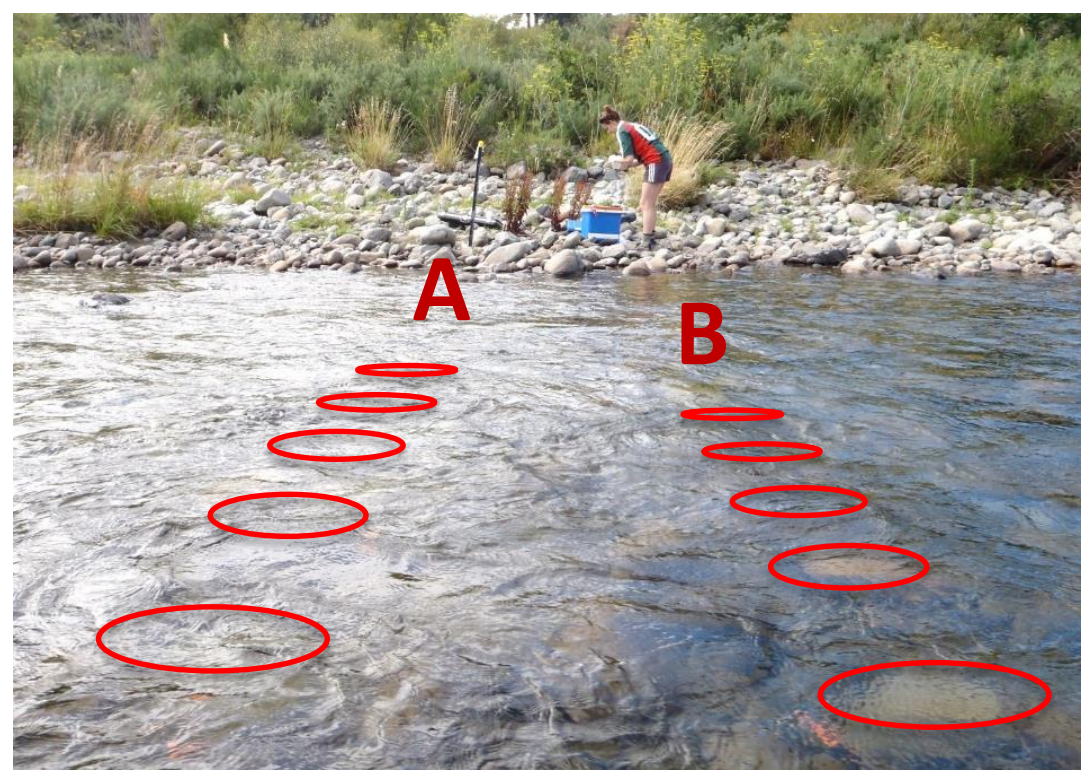

Figure 2.2 Site 1 set-up. Red rings indicate position of rocks under observation. Rocks to the left (A) were re-sampled for biofilm material, while rocks to the right (B) were undisturbed controls.

All rocks were photographed (Lumix DMC-FT20 digital camera, Panasonic, Japan) underwater via an underwater viewer (Nuova Rade) to visually record the extent of $P$. autumnale biofilm cover. Point velocity measurements were taken at the centre point in front of each rock using an OSS-PC1 pygmy current meter (Scottech, New Zealand) at $60 \%$ of the total water depth. Water conductivity was recorded at each site using a CyberScan CON 410 (Eutech) conductivity meter.

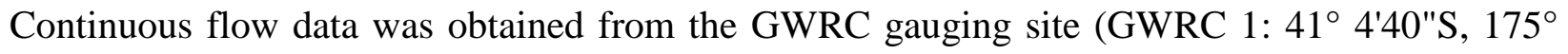
8'38"E, Figure 2.1) located $300 \mathrm{~m}$ upstream of Site 1, where the water level is measured inside a stilling tower with a float and counter weight system and is converted to a flow value using a rating curve relationship. Water temperature data, also from the GWRC gauging site, was measured using Campbell C107 and Unidata LM34 sensors. Water samples (120 mL) from each site were filtered directly into the sample bottles through a GF/C filter (Whatman) for analysis of dissolved nutrients 
(nitrite, nitrate, ammoniacal nitrogen, dissolved reactive phosphorous). Samples (50 mL) were also collected for total nutrients (nitrogen and phosphorus). These were stored on ice during transport and frozen at $-20^{\circ} \mathrm{C}$ within $6 \mathrm{hrs}$.

Biofilms samples were taken by swabbing a ca. $254 \mathrm{~mm}^{2}$ area of five rocks (A, Figure 2.3) using sterile Whirl-pak ${ }^{\mathrm{TM}}$ Speci-sponges ${ }^{\mathrm{TM}}$ (Nasco). A metal ring was used to mark the outside circumference of the sampling area (Figure 2.3). Two duplicate areas were sampled per rock and the sponges were placed in separate sterile Whirl-pak ${ }^{\mathrm{TM}}$ bags. Sponge samples for later molecular and toxin analysis were put on ice immediately and frozen $\left(-20^{\circ} \mathrm{C}\right)$ on return to the laboratory. Sponge samples for morphological analysis of the biofilm community were placed in Whirl-pak ${ }^{\mathrm{TM}}$ bags with distilled water $(50 \mathrm{~mL})$ and preserved immediately with 3-4 drops of Lugol's iodine solution (10\% (w/v) potassium iodide, $5 \%(\mathrm{w} / \mathrm{v})$ iodine, $10 \%(\mathrm{v} / \mathrm{v})$ acetic acid) and stored in the dark for microscopic analysis. Due to the heterogeneous distribution of growth of multiple types of algae/cyanobacteria on the rocks, both samples were taken from the largest visible area of biofilm growth.

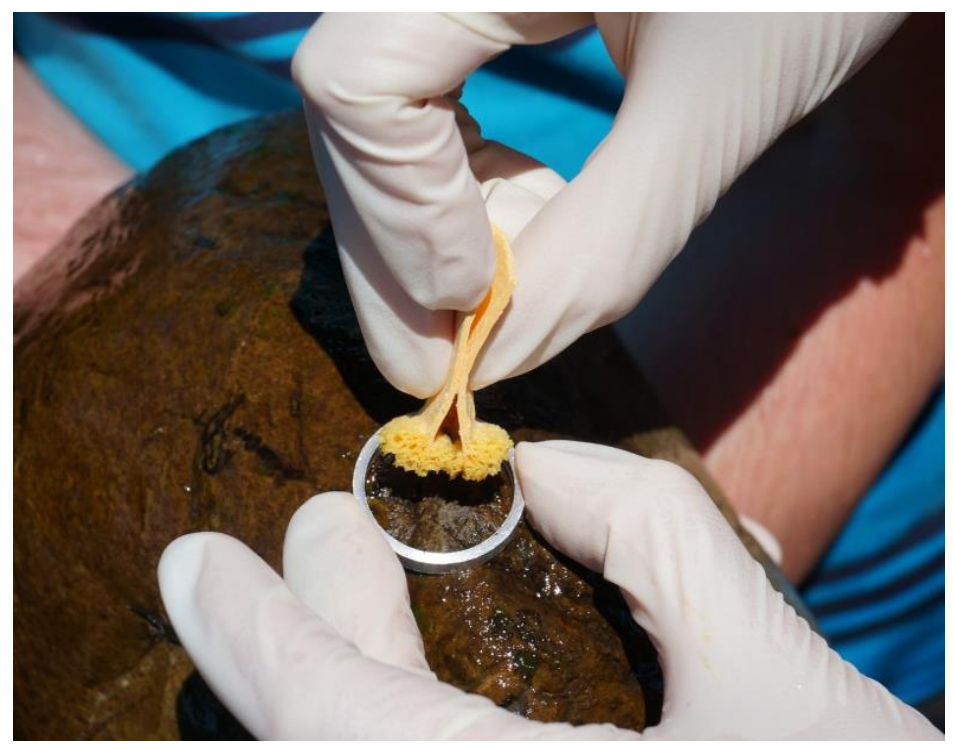

Figure 2.3 Rock sampling technique. Metal ring used to mark circumference of sampled area. 


\subsubsection{Nutrient Analysis}

Total phosphorus (TP) was analysed by acid persulphate digestion and ascorbic acid colorimetry, while total nitrogen (TN) was determined using a Lachat QuickChem ${ }^{\circledR}$ Flow Injection Analyser (FIA+ 8000 Series; Zellweger Analytics, Inc., Milwaukee, WI, USA) and Konelab Aquakem 600 Discrete Analyser (Thermo Scientific) according to methods of APHA (2005). Detection limits were $0.004 \mathrm{~g} \mathrm{~m}^{-3}$ and $0.02 \mathrm{~g} \mathrm{~m}^{-3}$, respectively. Nitrate- $\mathrm{N}$ and nitrite-N were analysed by Ion chromatography (Konelab Aquakem 600 Discrete Analyser; Thermo Scientific) with a detection limit of $0.002 \mathrm{~g} \mathrm{~m}^{-3}$ and ammoniacal-N by colorimetry (Konelab Aquakem 600 Discrete Analyser; Thermo Scientific) with a detection limit of $0.005 \mathrm{~g} \mathrm{~m}^{-3}$. Dissolved inorganic nitrogen (DIN) was taken as the sum of nitrite-N, nitrate-N and ammoniacal-N. Dissolved Reactive Phosphorus (DRP) was analysed by Molybdenum blue colorimetry (Konelab Aquakem 600 Discrete Analyser;

Thermo Scientific) with a detection limit of $0.004 \mathrm{~g} \mathrm{~m}^{-3}$. Nitrogen analyses were carried out by Water Care Laboratory Services (Auckland, New Zealand) and phosphorus analyses by Hill Laboratories (Hamilton, New Zealand).

\subsubsection{Morphological identification}

Due to very low biofilm coverage of study rocks at Site 2 and 3, Site 1 was the only location with sufficient coverage to be used for analysis of the biofilm community and all subsequent methods refer to samples and data from Site 1 only.

Speci-sponges ${ }^{\mathrm{TM}}$ and surrounding $50 \mathrm{~mL}$ liquid were transferred into a sealed plastic bag. Each sample was placed in a Colworth 400 laboratory stomacher (AJ Seward, UK) for 2 min to separate biofilm material from the Speci-sponges ${ }^{\mathrm{TM}}$. Sponges were squeezed to remove excess liquid and any material remaining on the sponge was removed with tweezers. The suspended material was transferred to Falcon tubes $(50 \mathrm{~mL})$ then homogenised (LabServ D130) and subsamples (0.5 to 4 
$\mathrm{mL}$ depending on the cell concentration) pipetted into Utermöhl chambers (Utermöhl, 1958) and distilled water (6-9 mL) added to the chamber. Samples with extremely low cell concentrations (days 4-8) were settled in their tubes (24 hr) and the overlying water (ca. $40 \mathrm{~mL}$ ) decanted. Morphological identification and enumeration of micro-algal taxa were carried out using an inverted microscope (Olympus CKX41; note: hereafter reference to micro-algae include true eukaryotic algal taxa, e.g. green algae and diatoms, as well as the cyanobacteria that were visible under the microscope at $1000 \times$ magnification). Identifications were made with the taxonomic guides of Biggs and Kilroy (2000), Canter-Lund, Lund and Fogg (1995) and McGregor (2007). Trichome lengths of filamentous species were measured and divided by the average cell length to give an estimate of cell number per filament.

\subsubsection{Biovolumes}

Samples from Site 1 at four time points throughout the sampling period (days 8, 20, 27 and 33) were used to calculate cell biovolumes for each of the 19 genera identified, using median cell dimensions ( $n=30$ to 40$)$ and volumetric equations of geometric shapes closest to each cell shape, as described in Sun \& Liu (2003). Measurements were undertaken at 400× magnification using an Olympus CKX41 inverted microscope and 1000× magnification using a Leica DMRBE compound microscope.

\subsubsection{DNA extraction and Automated Ribosomal Intergenic Spacer Analysis (ARISA)}

Speci-sponges $^{\mathrm{TM}}$ were thawed and $30 \mathrm{~mL}$ of RNA/DNA free water (Life Technologies) added, followed by maceration using a Colworth 400 laboratory stomacher (AJ Steward, UK) for 2 mins. Excess liquid was squeezed from the sponges. Subsamples $(10 \mathrm{~mL})$ were frozen $\left(-20{ }^{\circ} \mathrm{C}\right)$ for toxin analysis (described in Chapter 3). The remaining biofilm suspension was pelleted by centrifugation 
$(3000 \times g, 15 \mathrm{~min})$. The supernatant was discarded and DNA extracted from the pellet using a Power Biofilm ${ }^{\circledR}$ DNA Isolation Kit (MOBIO, USA) following the manufacturer's instructions.

A region of the internal transcribed spacer (ITS) region was amplified by PCR (iCycler; Biorad) using bacterial-specific primers ITSF (5'-TCGTAACAAGGTAGCCGTA-3') and ITSReub (5'GCCAAGGCATCCACC-3'; Cardinale et al., 2004). PCR reactions were performed in $20 \mu \mathrm{L}$ volumes with the reaction mixture containing $12.5 \mu \mathrm{L}$ of $\mathrm{i}$-Taq $2 \mathrm{x}$ PCR master mix (Intron Biotechnology, Korea), $0.4 \mu \mathrm{M}$ of each primer, and 15-20 ng of the template DNA. The reaction mixture was held at $94{ }^{\circ} \mathrm{C}$ for 3 min followed by 30 cycles of $94{ }^{\circ} \mathrm{C}$ for $45 \mathrm{~s}, 52{ }^{\circ} \mathrm{C}$ for $60 \mathrm{~s}, 72{ }^{\circ} \mathrm{C}$ for $2 \mathrm{~min}$, with a final extension step at $72{ }^{\circ} \mathrm{C}$ for $7 \mathrm{~min}$. Amplified products were diluted (1:20) with Milli-Q water and sent to Waikato University (Hamilton, New Zealand) for automated ribosomal intergenic spacer analysis (ARISA). Amplicon lengths were resolved on an ABI 3130xI Genetic Analyser (Applied Biosystems) and run under GeneScan mode at $15 \mathrm{kV}$ for $45 \mathrm{~min}$ according to the manufacturer's protocol. Each sample contained $0.25 \mu \mathrm{L}$ of the internal Standard (Applied Biosystems) to determine the size of fluorescently labelled fragments during analysis. The resulting electropherograms were processed using the PeakScanner ${ }^{\mathrm{TM}}$ software v1.0 (Applied Biosystems) and an in-house pipeline modified from Abdo et al. (2006) written using Python 2.7.1 (Python Software Foundation) and R (http://www.r-project.org).

Peaks included in the analysis were those of greater than 30 relative fluorescence units, between 100 and 1200 base pairs, and that comprised at least $0.1 \%$ of the entire signal. Peaks were binned to the nearest 1 base pair. 


\subsubsection{Illumina Next-Generation Sequencing}

A region of the 16S rRNA gene covering the V3 and 4 sections was amplified by PCR (iCycler; Biorad) for Next-Generation Sequencing (NGS) using bacterial-specific primers 515F (5'TCGTCGGCAGCGTCAGATGTGTATAAGAGACAGGTGCCAGCMGCCGCGGTAA-3') and 806R (5'GTCTCGTGGGCTCGGAGATGTGTATAAGAGACAGGGACTACHVGGGTWTCTAAT-3'; Caporaso et al., 2011). PCR reactions were performed in $50 \mu \mathrm{L}$ volumes with the reaction mixture containing 45 $\mu \mathrm{L}$ of Platinum ${ }^{\circledR}$ PCR SuperMix High Fidelity (Invitrogen), $10 \mathrm{uM}$ of each primer, and 10-20 ng of template DNA. The reaction mixture was held at $94{ }^{\circ} \mathrm{C}$ for 2 min followed by 27 cycles of 94 ${ }^{\circ} \mathrm{C}$ for $30 \mathrm{~s}, 54{ }^{\circ} \mathrm{C}$ for $30 \mathrm{~s}, 68{ }^{\circ} \mathrm{C}$ for $45 \mathrm{~s}$, with a final extension step at $68{ }^{\circ} \mathrm{C}$ for $5 \mathrm{~min}$. Amplified products were visualised by $1 \%$ agarose gel electrophoresis with an ethidium bromide stain and UV illumination. Amplicons of the correct size were purified using Agencourt ${ }^{\circledR}$ AMPure ${ }^{\circledR}$ XP PCR Purification beads following the manufacturers' instructions. Purified products were quantified using a Qbit (Invitrogen), and diluted to $1 \mathrm{ng} / \mu \mathrm{L}$ using Milli-Q water and sent to New Zealand Genomics Ltd. (Auckland, New Zealand) for library preparation. The libraries were sequenced on MiSeq Illumina ${ }^{\mathrm{TM}}$ platform using a $2 \times 250$ bp paired end protocol.

DNA from eighteen biofilm samples were successfully extracted, PCR amplified and purified (Appendix 4). The V4-V5 Illumina ${ }^{\mathrm{TM}}$ datasets were demultiplexed using MiSeq Reporter v2.0. All further analyses were performed using MOTHUR (Schloss et al., 2009). The sequences corresponding to the forward and reverse primers were trimmed, and merged into single contigs (maximum length of 292 nucleotides). Contigs were aligned to the SILVA bacteria reference alignment (Pruesse et al., 2007) and chimera removal was performed using the UCHIME algorithm and sequences aligned to the reference alignment. Sequences were classified to identify taxonomic annotation using the Ribosomal Database Project (RDP) taxonomic database Version 9 (Cole et 
al., 2014). Mitochondrial, unknown, archaeal or eukaryotic sequences were filtered and removed from the dataset and sequences were clustered into operational taxonomic units (OTUs). Sequences were first grouped by at the Order level and sorted, before OTUs were created independently in each of the corresponding bins using 0.01 and 0.03 pairwise sequence distance cut-off values.

\subsubsection{Statistical Analyses}

Friedman two-way ANOVAs were performed to detect a difference in average percent biofilm cover over time among the three sites. If a statistical difference was found, Mann-Whitney U tests were used to compare percent cover between each site for days 30-36 (only time points that met assumption of homogenous variances), with Bonferroni corrections for multiple comparisons. A one-way repeated measures ANOVA (with a Greenhouse-Geisser correction if the assumption of sphericity was violated) was used to determine the effect on percent biofilm cover of removing biofilm material versus leaving the undisturbed controls. If a statistical difference was found, independent sample $t$ tests were used for the comparison between sampled and untouched rocks for days 12, 18, 24 and 36 (days 12-36 were the only time points with normal distributions), with Bonferroni corrections for multiple comparisons.

The average micro-algal and bacterial diversity (number of ARISA peaks and genera OTUs, respectively

) were calculated using the Shannon-Weiner Index (Smith and Wilson, 1996), defined as:

$$
H^{\prime}=-\sum_{i=1}^{S} p_{i} \ln p_{i}
$$


Where $p_{i}$ is the proportion of the entire population comprising taxa $i$ and $S$ is the total number of taxa encountered (taxon richness). Values of $H^{\prime}$ are $>0$, with larger values indicating greater diversity. The Pielou Index (Smith and Wilson, 1996) was used to indicate the spread of abundances across taxa (evenness) and is denoted as: $J=H^{\prime} / H_{\max }$, where $H^{\prime}$ is the ShannonWeiner Index and $H_{\max }$ is the maximal diversity (the natural $\log$ of $S$ ). Values of $J$ range between 0 and 1 , where 0 indicates a highly uneven distribution and 1 indicates a uniform distribution of abundances. One-way repeated measures ANOVAs (with a Greenhouse-Geisser correction because the assumption of sphericity was violated) were used to determine if micro-algal and ARISA genera richness varied significantly over time. All micro-algal and ARISA richness data was normally distributed and had homogenous variances except day 24 , which was excluded so that the more powerful parametric repeated measures ANOVA could be used - hence the degrees of freedom were reduced from 8 to 7. For micro-algal and ARISA diversity and evenness, the assumptions of normality and/or homogenous variances were violated and a Friedman two-way ANOVA was used, followed by Wilcoxon signed rank tests to assess which days differed from each other. The Illumina ${ }^{\mathrm{TM}}$ OTU data was grouped into the three phases identified from the cluster analysis and one-way repeated measures ANOVAs (with a Greenhouse-Geisser correction because the assumption of sphericity was violated) performed to determine if genera richness, Shannon diversity and evenness varied significantly over time.

A repeated measures Permutational Multivariate Analysis of Variance (PERMANOVA) was used to compare the variation in micro-algal abundances (using Bray-Curtis similarities) and bacterial assemblages (number of ARISA peaks, using Sørensen similarities) with five environmental variables (water velocity, depth, conductivity, flow and temperature) using 9,999 permutations. Analyses were performed using the 'adonis' function of the program 'vegan' in the R software 
package version 3.0.1 (R Development Core Team, 2010). PERMANOVA obtains $P$-values based on permutations and therefore does not rely on assumptions about the data distribution (Anderson, 2001, Lear et al., 2008). The taxa abundances were log transformed prior to analysis.

Cluster analyses based on Bray-Curtis/Sørensen similarity matrices were performed on the microalgal abundances, bacterial ARISA peaks and bacterial Illumina ${ }^{\mathrm{TM}}$ sequence reads to check for any distinct community assemblages, using the CLUSTER function in the PRIMER 6 software package (Clarke and Gorley, 2006). Micro-algal abundances and bacterial sequences were fourth root transformed and bacterial ARISA fragment lengths converted to presence/absence data prior to analysis. Distinct groups were identified from the micro-algal cluster analysis and the taxa primarily responsible for distinguishing between these groups were determined using the similarity percentages (SIMPER) procedure (Clarke and Warwick, 2001) using the PRIMER 6 software. 


\subsection{Results}

\subsubsection{Microbial biofilm coverage}

Percent microbial biofilm cover of the study rocks differed significantly over time among the three sites $\left(\mathrm{df}=14, \chi^{2}=231.2, p=<0.001\right)$. From day 30 onwards, Site 1 had statistically greater average percent cover, while there was no significant difference between Site 2 and 3 (Table 2.1). Days 4 to 22 did not meet the assumption of normality due to high frequency of values of zero consequently, only days 24 to 36 could be analysed for between-site differences. Site 1 was the only location with sufficient $P$. autumnale growth for an accurate analysis of the microbial community in relation to $P$. autumnale growth (Figure 2.4). Of the ten study rocks at Site 1, there was no significant difference in percent biofilm cover between rocks that were re-sampled and the undisturbed controls ( $\mathrm{df}=1,8, F=1.224, p=0.301)$, despite a visual difference in error bars in Figure 2.5. The independent sample $\mathrm{t}$ tests for day $36(\mathrm{df}=8, t=-1.57, p=0.154)$ confirmed no statistical difference between sampled and undisturbed rocks even at the final sampling date.

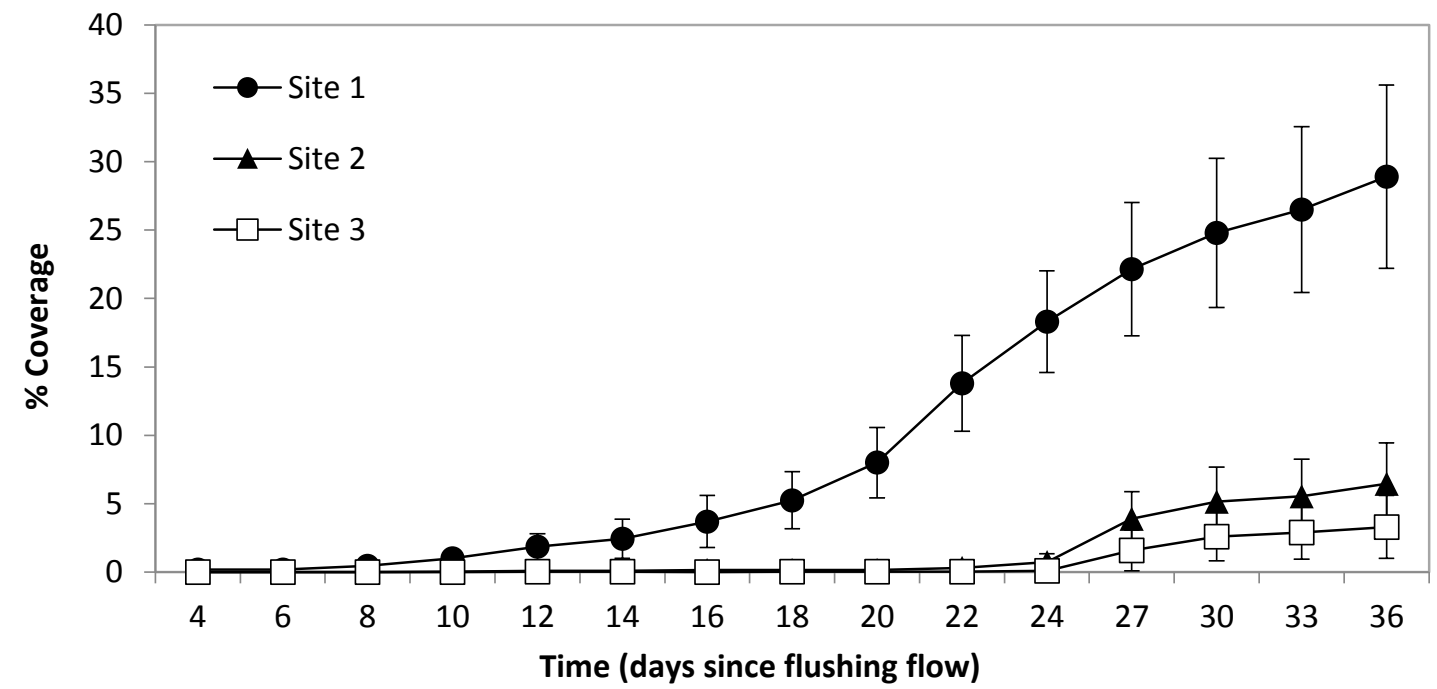

Figure 2.4 Mean daily percent biofilm cover for Site 1, Site 2 and Site 3. Error bars displaying one standard error $(n=10)$. 
Table 2.1. Results from the Mann-Whitney $U$ tests comparing mean percent cover between Site 1,2 and $3(n=10)$. Bonferroni adjusted alpha $=0.017 . *$ indicate values significant at the $5 \%$ level.

\begin{tabular}{ccccc}
\hline \multirow{2}{*}{ Day } & $\begin{array}{c}\text { Pairwise } \\
\text { comparisons }\end{array}$ & Mann-Whitney $\boldsymbol{U}$ & $\boldsymbol{Z}$ statistic & $\boldsymbol{p}$-value \\
\cline { 2 - 5 } 30 & Site 1, 2 & 10.5 & -2.997 & $0.003^{*}$ \\
& Site 1, 3 & 4.5 & -3.517 & $<0.001^{*}$ \\
& Site 2, 3 & 32.5 & -1.416 & 0.157 \\
\cline { 2 - 5 } 33 & Site 1, 2 & 11.0 & -2.965 & $0.003^{*}$ \\
& Site 1, 3 & 5.0 & -3.48 & $0.001^{*}$ \\
& Site 2, 3 & 36.0 & -1.161 & 0.246 \\
\cline { 2 - 5 } 36 & Site 1, 2 & 12.0 & -2.889 & $0.004^{*}$ \\
& Site 1, 3 & 6.0 & -3.4 & $0.001^{*}$ \\
\hline
\end{tabular}

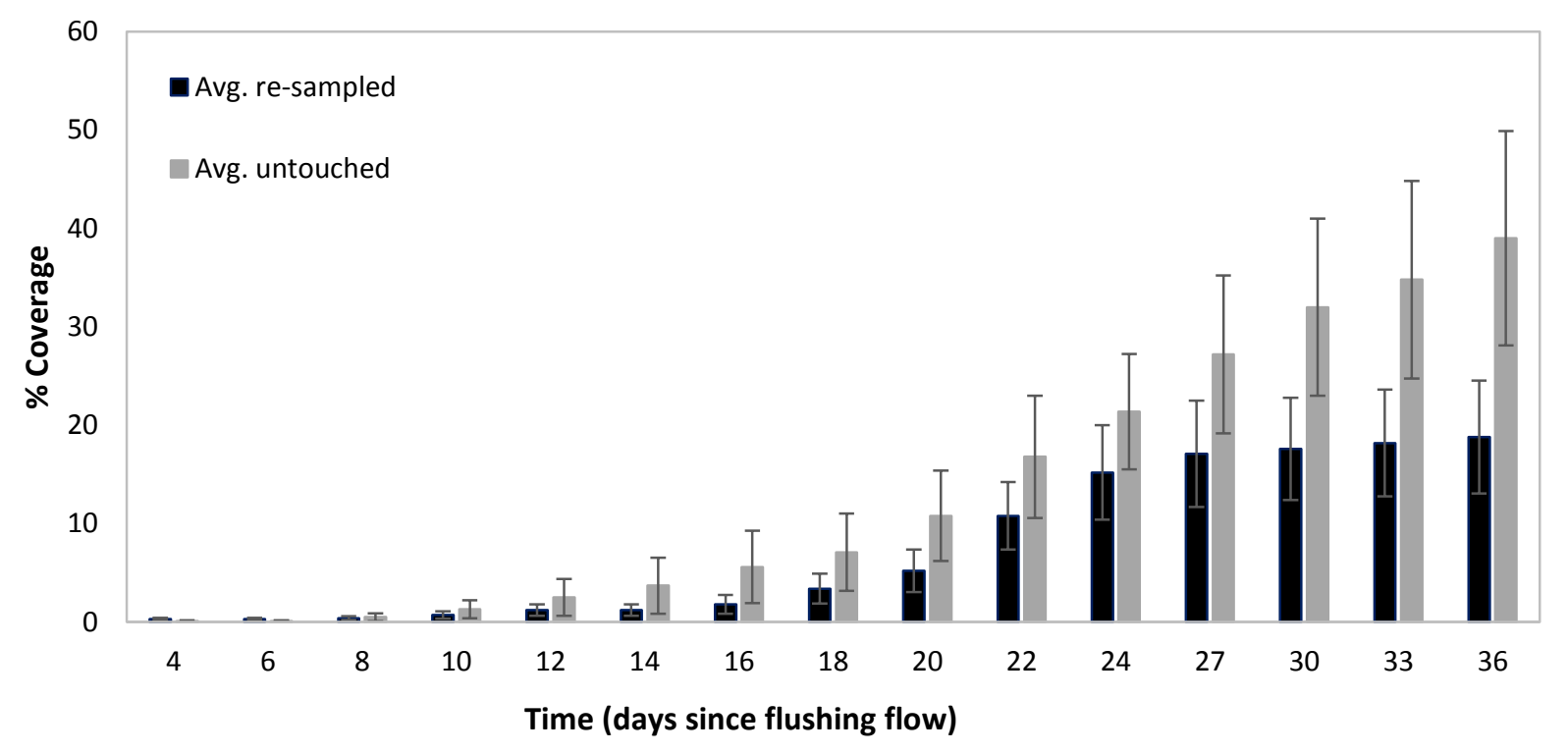

Figure 2.5 Mean percent biofilm cover from Site 1 for re-sampled (black) and untouched controls (blue). Error bars show one standard error $(\mathrm{n}=10)$. 


\subsubsection{Environmental factors}

Nutrient concentrations of the bulk water showed few changes over the study period. Dissolved Inorganic Nitrogen $(\mathrm{DIN}=$ nitrate- $\mathrm{N}+$ nitrite- $\mathrm{N}+$ ammonical-N) levels at Site 1 were consistently at or below the suggested ca. $0.1 \mathrm{mg} \mathrm{L}^{-1}$ threshold for optimum $P$. autumnale bloom formation (Wood and Young, 2012), while Site 2 and 3 were above this threshold (excluding day 12 for Site 2 and day 16 for Site 3; Figure 2.6 A; Table 2.2). Dissolved Reactive Phosphorus (DRP) was below the suggested ca. $<0.01 \mathrm{mg} \mathrm{L}^{-1}$ threshold for $P$. autumnale bloom formation at all locations (Figure 2.6 B; Table 2.2).

Table 2.2 Means \pm one standard deviation over the whole sampling period for all nutrients tested and their detection limits. $\mathrm{ND}=$ not detected.

\begin{tabular}{lcccc}
\hline Nutrient & Mean $\left(\mathbf{m g ~ L}^{-1}\right)$ & Site & $\begin{array}{c}\text { Detection limit } \\
\left(\mathbf{m g ~ L}^{-1}\right)\end{array}$ \\
& Site 1 & Site 2 & Site 3 & \\
\hline Nitrate & $0.079( \pm 0.005)$ & $0.120( \pm 0.011)$ & $0.168( \pm 0.016)$ & 0.002 \\
Nitrite & ND & ND & ND & 0.002 \\
Dissolved ammonical nitrogen & $0.005( \pm 0.001)$ & $0.008( \pm 0.002)$ & $0.006( \pm 0.002)$ & 0.005 \\
Total nitrogen & $0.108( \pm 0.008)$ & $0.144( \pm 0.011)$ & $0.189( \pm 0.017)$ & 0.005 \\
Dissolved reactive phosphorus & $0.005( \pm 0.001)$ & $0.004( \pm 0.000)$ & $0.003( \pm 0.001)$ & 0.004 \\
Total phosphorus & $0.008( \pm 0.001)$ & $0.007( \pm 0.001)$ & $0.003( \pm 0.001)$ & 0.004 \\
\hline
\end{tabular}

Point water velocity decreased steadily over the study period, by day 36 it had dropped to less than half the velocity of day 4 at all 3 sites. Sites 1 and 2 had similar velocities, while Site 3 experienced higher velocities and had greater fluctuations (Figure 2.7 A). Depth decreased at an even rate across the three sites; Site $1(49.8-27.6 \mathrm{~cm})$ remained approximately twice the depth as Sites 2 $(32.6-5.6 \mathrm{~cm})$ and $3(33.9-7.1 \mathrm{~cm})$ throughout the sampling period (Figure $2.7 \mathrm{~B})$. Conductivity 
increased over time across all three sites; Sites $1(81.6-96.7 \mu \mathrm{S})$ and $2(84.6-103.2 \mu \mathrm{S})$ had the lowest conductivities, while Site 3 (98.3-113.2 $\mu \mathrm{S}$ ) was approximately15\% higher (Figure 2.7 C).
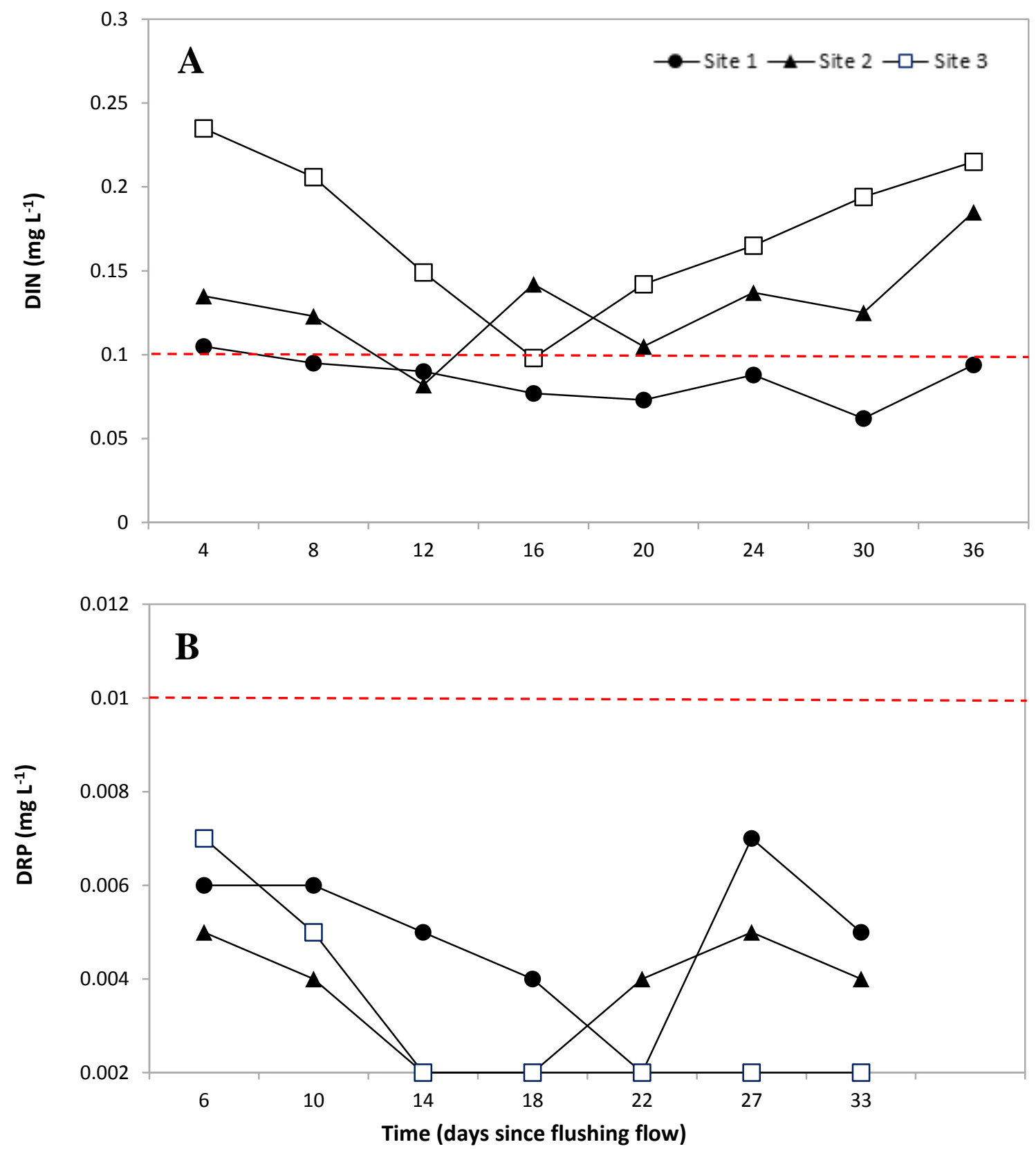

Figure 2.6 Concentration of A: Dissolved Inorganic Nitrogen (DIN), and B: Dissolved Reactive Phosphorus (DRP) for Site 1, 2 and $3(\mathrm{n}=1)$. Dashed line indicates suggested thresholds for $P$. autumnale bloom formation in New Zealand (Wood and Young, 2012). Note: data points for DRP are from different days to those of DIN, due to poor quality data from the initial analysis. 

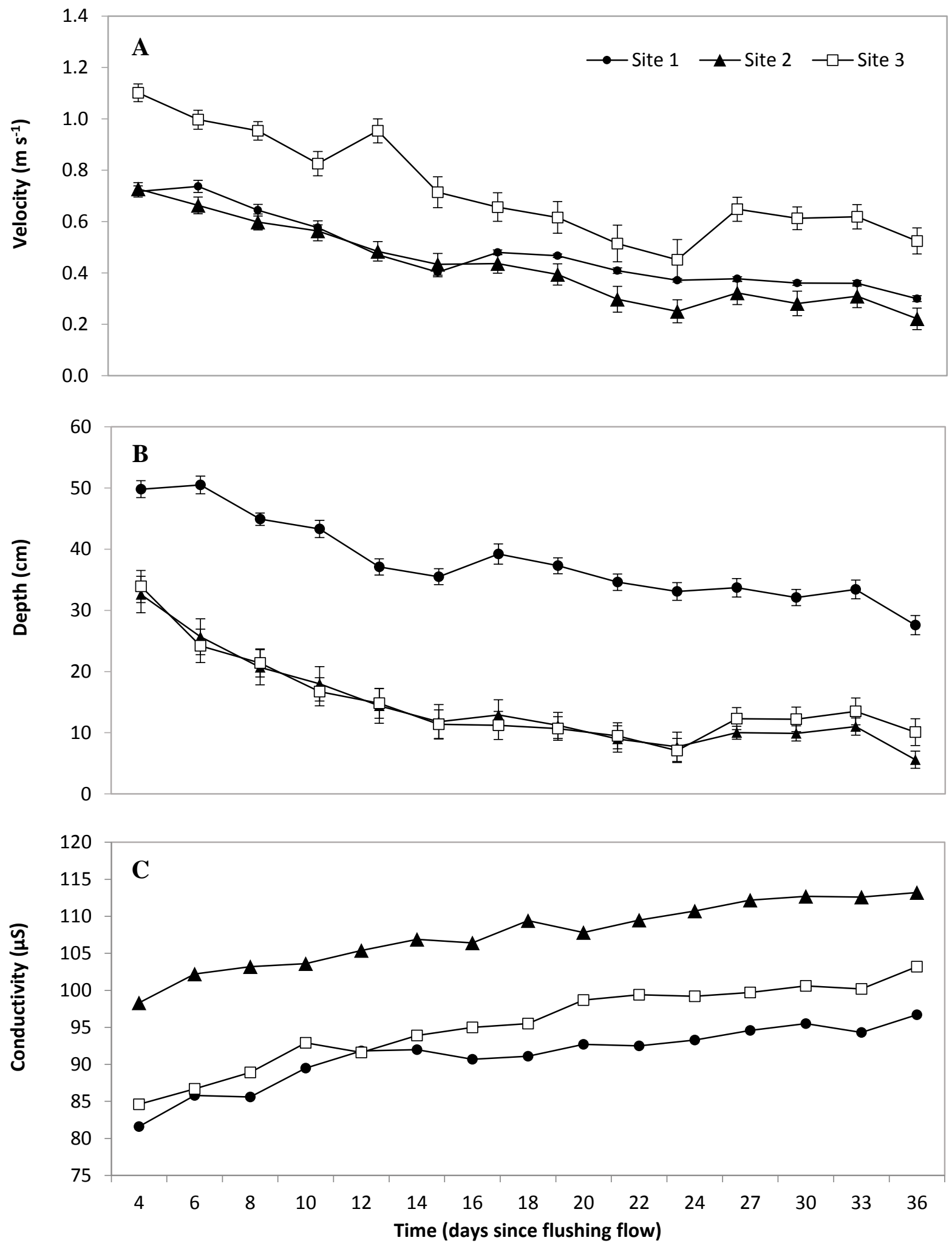

Figure 2.7 Environmental parameters recorded at Sites 1, 2 and 3 between 9 February and 13 March 2013. A: Mean point water velocity $(n=10), B$ : average depth $(n=10)$, and C: water conductivity $(\mathrm{n}=1)$. Error bars in A and B show one standard error. 
Flow velocity, measured at the GWRC gauging site above Site 1, decreased by $80 \%$ within 24 hours of the peak flow $\left(55.5 \mathrm{~m}^{3} \mathrm{~s}^{-1}\right)$ that occurred on 5 Feb 2013 (day 0; Figure 2.8), reducing to $1 \%\left(0.795 \mathrm{~m}^{3} \mathrm{~s}^{-1}\right)$ of the peak flow after 36 days. A drop in water temperature coincided with the peak flow on day 0 and increased by $2-3^{\circ} \mathrm{C}$ from day 4 but remained stable $\left(15-16^{\circ} \mathrm{C}\right)$ for the duration of the sampling period (Figure 2.8).

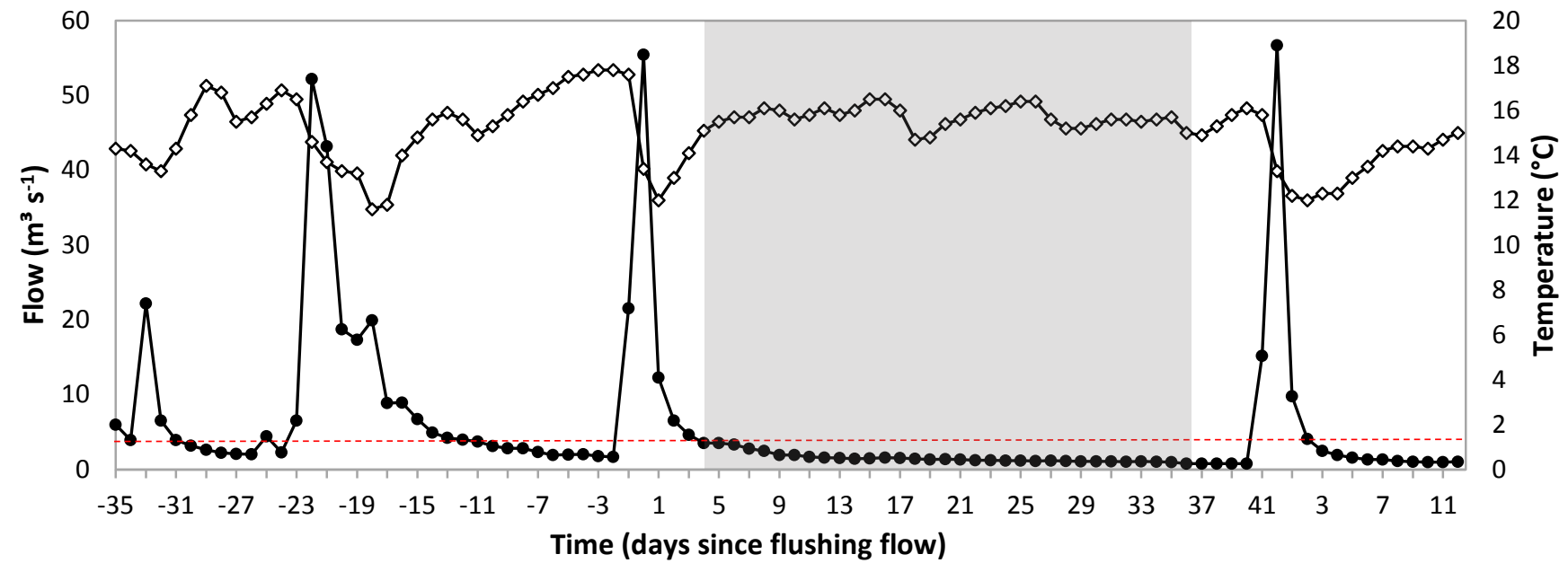

Figure 2.8 Summary of daily flow (solid) and temperature (white) data from 1 January to 31 March 2013, showing sampling period from 9 February to 13 March (shaded area); dotted line indicates the yearly median flow recorded at the Greater Wellington Regional Council gauging station at Te Marua (GWRC 1, Figure 2.1).

\subsubsection{Micro-algal community succession}

In total, 19 different micro-algal genera were identified from the biofilms at Site 1 (Appendix 5). The total biovolume of $P$. autumnale increased through time, starting at ca. $1.3 \times 10^{3} \mu^{3} / \mathrm{mm}^{2}$ on day 4 and peaking at day 33 with ca. $2.6 \times 10^{6} \mu \mathrm{m}^{3} / \mathrm{mm}^{2}$ (Figure 2.9). Likewise, the proportion of $P$. autumnale constituting the total micro-algal biovolume increased from $17 \%$ at day 4 to a maximum of $86 \%$ by day 33 (Figure 2.10). The pico-cyanobacteria Heteroleibleinia was initially (day 4) a prominent biofilm component, accounting for the majority of other cyanobacteria 
encountered, where it made up ca. $50 \%$ of the total biovolume (Figure 2.9). But the biovolume reduced to $5-10 \%$ between day 8 and 24, after which it became negligible (Figure 2.10). Diatoms (mainly Navicula spp., Synydra spp., Fragilaria spp. and Achnanthidium spp.; Appendix 1) comprised the majority (75\%) of the biovolume on day 8 but their dominance fluctuated over time, and reduced to $<15 \%$ by day 33. Green algae and Desmids (Desmidaceae) accounted for $<5 \%$ over the entire study period.

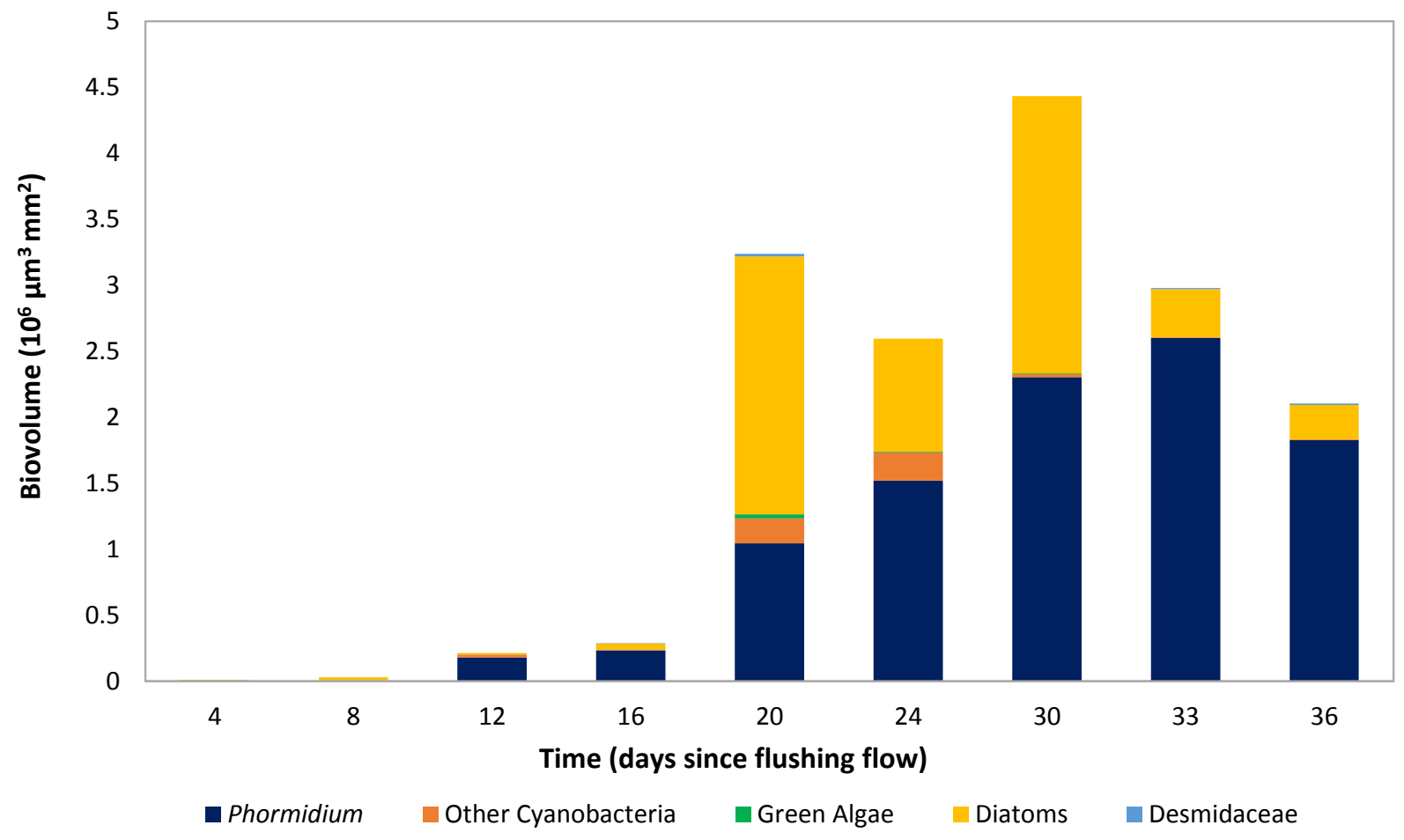

Figure 2.9 Mean micro-algal biovolumes $(n=3)$ per day at Site 1 in the Hutt River, Wellington between 9 February and 13 March 2013.

There was no statistically significant difference in the mean ranks for micro-algal richness $(S)$ diversity $\left(H^{\prime}\right)$ or genera evenness $(J)$ over time $\left(\mathrm{df}=8\right.$ and $\chi^{2}=12.837,12.267,11.733$, respectively, $p>0.05$; Figure 2.11, Appendix 2). However, a significant change in micro-algal composition over time was identified $(\mathrm{df}=8,14, F=3.86, p=0.0001)$ from the PERMANOVA (Table 2.3), with time (days since flushing flow) explaining $65 \%$ of the variation. There was also 
a significant difference in micro-algal composition between the three rocks that were analysed (df $=2,14, F=1.065, p=0.0001)$. These changes in biofilm composition over time could not be explained by any of the environmental variables tested (velocity, depth, flow, temperature and conductivity; $p>0.05)$.

Three micro-algal phases were identified from the cluster analysis (Figure 2.12). Groups A, B and C align approximately with early (days 4-16), mid (days 20-30) and late (days 33-36) phases of biofilm succession respectively, apart from three samples from days 4 and 8 that did not cluster with any other samples ( $<30 \%$ similar to majority of samples) and one from day 16 that clustered with days 33-36. The three micro-algae groups were 50\% similar to each other overall (Figure 2.12). Based on the SIMPER analysis, the mid and late phases were the most similar to each other (45\%), the early and mid-phases were the next most similar (32\%), while the early and late phases were the least similar (30\%). Within their respective phases the samples were 58\% (A), 68\% (B) and $70 \%$ (C) similar. Cyanobacteria were the most influential to similarities within each phase of

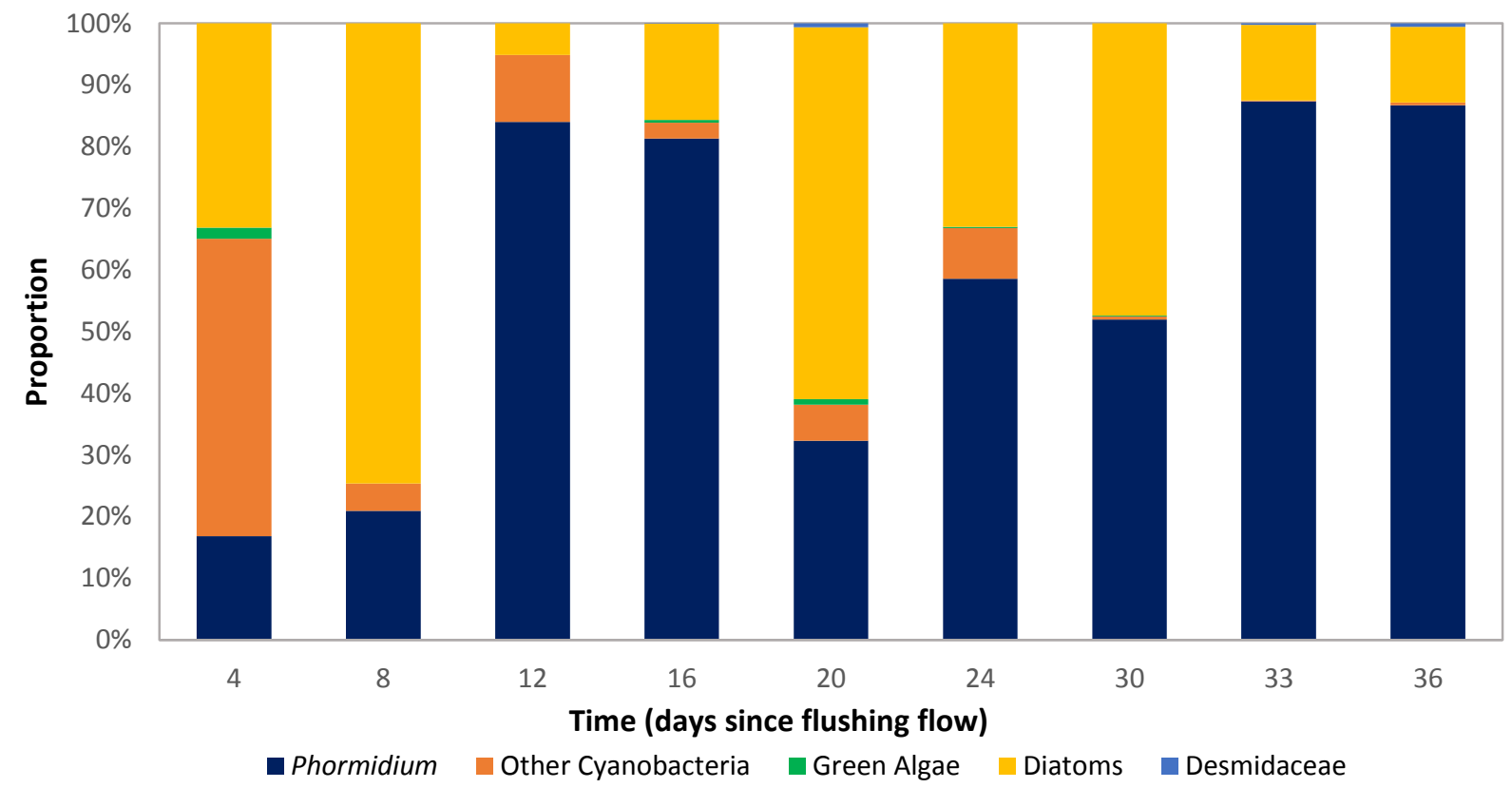

Figure 2.10 Mean micro-algal biovolumes $(\mathrm{n}=3)$ per day as a proportion of the total biofilm biovolume at Site 1 in the Hutt River, Wellington between 9 February and 13 March 2013. 
succession, with a 73 to $79 \%$ cumulative contribution to the similarities, while five diatom genera made a minor contribution (Table 2.4). Heteroleibleinia contributed the most to the similarities within the early and mid-phases, however, $P$. autumnale became increasingly important in each successive phase.

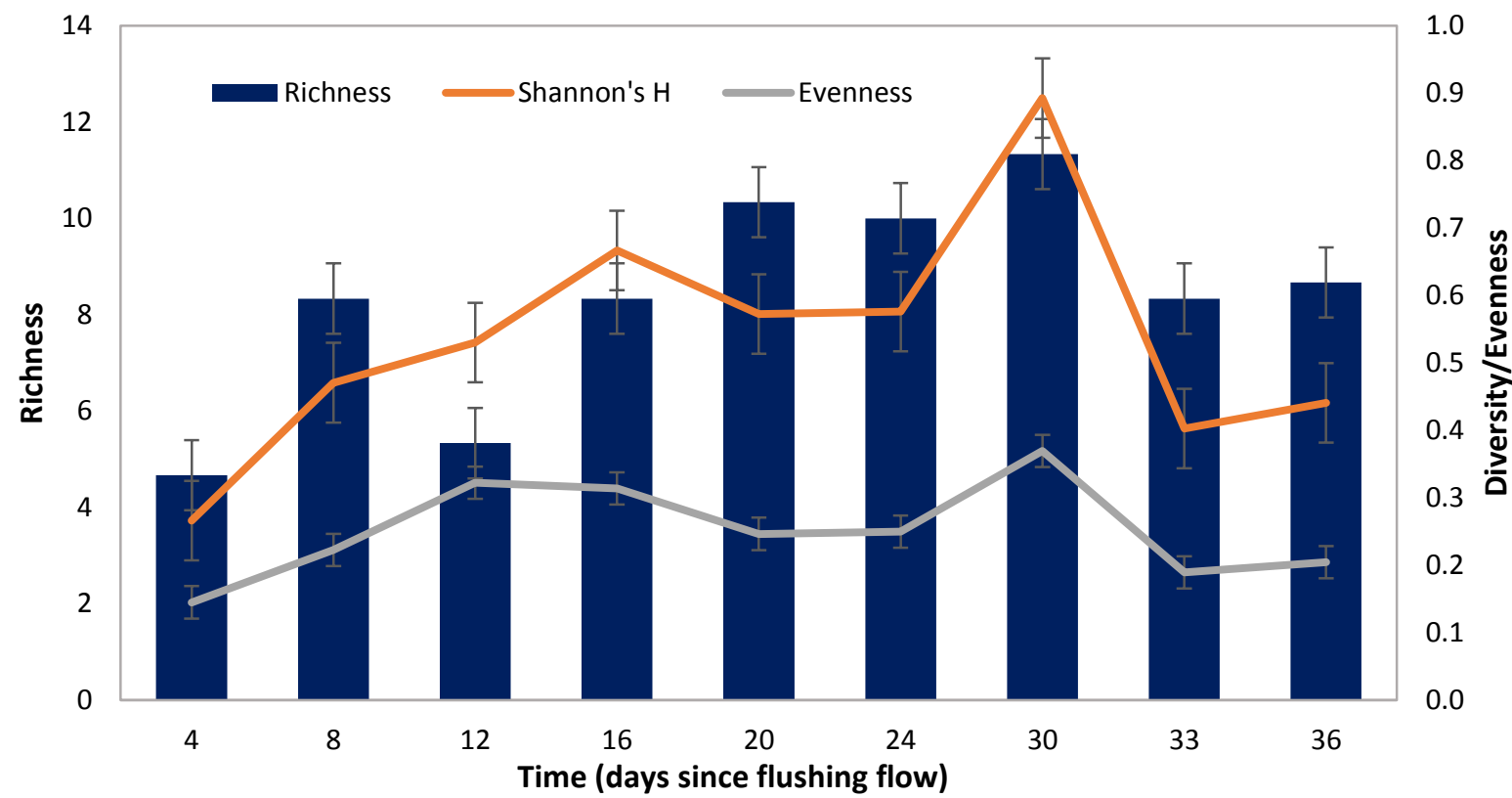

Figure 2.11 Measures of micro-algal community diversity. Mean micro-algal richness $(S)$, diversity $\left(H^{\prime}\right)$, and evenness $(J)$ for Site 1 in the Hutt River, Wellington between 9 February and 13 March 2013. Error bars show one standard error $(n=3)$.

Table 2.3 Micro-algal abundance PERMANOVA summary showing significant variation in abundances over time (days).

\begin{tabular}{lllllll}
\hline & $\mathrm{df}$ & $\mathrm{SS}$ & $\mathrm{MS}$ & $F$ statistic & $\mathrm{R}^{2}$ & $p$-value \\
\hline Rock & 2 & 0.101 & 0.051 & 1.065 & 0.044 & $<0.001$ \\
Day & 8 & 1.520 & 0.190 & 3.992 & 0.651 & $<0.001$ \\
Velocity & 1 & 0.009 & 0.009 & 0.182 & 0.004 & 0.952 \\
Depth & 1 & 0.036 & 0.036 & 0.755 & 0.015 & 0.558 \\
Residual & 14 & 0.666 & 0.048 & & 0.286 & \\
Total & 26 & 2.332 & & & 1.000 & \\
\hline
\end{tabular}




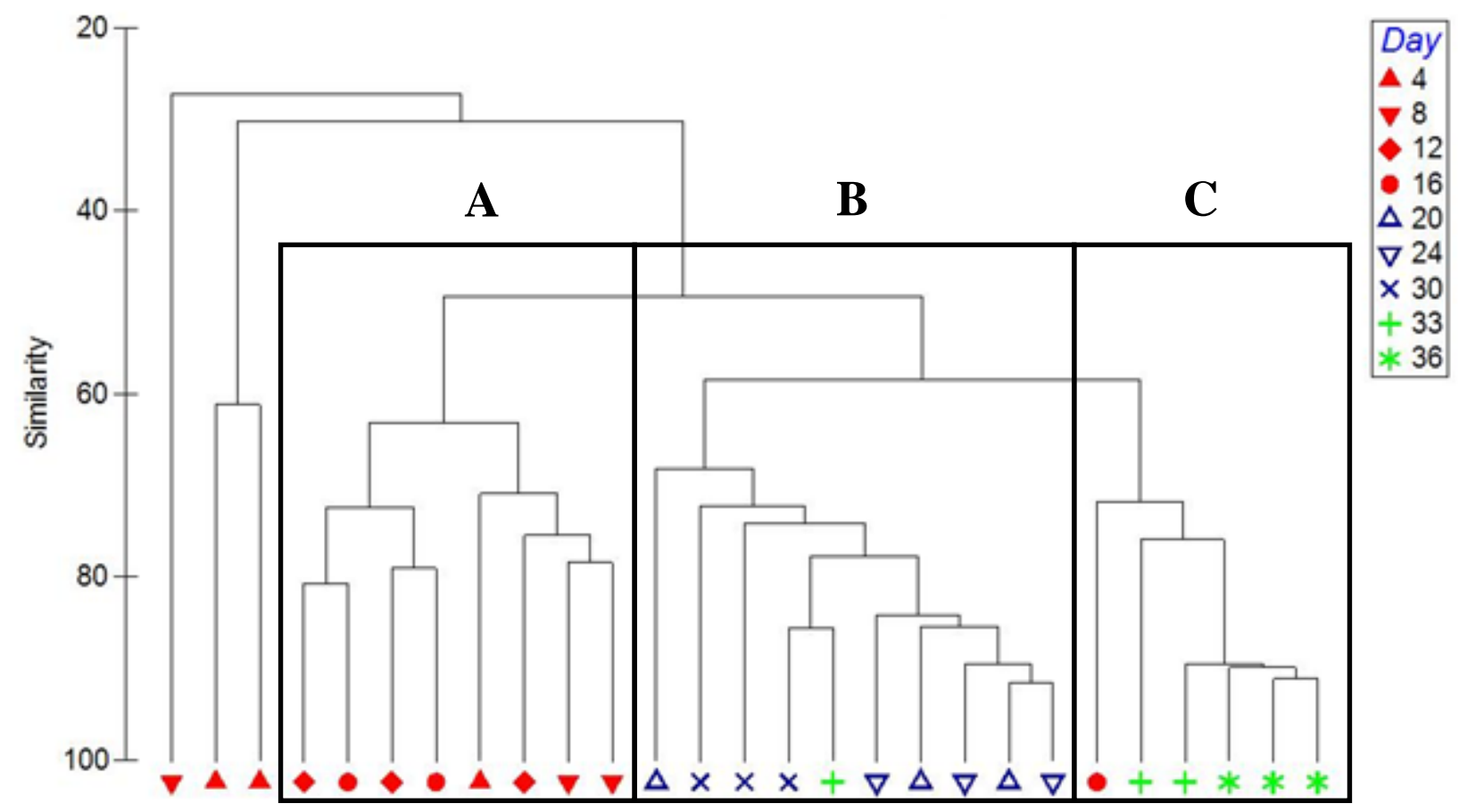

Figure 2.12 Cluster analysis of micro-algal communities from microscope identifications (data fourth root transformed) based on Bray-Curtis similarities. Groupings represent an early (A; day 4-16), mid (B; day 20-30) and late (C; day 33-36) phase of community succession.

Table 2.4 Similarity percentages (SIMPER) of micro-algal taxa contributing to composition of the successional phases (A, B and C) identified in the cluster analysis (Figure 2.12). Only taxa with the highest percent contributions that cumulatively comprised $>90 \%$ are reported.

\begin{tabular}{lccc}
\hline & \multicolumn{3}{c}{ \% Contribution within phases } \\
& Early (A) & Mid (B) & Late (C) \\
\cline { 2 - 4 } \multicolumn{1}{c}{ Average similarity } & 58 & 68 & 70 \\
\hline Heteroleibleinia & 54 & 38 & - \\
Phormidium autumnale & 25 & 37 & 61 \\
Leptolyngbya & - & - & 12 \\
Melosira & 8 & - & - \\
Gomphonema & 4 & 6 & 4 \\
Fragilaria & - & 7 & 6 \\
Achnantidium & - & 5 & - \\
Cymbella & - & - & 3 \\
\hline
\end{tabular}




\subsubsection{Automated Ribosomal Intergenic Spacer Analysis (ARISA) of bacterial community succession}

There was no significant variation in bacterial community structure (ARISA peaks) in richness ( $S$, $\mathrm{df}=7, F=2.448)$, diversity $\left(H^{\prime}\right)$ and evenness $(J)$ over time $\left(\mathrm{df}=8, \chi^{2}=2.311,6.578\right.$ respectively, $p>0.05$; Figure 2.13, Appendix 3). A significant change in bacterial community composition over time (df $=8,14, F=3.86, p=0.0001)$ was identified from the PERMANOVA (Table 2.6), with $36 \%$ of the differences in bacterial community composition explained by the days since flushing flow. These difference in composition over time could not be explained by any of the environmental variables tested (velocity, depth, flow, temperature and conductivity; $p>0.05$ ).

As with the micro-algal cluster analysis, there were three distinct groups of similar bacterial composition, which also consisted of an early (A), mid (B), and late phase (C) of biofilm development (Figure 2.14). These groups align closely with the micro-algal clusters, particularly the early phase, but the bacterial community changed faster than that of the micro-algae. The three phases were less than $20 \%$ similar to each other and 20\% (A), 36\% (B) and 33\% (C) similar within the respective groups (Figure 2.14). 


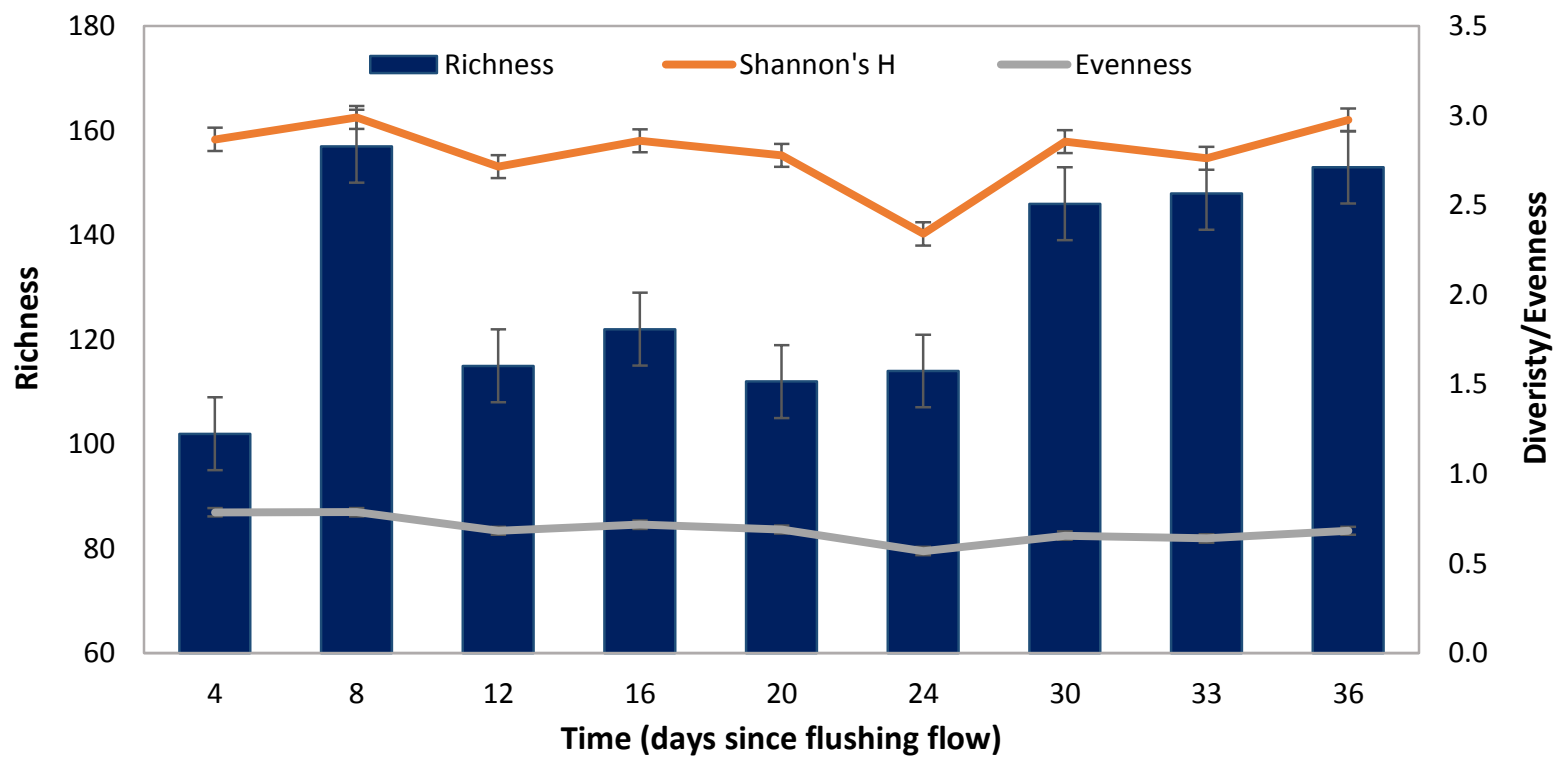

Figure 2.13 Summary of bacterial community diversity (ARISA peaks). Mean OTU richness $(S)$, diversity $\left(H^{\prime}\right)$, and evenness $(J)$ for Site 1 in the Hutt River, Wellington between 9 February and 13 March 2013. Error bars show one standard error $(\mathrm{n}=3)$.

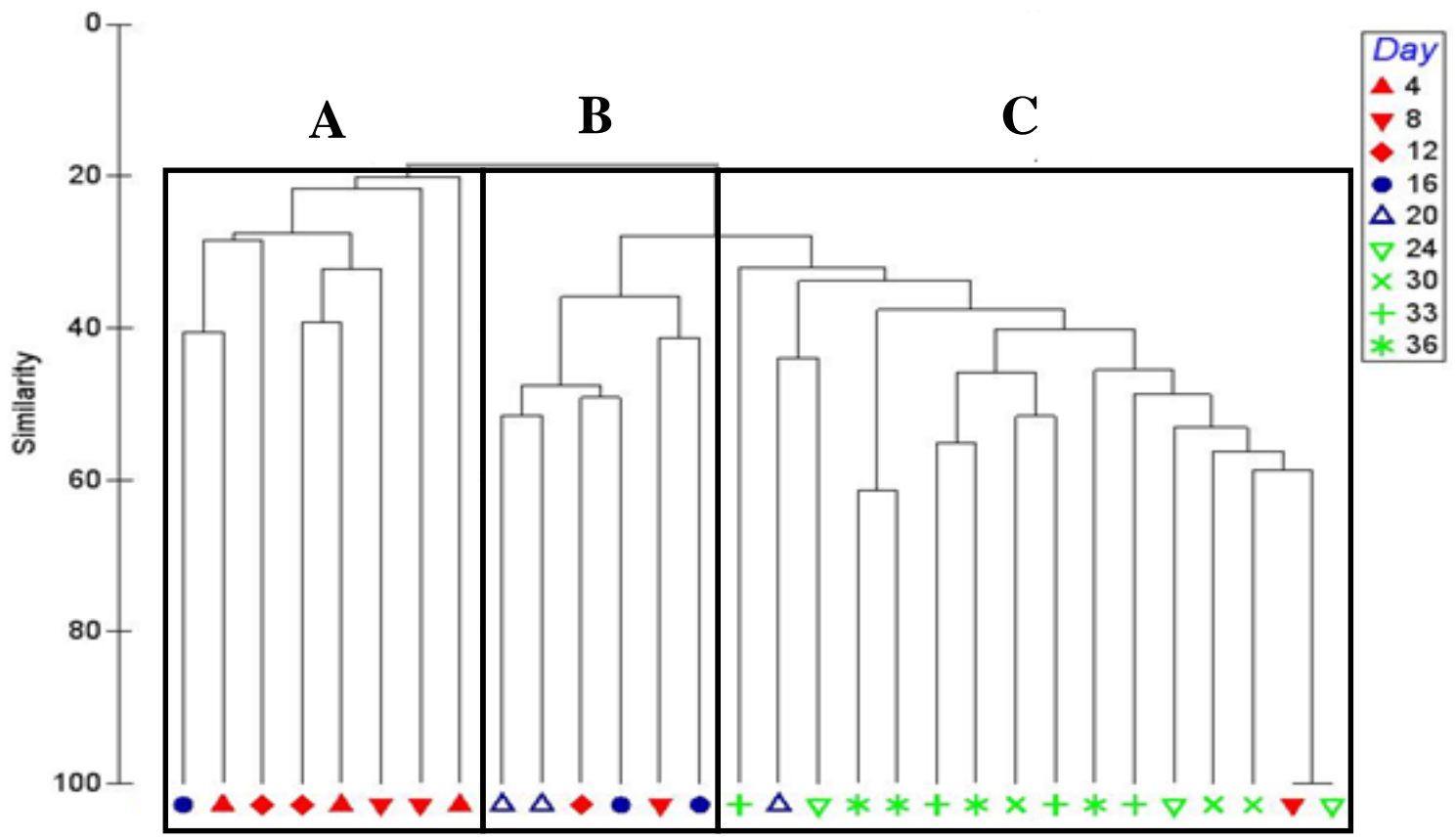

Figure 2.14 Cluster analysis of bacterial ARISA peaks based on Sørensen similarity, showing individual replicates from each sampling day. Boxes represent groupings in early (A; day 4-12) mid (B; day 12-20) and late (C; day 20-36) phases of succession. 
Table 2.6 Bacterial PERMANOVA showing significant variation in bacterial assemblages (ARISA peaks) over time (days).

\begin{tabular}{lllllll}
\hline & $\mathrm{df}$ & $\mathrm{SS}$ & $\mathrm{MS}$ & $F$ statistic & $\mathrm{R}^{2}$ & $\mathrm{p}$-value \\
\hline Rock & 3 & 1.141 & 0.381 & 1.304 & 0.113 & $<0.001$ \\
Day & 8 & 3.644 & 0.456 & 1.561 & 0.360 & $<0.001$ \\
Velocity & 1 & 0.318 & 0.318 & 1.091 & 0.031 & 0.304 \\
Depth & 1 & 0.354 & 0.354 & 1.214 & 0.035 & 0.158 \\
Residual & 16 & 4.669 & 0.292 & & 0.461 & \\
Total & 29 & 10.127 & & & 1.000 & \\
\hline
\end{tabular}

\subsubsection{Illumina ${ }^{\mathrm{TM}}$ bacterial community sequencing analysis}

The raw sequencing data produced $2,175,337$ reads. The sequence filtering parameters resulted in the removal of 762,251 reads $(35 \%)$ after quality filtering, chimera removal and alignment. The number of high-quality reads usable for downstream analyses were 1,413,086 reads or 78,505 reads per sample $(\mathrm{n}=18)$.

Concordant with the previous two cluster analyses, the bacterial communities (excluding cyanobacteria) clustered into three phases: early (A; days 8 - 12), mid (B; days $16-24)$ and late (C; days 30 - 36; Figure 2.16). The SIMPER analysis showed that all three groups were at least $36 \%$ similar overall, and samples within each group became increasingly similar to each other over time $(36 \%, 53 \%$ and $64 \%$, respectively; Table 2.7$)$. The early and mid-phases were most similar $(56 \%)$ to each other and the mid and late phases were least similar (46\%), while the early and late phases were less similar (55\%) than the early and mid-phases. No significant difference was detected $(p>0.05)$ for genera richness $(S)$, diversity $\left(H^{\prime}\right)$ or evenness $(J)$ between the three phases over time (Figure 2.15). 
Cyanobacteria were the dominant class throughout the biofilm succession (Figure 2.16, top), and of the other bacteria the Alphaproteobacteria, Betaproteobacteria and Sphingobacteria contributed the most to the similarities within the three phases (Table 2.7). In the early and mid-phases the Alphaproteobacteria made the highest contribution to the similarities within the phases, but they were surpassed by Sphingobacteria in the late phase. The bacterial genera Litromicrobium, Ahrensia, Catellibacterium and Sphingomonas were dominant (24\%, 16\%, 11\% and 9\% on average, respectively) in the early phase (A), while Pedobacter, Flavobacterium and Pandoraea became prominent $(27 \%, 15 \%$ and $20 \%$ on average, respectively) in the mid phase (B; Figure 2.16). Runella also became prominent (20\% on average) in the late phase, while Pedobacter and Flavobacterium remained relatively abundant (22\% and $13 \%$ on average).

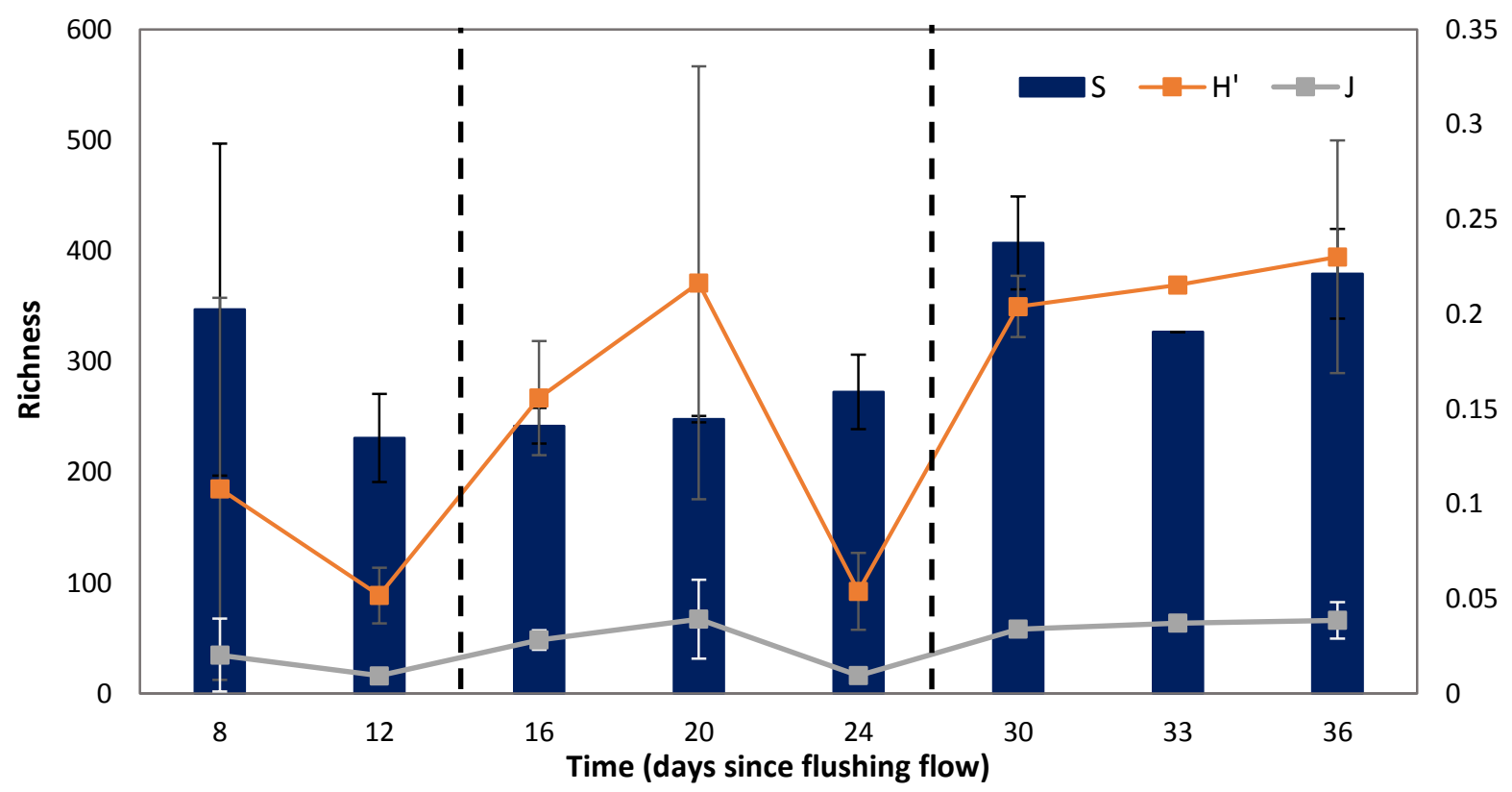

Figure 2.15 Measures of diversity for bacterial genera (excluding cyanobacteria). Mean genera richness $(S)$, Shannon Diversity $\left(H^{\prime}\right)$ and evenness $(J)$ of the Illumina ${ }^{\mathrm{TM}}$ bacterial community analysis, collected from Site 1 between 9 February and 13 March 2013. Error bars display one standard error ( $n=2$ to 3 ). Dashed lines indicate separation of the three phases identified in the Illumina $^{\mathrm{TM}}$ cluster analysis (Figure 2.16). Note no error bar for day $33(\mathrm{n}=1)$. 
Table 2.7 Similarity percentages (SIMPER) of bacterial classes determined by Illumina ${ }^{\mathrm{TM}}$ sequencing analysis (excluding cyanobacteria) contributing to composition of the successional phases (A, B and C) identified in the cluster analysis (Figure 2.15). Only classes with the highest percent contributions that cumulatively contributed $>90 \%$ similarity are reported.

\begin{tabular}{|c|c|c|c|}
\hline & \multicolumn{3}{|c|}{$\%$ Contribution within phases } \\
\hline & Early (A) & Mid (B) & Late $(\mathrm{C})$ \\
\hline Average similarity & 78 & 80 & 84 \\
\hline Alphaproteobacteria & 19.9 & 17.8 & 15.9 \\
\hline Betaproteobacteria & 15.9 & 16.4 & 14.6 \\
\hline Gammaproteobacteria & 9.1 & 6.0 & 4.8 \\
\hline Deltaproteobacteria & 4.0 & 2.0 & 2.7 \\
\hline Epsilonproteobacteria & 2.5 & 1.6 & - \\
\hline Sphingobacteria & 13.2 & 16.7 & 17.6 \\
\hline Flavobacteria & 6.4 & 9.5 & 7.7 \\
\hline Bacteroidia & 2.0 & - & 4.7 \\
\hline Deinococci & 2.4 & 2.0 & 2.5 \\
\hline Clostridia & 2.2 & 2.1 & 2.6 \\
\hline Lentisphaeria & 1.7 & - & - \\
\hline Actinobacteria & 1.6 & - & 1.7 \\
\hline Bacilli & 1.4 & - & 1.3 \\
\hline Verrucomicrobiae & - & - & 2.4 \\
\hline Planctomycetacia & - & 1.3 & 1.9 \\
\hline Opitutae & - & - & 1.8 \\
\hline Fusobacteria & - & 1.5 & 1.3 \\
\hline
\end{tabular}




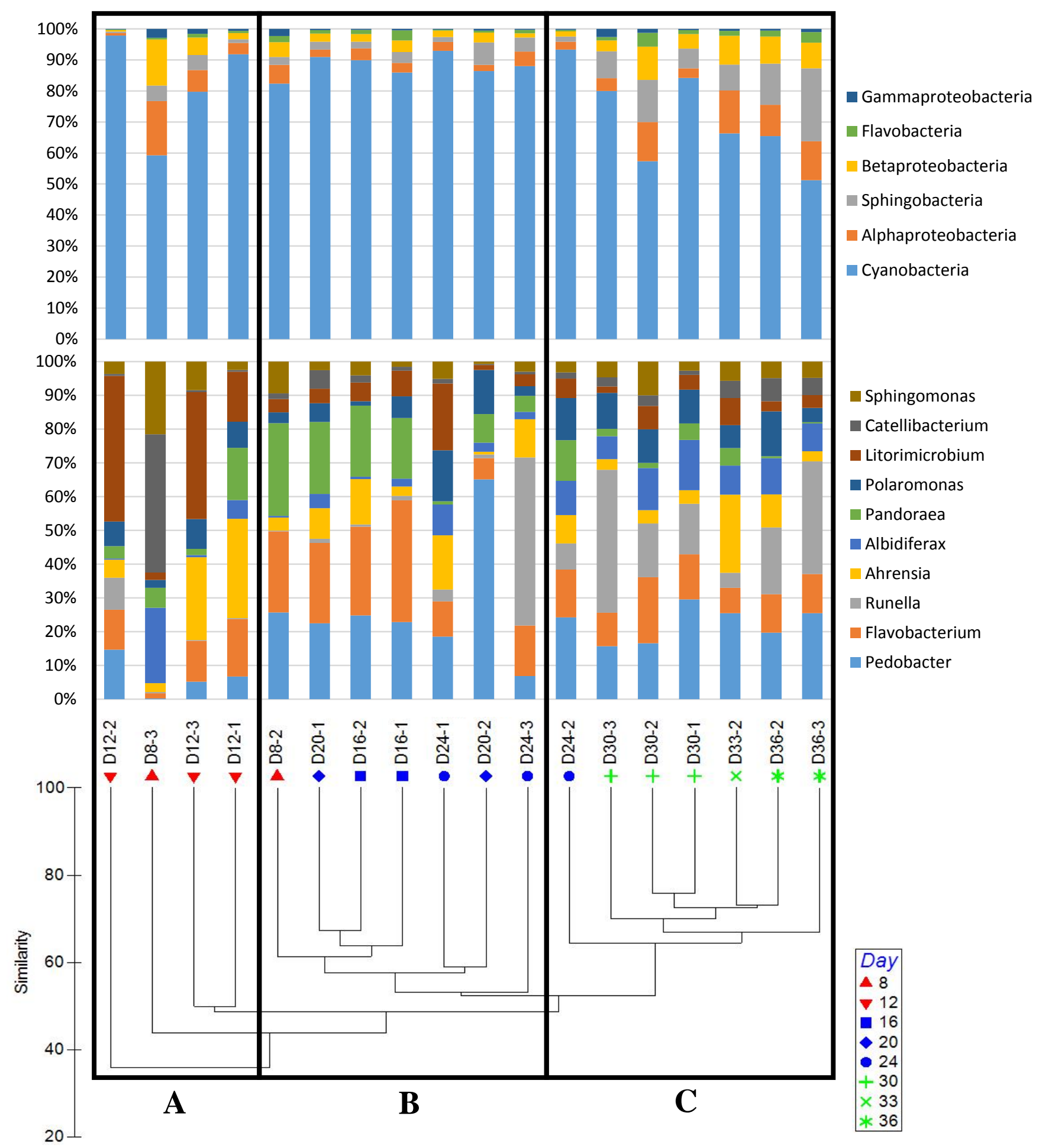

Figure 2.16 Composition of bacterial classes (Top; excluding classes that comprised $<1 \%$ of the total sequences), composition of bacterial genera (Middle; 10 most common genera, comprising 39\% of total sequences (minus Cyanobacterial and Diatom sequences) and cluster analysis of bacterial genera based on Bray-Curtis similarities (Bottom). Boxes indicate three successional phases (early, mid and late) determined in the cluster analysis (A, B and $\mathrm{C}$, respectively). 


\subsection{Discussion}

This study is the first to characterise microbial succession in P. autumnale-dominated biofilms, and one of few in situ successional studies of benthic biofilms carried out with minimal environmental manipulation. This study detected fine scale bacterial and micro-algal community changes through intensive sampling and use of a combination of morphological and molecular characterisation approaches.

\subsubsection{Microbial community succession}

A distinct succession of micro-algal and bacterial assemblages was observed during this study. All three analyses, the micro-algal abundance, bacterial ARISA and bacterial Illumina ${ }^{\mathrm{TM}}$ sequencing, identified three distinct community assemblages, which clustered into early, mid and late phases of growth. Despite being analysed using three completely different protocols the two microbial assemblages split into three clusters in strikingly similar time periods, with the bacterial community shifts occurring four days (from early-mid phase) and nine days (from mid-late phase) before the micro-algae community. Bacterial community turnover occurs earlier and faster than that of micro-algae, and some marine bacterial communities may change within the first nine hours of substrate colonisation (Pohlon et al., 2010). In the current study, it is likely the bacterial community had reached a period of stability in late succession (day 24-36). At approximately day 20 in this study, $P$. autumnale began to grow rapidly - indicating the introduction or increase of one or many bacteria, or the conditions that they create, which may benefit $P$. autumnale.

The initial micro-algal community consisted mainly of the pico-cyanobacteria Heteroleibleinia spp. and diatoms, with very little P. autumnale. However, by day 12 (within the early phase, based on Figure 2.12), P. autumnale was clearly dominant and reached a phase of rapid growth after day 
20 , which coincided with the first micro-algal community shift from early to mid-phase of succession (Figure $2.12 \& 2.14$ ). These findings contradict previous studies of benthic microbial assemblages where micro-algae, such as diatoms or green algae usually follow the colonisation of bacteria, while cyanobacteria often do not dominate until late succession (Barranguet et al., 2005, Besemer et al., 2007, Roeselers et al., 2007). Phormidium autumnale abundance increased through time, despite a transient addition of diatoms on day 20 , and only began to subside in the very mature stages of development (Figure 2.9). There was no co-occurring increase in bulk water nutrients that may have driven this sudden biomass increase, nor were there any coincident changes in point velocity, depth, conductivity, flow or temperature - indicating that some other intrinsic factor is driving these changes.

The major differences between the early and mid-phases were the increase in both $P$. autumnale and diatom growth seen on day 20 at Site 1 (Figure 2.14). It is unclear whether the drivers of this change were the micro-algae themselves or some aspect of the bacterial community. Biofilm succession is usually driven by photosynthetic algal components once they have established within the biofilm and bacteria are able to utilise algal photosynthates for nutrition (Barranguet et al., 2005, Besemer et al., 2007, Roeselers et al., 2007). In this case $P$. autumnale is also a photoautotroph and may function within the mat on the same level as diatoms - most likely as competitors. The shift on day 20 was preceded by a shift in the bacterial community ca. days 8-16 (Figure 2.16), showing there is an obvious lag in the timing of micro-algal community shift in relation to the bacterial community at this point. Heterotrophic bacteria rely less on external sources for nutrition in mid-phase succession and become increasingly dependent on algal photosynthates as autotrophic microbes colonise and proliferate in the biofilm - forming a closed system within the biofilm matrix (Barranguet et al., 2005, Besemer et al., 2007). The bacterial 
genera that became dominant in the mid-phase (Pedobacter, Flavobacterium and Pandoraea) had no distinct features that would implicate them in driving these changes in the micro-algae, such as high exopolysaccharide production. Conversely, it could be expected that as the biofilm matrix thickens and is able to shelter microbes from the effects of river flow, a reduction in aerobic and increase in anaerobic bacteria may occur, indicating a change in redox potential that facilitates mobilisation of phosphates (House, 2003). Collectively these results suggest succession is driven by bacteria in the early stages but becomes dependent on micro-algae in the mid and late stages, as bacteria metabolise photosynthates trapped in the biofilm matrix. However, there is still a very limited understanding of the functional roles of most bacteria and many cyanobacteria remain poorly characterised - making it difficult to infer relationships among these groups.

The shift from mid to late phase succession is likely due to the reduction of diatoms and the increase in bacterial taxa abundance (Figure 2.9, Figure 2.16, top). Bacteria are well known decomposers and tend to scavenge cellular by-products, effectively recycling them in the biofilm (Pohlon et al., 2010). The class Flavobacteria (sometimes referred to as Cytophaga-Flavobacteria) are proficient degraders of biopolymers such as cellulose and chitin (Kirchman, 2002), and were a dominant class that increased in mid to late succession in this study. Two genera belonging to this group, Flavobacterium and Runella, collectively accounted for 35\% of the bacterial genera in the late phase, and were likely involved in degrading micro-algal by-products. The reduction in micro-algae in the late phase is probably due to natural cell lysis, which would provide organic matter for bacterial metabolism, enabling them to persist and proliferate in late succession.

Initial settlement of bacterial colonisers onto a substrate is largely controlled by physical factors (the interplay of flow transport and cell re-suspension by shear stress); but biological factors, such as active cell motility, cell adhesion and quorum sensing (the chemical signalling between cells), 
become much more important as succession progresses and microbial colonisers attenuate the effects of flow (Augspurger et al., 2010, Rice et al., 2000). The bacterium Sphingomonas was a prominent component in the early phase but less important in the following phases. It is also a common exopolysaccharide producer, and is likely to have an important role in attachment of microbes to the substrate (Azeredo and Oliveira, 2000). Sphingomonas may have been even more abundant prior to the start of the study period, however, bacteria are able to rapidly colonise after substrate clearance and some of these very early changes in bacterial composition may have been missed in this study. Most studies of the early biofilm successional stages are highly manipulated and often use artificial substrates (Besemer et al., 2007, McCormick and Stevenson, 1991, Sekar et al., 2002), whereas this study investigated in situ succession with minimal substrate manipulation. More experimental approaches may be needed to study how the fine-scale physical factors interact with bacterial-driven processes to form nascent biofilms in rivers where $P$. autumnale blooms occur.

Biofilm grazers, including protozoans and macroinvertebrates, can influence biofilm formation by selective grazing (Barranguet et al., 2005, Dopheide et al., 2011). This was not the focus of the current study but warrants further investigation as some $P$. autumnale biofilms with high densities of caddisfly larvae have been observed in New Zealand rivers (Bee et al., 2012).

\subsubsection{Environmental parameters}

None of the five environmental factors measured in this study (point velocity, depth, flow, water temperature and conductivity) could explain the changes in either the micro-algal or bacterial community compositions, despite significant differences in community compositions over time and between rocks within Site 1 . Previous studies have commonly identified water velocity as the main predictor of community variation (Besemer et al 2007). However, a study of $P$. autumnale 
habitat suitability criteria indicated that it can bloom in a wide range of velocities, depths and temperatures (Heath et al., 2013). They measured a 6-fold difference in velocity from 0.07-0.39 m $\mathrm{s}^{-1}$, in comparison to a much smaller 3.5-fold decrease in average velocity seen in the current study (Figure $2.7 \mathrm{~A}$ ), hence velocity is not likely to be contributing to the variation in $P$. autumnale cover in this study. However, even smaller-scale differences in velocity and substrate topography at the substrate-water interface may influence the initial settlement of microbes in biofilms (Augspurger et al., 2010) and could account for the observed variability in both the micro-algal and bacterial assemblages among rocks (Table 2.3).

Water nutrient conditions were largely consistent with past studies in the Hutt River and several other rivers around New Zealand (Heath et al., 2010, Heath et al., 2011). From day 8, nutrient levels remained below the suggested thresholds that favour $P$. autumnale blooms (ca. $>0.1 \mathrm{mg} \mathrm{L}^{-}$ ${ }^{1}$ DIN and ca. $<0.01$ DRP, Wood and Young 2012) at Site 1, while DIN was above these thresholds at Sites 2 and 3, where $P$. autumnale growth was significantly less than Site 1 . It is not likely that the levels of DIN were responsible for the low $P$. autumnale coverage on the study rocks at Site 2 and 3, as these were no greater than DIN concentrations reported during previous $P$. autumnale blooms (Heath et al., 2013, Heath et al., 2011). In this study and others conducted in rivers around New Zealand (Wood and Young, 2012), it appears that measuring nutrients only in the bulk water gives a poor indication of the delivery and use of nutrients in biofilm communities. Further studies should investigate other sources and sinks of nutrients (e.g. ground water, sediment deposits and microbial nutrient cycling) within river systems additional to bulk water nutrients.

Concentrations of DRP in the water column were very low throughout the study. Access to additional sources of phosphorus might explain how $P$. autumnale is able to produce such high biomass in relatively low nutrient rivers. A unique feature of $P$. autumnale is the accumulation of 
a thin layer of fine sediment at the substrate-biofilm interface. Wood and Young (2012) proposed that chemical conditions created in well-developed biofilms may increase the biological availability of sediment bound phosphorus that can be utilised by $P$. autumnale, allowing increased growth. The release of sediment-bound $\mathrm{P}$ from the substrate can occur in lakes and rivers due to a change in the redox potential, usually associated with a decrease in oxygen concentration and/or an increase in pH (House, 2003, Søndergaard et al., 2003). It is possible that such conditions exist underneath the $P$. autumnale biofilms, allowing the release of DRP from the sediment thus facilitating growth. Once released, this phosphorus would remain and be recycled within the biofilm matrix, fuelling further growth. A likely mechanism driving these processes is alkaline phosphatase activity - the enzymatic release of $\mathrm{P}$ bound to sediments and is a common response of biofilm microbes to P deprivation (Espeland and Wetzel, 2001a, Espeland and Wetzel, 2001b, Huang et al., 1998, Romani and Sabater, 2000).

Alkaline phosphatase is produced by multiple biofilm components, including bacteria, cyanobacteria, algae and protozoans, and usually only occurs in P-starved conditions (Espeland and Wetzel, 2001b), such as those found in the Hutt River. This enzyme activity may be important in early colonisation of substrates and has been detected in biofilms after just 4 hours colonisation time (Pohlon et al., 2010). Several of the prominent bacterial genera identified in this study (Sphingomonas, Catellibacterium, Pedobacter and Pandoraea) produce alkaline phosphatase and these were present throughout biofilm development. Nearly all of the dominant bacterial genera identified were strictly aerobic, although a few were facultative anaerobes (Catellibacterium, Flavobacterium and Albidiferax; Zhang et al., 2012, Bernardet and Bowman, 2006, Finneran et al., 2003) - suggesting it is possible that changes in redox potential occurring within the biofilms that could facilitate phosphatase activity. 
There was no apparent linkage between exponential $P$. autumnale growth and alkaline phosphatase-producing bacteria in this study; $P$. autumnale could possibly produce this enzyme itself, and if so, may compete for sediment-bound P. Alkaline phosphatase is most efficient in alkaline conditions but the $\mathrm{pH}$ conditions within $P$. autumnale-dominated biofilms have not yet been studied. Availability of organic carbon, for example, from algal photosynthates, can also affect alkaline phosphatase production (Espeland and Wetzel, 2001b). The bacterium Pseudomonas was able to outcompete the green algae Scenedesmus for phosphate uptake in the presence of glucose (Jansson, 1993), which may mean $P$. autumnale could also outcompete other benthic algae for limited phosphates in the presence of an abundant organic carbon source. Further investigation of alkaline phosphatase producers and the cycling of organic carbon within the biofilms are needed to determine which processes are driving the dominance of P. autumnale.

The production of secondary metabolites by various biofilm microbes may potentially influence the community structure of $P$. autumnale biofilms. The importance of bio-chemical factors (e.g. cell-cell signalling) in structuring community assemblages is well studied in planktonic species but poorly understood in benthic communities (Leflaive et al., 2008). A successional study of diatom-dominated biofilms in France attempted to determine the role of allelopathy (the phenomenon where bio-chemicals influence the growth, survival, and reproduction of other organisms) in biofilm succession, concluding that intrinsic (rather than extrinsic) chemical factors had inhibitory effects on certain diatom species but they were unable to determine what these were and if they were produced by biofilm microbes (Leflaive et al., 2008). Most of the allelopathic compounds that have been purified and identified are produced by benthic cyanobacteria (Leflaive et al., 2008). The extent to which bio-chemicals could be involved in $P$. autumnale dominance within the biofilms were not the focus of this study, however, the production of anatoxins by $P$. 
autumnale provides an interesting case for potential allelopathic roles and is explored further in Chapter 3.

\subsubsection{Biofilm coverage}

It is not clear why biofilm cover on the study rocks at Sites 2 and 3 was so low compared to Site 1. Previous studies have reported P. autumnale blooms at Site 2 and 3, with Site 3 having some of the most extensive blooms seen in New Zealand to date (Heath et al., 2011, Milne and Watts, 2007). Given the severity of the flushing flow that occurred prior to the study period (14 times median flow), it is possible there was a reduction of inoculum in the upper reaches of the Hutt River (the majority of which would have been scoured off the substrate and washed away during the flush), hence lengthening the re-colonisation period. There was no apparent effect of removing biofilm material from the re-sampled rocks, although the untouched rocks had a greater range in the percent cover. This was likely due to a single rock that had much higher percent coverage than the rest, disproportionately influencing the within-site average. Adding more rocks in the initial experimental analysis would better capture the true within-site variability in biofilm coverage and reduce the statistical effects of outliers in the data set.

\subsubsection{Conclusion}

Distinct and concordant phases of microbial community succession were identified in both microalgae and bacterial assemblages within the $P$. autumnale-dominated biofilms forming in the Hutt River. There is some indication of bacterial driven succession, potentially through alteration of physio- and bio-chemical conditions within the biofilm matrix, but most likely a combination of bacterial and algal drivers that create a feedback loop. The mechanisms of this warrant further investigation to determine the functional roles of bacteria throughout biofilm succession and 
identify specific drivers of $P$. autumnale dominance, focusing on the fine-scale bio-chemical activities and/or allelopathic interactions within the biofilm matrix. 


\section{Chapter 3: Anatoxin production and variability during biofilm succession}

\subsection{Introduction}

Cyanobacteria produce a range of secondary metabolites, many of which are toxic to humans and other animals (Carmichael, 2001). Collectively these are known as cyanotoxins and they can be produced by both planktonic and benthic species. The health risks posed to humans and animals by toxic cyanobacteria are now recognised worldwide (Chorus and Bartram, 1999). When conditions are favourable (e.g. high temperatures and abundant nutrients), cyanobacterial blooms can form, and the toxins produced during these events can have severe implications for aquatic organisms and human and animal users of these ecosystems. One of the most severe cases of human poisoning from cyanotoxins occurred in Brazil in 1996 when a hospital's water supply was contaminated with cyanotoxins, leading to the death of 52 renal dialysis patients (Azevedo et al., 2002). There have also been multiple cases of death or poisoning of domestic and wild animals after consumption of cyanobacteria. For example, in a Japanese lake, 20 ducks died of hepatotoxicity after a bloom of microcystin-producing Microcystis auriginosa and in an extreme case, over 10,000 livestock died during a massive bloom of neurotoxic Anabeana circinalis in the Darling River, Australia (Briand et al., 2003).

In contrast to planktonic cyanobacteria, benthic species and their associated toxins are poorly studied, despite being linked to numerous animal deaths globally (Hamill, 2001, Mez et al., 1998, Gugger et al., 2005, Wood et al., 2007, Heath et al., 2011, Cadel-Six et al., 2007). Common species that dominate benthic biofilms include Oscillatoria, Phormidium, Leptolyngbya and Tychonema (Quiblier et al., 2013). Toxin production and/or toxicosis from benthic cyanobacteria has been reported from France (Gugger et al., 2005), Spain (Hurtado et al., 2008), the Netherlands (Fiore et 
al., 2009), Switzerland (Mez et al., 1998), Scotland (Edwards et al., 1992), Ireland (James et al., 1997), USA (Izaguirre et al., 2007), Canada (Lajeunesse et al., 2012), Australia (Seifert et al., 2007), New Zealand (Wood et al., 2012a), Kenya (Krienitz et al., 2003), Egypt (Mohamed et al., 2006) and the Baltic sea (Surakka et al., 2005).

Over the last decade there has been an increase in the prevalence and intensity of benthic cyanobacterial blooms in New Zealand rivers (Milne and Watts, 2007, Wood and Young, 2012). This has primarily been identified due to increased reports of dog deaths after consumption of benthic cyanobacterial material (Hamill, 2001, Wood et al., 2007). As a result, New Zealand is one of the first nations to explore the biotic and abiotic variables that influence anatoxin production in benthic cyanobacteria.

The first report of dog neurotoxicosis in New Zealand after ingestion of benthic cyanobacteria was in 1998 (Hamill, 2001). The cyanobacteria responsible were from the order Oscillatoriales. Subsequently, five dogs died in 2005 after visiting the Hutt River (Wellington, New Zealand). Analysis of stomach contents and cyanobacteria biofilms confirmed the presence of the potent neurotoxins anatoxin-a (ATX) and homoanatoxin-a (HTX). Phormidium autumnale (Oscillatoriales) was identified as the causative species (Wood et al., 2007). Further studies have shown P. autumnale is dominant in toxic benthic cyanobacterial blooms in New Zealand rivers (Heath et al., 2010).

The majority of known cyanotoxins have been identified from benthic blooms, this includes hepatotoxins (microcystins; MC, nodularins and cylindrospermopsins) and neurotoxins (ATX, HTX and saxitoxins; STX; Quiblier et al., 2013), and of these, MC and ATX are the most common (Edwards et al., 1992, Gugger et al., 2005, Quiblier et al., 2013, Wood et al., 2007). However, the 
frequent detection of MC and ATX may be due to sampling biases and the availability of routine tests for these toxins. In New Zealand benthic blooms, ATX and HTX are the most commonly detected cyanotoxins (Heath et al., 2011, Milne and Watts, 2007, Wood et al., 2012b). Anatoxina and HTX (its methylene homologue; Figure 3.1) are alkaloid toxins and potent neuromuscular blocking agents that act by binding to nicotinic acetylcholine receptors, causing symptoms that include convulsions, paralysis, hyper-salivation and respiratory arrest leading to death (Aráoz et al., 2010, Carmichael, 2001). Deaths and sub-lethal effects from ATX/HTX toxicosis have thus far been reported in mammals, birds, reptiles and fish (Aráoz et al., 2010, Osswald et al., 2009). The dihydrogen derivatives of ATX, dihydroanatoxin-a (dhATX) and dihydrohomoanatoxin-a (dhHTX), also bind to nicotinic acetylcholine receptors but have a ten-fold reduction in binding efficiency and are therefore much less toxic than ATX and HTX (Mann et al., 2012). Collectively, these different variants are referred to as anatoxins.

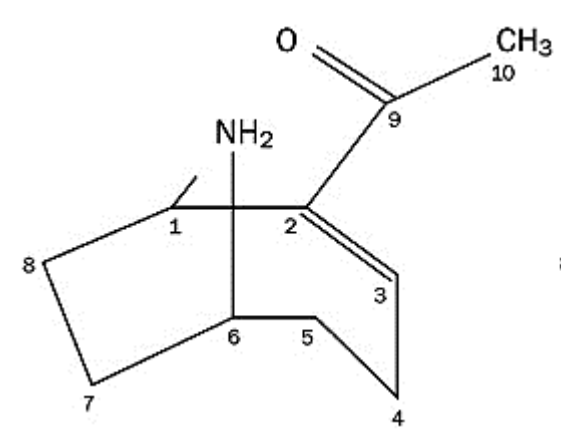

Anatoxin-a

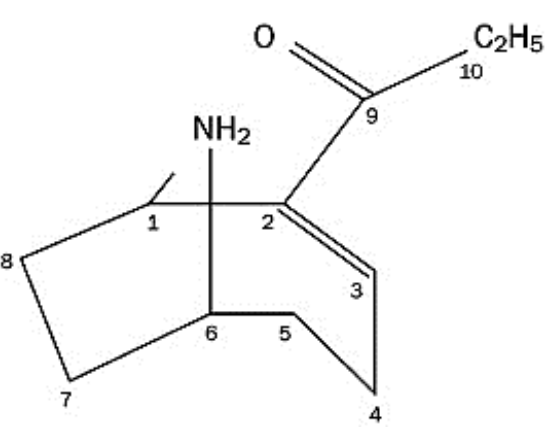

Homoanatoxin-a

Figure 3.1. Chemical structure of anatoxin-a and its methylene homolog homoanatoxin-a, adapted from Osswald et al. (2007).

The function of toxins in both planktonic and benthic cyanobacteria is still unclear. A large amount of research has been undertaken on the regulation of toxin production and the ecological functions of the toxins for planktonic species - especially MC-producing Microcystis. Hypotheses for the 
biological role of MC include defence against grazers (Lürling, 2003), gene regulation (Žegura et al., 2008), colony formation (Gan et al., 2012), scavenging of metals (Sevilla et al., 2008) and protein-modulation (Zilliges et al., 2011). In planktonic species, anatoxin production and the ratio of toxic to non-toxic strains are known to vary with changes in light intensity, temperature and carbon and nitrogen concentration (Gagnon and Pick, 2012, Rapala and Sivonen, 1998, Rapala et al., 1993); although none of these could be directly linked to functionality of anatoxins. There are a limited number of studies investigating the same questions in benthic cyanobacteria.

Co-occurrence of toxic and non-toxic genotypes within the same bloom is well documented in planktonic species (Ballot et al., 2004, Wood, 2004, Wood et al., 2006). However, investigations of toxic and non-toxic genotypes in benthic blooms are scarce. Heath et al. (2010) found that only five of the seven $P$. autumnale strains isolated from environmental samples, which had tested positive for anatoxins via Liquid Chromatography-Mass Spectrometry (LC-MS), produced anatoxins in culture. Additionally, Cadel-Six et al. (2007) found that a strain of P. autumnale, isolated from the Tarn River in France, produced anatoxin although it was collected from a 'nontoxic' biofilm. Wood et al. (2012b) demonstrated that toxic and non-toxic P. autumnale genotypes can occur in the same biofilm within a $1 \mathrm{~cm}^{2}$ area of mat, and that different toxic genotypes vary dramatically in the amount of anatoxin they produce. Quantitative molecular techniques may help determine variables that cause toxic and non-toxic $P$. autumnale genotypes to dominate, and establish how the relative abundances of genotypes relate to actual toxin concentrations within a biofilm. Furthermore, anatoxin production varies under different nutrient culturing conditions (Smith, 2012) and also among localities over time (Heath et al., 2011).

Improved knowledge on the function of anatoxins in the environment and/or within biofilms requires further fine scale investigation to understand the relative quantities of toxic and non-toxic 
genotypes within mats. The amounts of toxin produced, and the way they change through successional stages of biofilm development are currently unknown. This study is the first to apply a combination of molecular methods to environmental $P$. autumnale biofilm samples from an early stage in biofilm formation. This chapter uses quantitative molecular techniques to determine how the overall anatoxin production and proportion of toxic to non-toxic genotypes varied through biofilm development, and whether this variation is related to changes in biofilm community composition. 


\subsection{Methods}

Refer to Chapter 2 (section 2.2.1) for sample collection and storage methods for samples/data collected from Site 1 in the Hutt River between 9 February and 13 March 2013.

\subsubsection{Anatoxin extraction and analysis}

The $10 \mathrm{~mL}$ frozen biofilm samples from Site 1 were lyophilized (FreeZone6, Labconco, USA) and $1 \mathrm{~mL}$ of Milli-Q water with $0.1 \%$ formic acid was added, followed by vortexing (30 s). Samples were sonicated (30 min, Cole Parmer 8890, Biolab, Auckland, NZ) on ice, centrifuged at $3000 \times$ $g, 10 \mathrm{~min}$ (Eppendorf, USA), and $1 \mathrm{~mL}$ of supernatant was transferred to a high performance liquid chromatography (HPLC) vial.

Samples were analysed for ATX, HTX, dihydroATX and dihydroHTX at the Cawthron Institute, Nelson on a Quattro Premier XE mass spectrometer (Waters-Micromass, Manchester). ATX and HTX were separated by ultra-performance liquid chromatography (Acuity UPLC, Waters Corp., MA, USA) using a $50 \times 0.1 \mathrm{~mm}$ Aquity BEH-C18 $(1.7 \mu \mathrm{m})$ column (Waters Corp., MA). The mobile phase A ( $0.1 \%$ formic acid in water) and mobile phase B ( $0.1 \%$ formic acid in acetonitrile) were used at a flow of $0.3 \mathrm{~mL} \mathrm{~min}^{-1}$, isocratic for $1 \mathrm{~min}$ at $100 \%$ A followed by a gradient to $50 \%$ B over 2 min, with an injection volume of $5 \mu \mathrm{L}$. The mass spectrometer was operated in ESI+ mode with capillary voltage $0.5 \mathrm{kV}$, desolvation gas $900 \mathrm{~L} \mathrm{~h}^{-1}$ at $400{ }^{\circ} \mathrm{C}$, cone gas $200 \mathrm{~L} \mathrm{~h}^{-1}$ and cone voltage $25 \mathrm{~V}$. Quantitative analysis was performed by multiple reaction monitoring (MRM) using MS-MS channels set up for ATX (166.15 > 149.1; Retention time (Rt) 1 min), HTX (180.2 $>163.15$; Rt $1.9 \mathrm{~min})$, dhATX $(168.1>56$; Rt $0.9 \mathrm{~min})$ and dhHTX $(182.1>57$; Rt $1.9 \mathrm{~min})$. The instrument was calibrated with authentic standards of ATX $\left(0.5-20 \mathrm{ng} \mathrm{mL}^{-1}\right.$; A.G. Scientific, USA) in $0.1 \%$ formic acid and assumed response factors of 1.0 to ATX were used for the other anatoxin variants. 


\subsubsection{Standard curve preparation}

A $10 \mathrm{~mL}$ aliquot of homogenized CAWBG32 culture was filtered (Whattman GF/C) and DNA extracted from the filter using a Power Biofilm ${ }^{\circledR}$ DNA Isolation Kit (MOBIO Laboratories, USA) following the manufacturer's instructions. A $50 \mu \mathrm{L}$ stock solution of CAWBG32 DNA, at $11 \mathrm{ng}$ $\mu \mathrm{L}^{-1}$ was serially diluted $\left(1.1,0.11,0.011,0.0011 \mathrm{ng} \mu \mathrm{L}^{-1}\right)$. To estimate cell concentrations, a sample of CAWBG32 strain was homogenised (LabServ D130) and a $1 \mathrm{~mL}$ aliquot transferred to a $1.5 \mathrm{~mL}$ eppendorf tube and preserved with Lugol's iodine solution. A $100 \mu \mathrm{L}$ aliquot of the preserved sample was transferred with 1-6 mL Milli-Q to an Utermöhl chamber (Utermöhl, 1958) and enumerated by measuring filament lengths of at least 100 filaments within transects $(23 \times$ $0.185 \mathrm{~mm}$ ) of the chamber, at $400 \mathrm{x}$ magnification using a CKX41 inverted microscope (Olympus, Tokyo). Cell numbers in the measured filaments were estimated by taking the mean length and width of 40 cells from 14 different filaments at high power (1000 x magnification) using a BX51 compound microscope (Olympus, Tokyo).

\subsubsection{Quantitative Polymerase Chain Reaction (QPCR) Analysis}

An internal-control assay to test for PCR inhibition was run in a separate $12.5 \mu \mathrm{L}$ reaction mix containing $2 \times$ Rotor Gene Probe PCR master mix ( $6.25 \mu \mathrm{L}$, Qiagen), primers targeting the internal transcribed spacer region 2 of the rRNA gene operon of chum salmon, Oncorhynchus keta $(0.4$ $\mu$ M Sketa F2 and Sketa R3; (Haugland et al., 2005), TaqMan probe (Haugland et al., 2005) synthesized with a CAL fluor red 610 reporter dye at the $5^{\prime}$-end and a Black Hole Quencher 2 at the 3'-end (0.2 $\mu \mathrm{M}$; Biosearch Technologies, United States), salmon sperm DNA (15 ng; Sigma, United States) and sample DNA (1 $\mu \mathrm{L})$. Samples were analysed in duplicate on a Rotor-Gene 6000 real-time rotary analyser (Qiagen, Netherlands). Reaction mixtures were held at $95{ }^{\circ} \mathrm{C}$ for $3 \mathrm{~min}$, followed by 50 cycles at $95{ }^{\circ} \mathrm{C}$ for $3 \mathrm{sec}$ and $58{ }^{\circ} \mathrm{C}$ for $10 \mathrm{~s}$. 
Biofilm samples were screened for the $a n a C$ region, a part of the ana gene cluster involved in anatoxin synthesis, using the primers anaC-gen-F (5'- TCTGGTATTCAGTCCCCTCTAT- 3') and anaC-gen-R (5'- CCCAATAGCCTGTCATCAA- 3'; Rantala-Ylinen, 2011). Reactions were performed in $12 \mu \mathrm{L}$ volumes with the reaction mixture containing $6.25 \mu \mathrm{L}$ of $2 \times$ Rotor-Gene SYBR Green PCR Master Mix, $1 \mu \mathrm{M}$ of each primer, $2.75 \mu \mathrm{L}$ of Bovine Serum Albumen (BSA) and 1$2 \mu \mathrm{L}$ of each dilution of template DNA and run in duplicate on a Rotor-Gene 6000 real-time rotary analyser (Qiagen, Netherlands). The reaction mixture was held at $95{ }^{\circ} \mathrm{C}$ for 5 min followed by 40 cycles of $95{ }^{\circ} \mathrm{C}$ for $55 \mathrm{~s}$ and $60{ }^{\circ} \mathrm{C}$ for $10 \mathrm{~s}$, followed by a melt step from $70-90{ }^{\circ} \mathrm{C}$ rising by 0.5 ${ }^{\circ} \mathrm{C}$. Amplification curves were visualised using the Rotor-Gene 6000 software. Quantification was based on a calibration curve produced from a dilution-series of DNA extracted from a pure culture of Phormidium strain CAWBG32.

Preliminary analysis of anatoxin production in the biofilms sampled from site 1 between 9 February and 13 March (2013), calculated by dividing total anatoxin (the sum of all anatoxin variant compounds detected; tATX) concentrations from the UPLC-MS data by the total number of $P$. autumnale cells (i.e. assuming that all cells are toxin-producers), found high levels (> 10 fold increase) of ATX per cell on day 4 and 8. Subsequently, a separate sample collection was carried out to further investigate anatoxin production in this early growth phase and is described in the next section (3.2.3). Anatoxin concentrations per cell, assuming only some cells are toxinproducers, were calculated by dividing the tATXs in each sample (as determined from the UPLCMS analysis) by the total number of toxic cells estimated from the QPCR analysis (the same biofilm sample was used for both of these analyses). Total $P$. autumnale cells counts from Site 1 (Chapter 2) were used to estimate the ratio of anatoxin-producing cells to non-anatoxin-producing cells over time. 


\subsubsection{Case study: Early anatoxin production}

A separate sample collection at Site 3 (Figure 2.1, Chapter 2) was conducted in November 2013 over 6 days, after the main sample collection in February/March, as a brief investigation into the variation of anatoxin production in the very early stages of biofilm succession. A flushing flow occurred on 7 November 2013 and sampling began on 20 November (once the flow had reduced to $<10 \mathrm{~m} \mathrm{~s}^{-1}$ and it was therefore safe to work in the river). Samples were collected every second day until 26 November 2013. Biofilm samples were taken from five randomly selected rocks of a similar size (cobble) and the entire top surface of the rock swabbed using sterile Whirl-pak ${ }^{\mathrm{TM}}$ Speci-sponges ${ }^{\mathrm{TM}}$ (Nasco) and placed in separate sterile Whirl-pak ${ }^{\mathrm{TM}}$ bags. The sponges were transport chilled $\left(4^{\circ} \mathrm{C}\right)$ to the laboratory and frozen $\left(-20^{\circ} \mathrm{C}\right)$ for later molecular and toxin analysis.

To remove biofilm material from the Speci-sponges ${ }^{\mathrm{TM}}$ (see Chapter 2), $30 \mathrm{~mL}$ of Milli-Q water was added to the Whirl-pak ${ }^{\mathrm{TM}}$ bags and these were macerated using a Colworth 400 laboratory stomacher (AJ Seward, UK) for 2 mins; any material remaining on the sponge was removed with tweezers, and the suspended material transferred to $50 \mathrm{~mL}$ Falcon tubes. A $10 \mathrm{~mL}$ aliquot was then transferred into a $15 \mathrm{~mL}$ Falcon tube and prepared for toxin analysis as described in Section 3.2.1. The remaining material was centrifuged $(3000 \times g, 15 \mathrm{mins})$, the supernatant discarded and pellet transferred to a $1.5 \mathrm{~mL}$ Eppendorf tube. Samples with large amounts of material were centrifuged 1 to 2 more times $(3000 \times g, 15$ mins), discarding supernatant after each centrifugation, until material formed a cohesive pellet. Wet weights were obtained for each sample and up to $25 \mathrm{mg}$ transferred to Power Bead tubes for DNA extraction using a Power Biofilm® DNA Isolation Kit (MOBIO Laboratories, USA) following the manufacturer's instructions. DNA samples were screened for the $a n a C$ region via the method described in Section 3.2.2. 


\subsubsection{Statistical Analysis}

The tATXs per cell data was binned into three groups according to the three successional phases identified from the micro-algal and bacterial cluster analyses in Chapter 2 (section 2.3.3), and a one-way ANOVA was used to test for differences in mean tATXs (fg cell $\left.{ }^{-1}\right)$. A post-hoc Bonferroni test was used to test for pairwise differences between each group. Data were log transformed prior to analysis to meet the assumptions of normality and homogenous variances. This grouping method could not be applied for the bacterial succession phases identified from the cluster analysis in Chapter 2 section 2.3.4 due to insufficient sample replication, and was therefore not used for this analysis.

Mantel's tests (Mantel, 1967) were used to test for autocorrelations between the micro-algal community composition and anatoxin variants, and the bacterial community composition and anatoxin variants over time, using the anatoxin data from the UPLC-MS. Bray-Curtis distances were computed for all three data sets and the standardised Mantel statistic $(r)$ computed between Bray-Curtis dissimilarities of micro-algal and anatoxin composition and bacterial and anatoxin composition. The significance of $r$ was tested using 9,999 permutations and the analysis was run using the mantel function within the vegan program in the $\mathrm{R}$ software package version 3.0.1 ( $\mathrm{R}$ Development Core Team, 2010). 


\subsection{Results}

\subsubsection{Quantitative anatoxin production analysis}

Toxins were detected in all samples collected from Site 1 between 9 February and 13 March 2013, except those from day 10. Three of the four known variants (ATX, HTX and dhATX) were detected (Figure 3.2); HTX was detected throughout the study period, ATX was only detected in the early stages (day 4 to 16), while dhATX was mostly detected from day 22 to 36 .

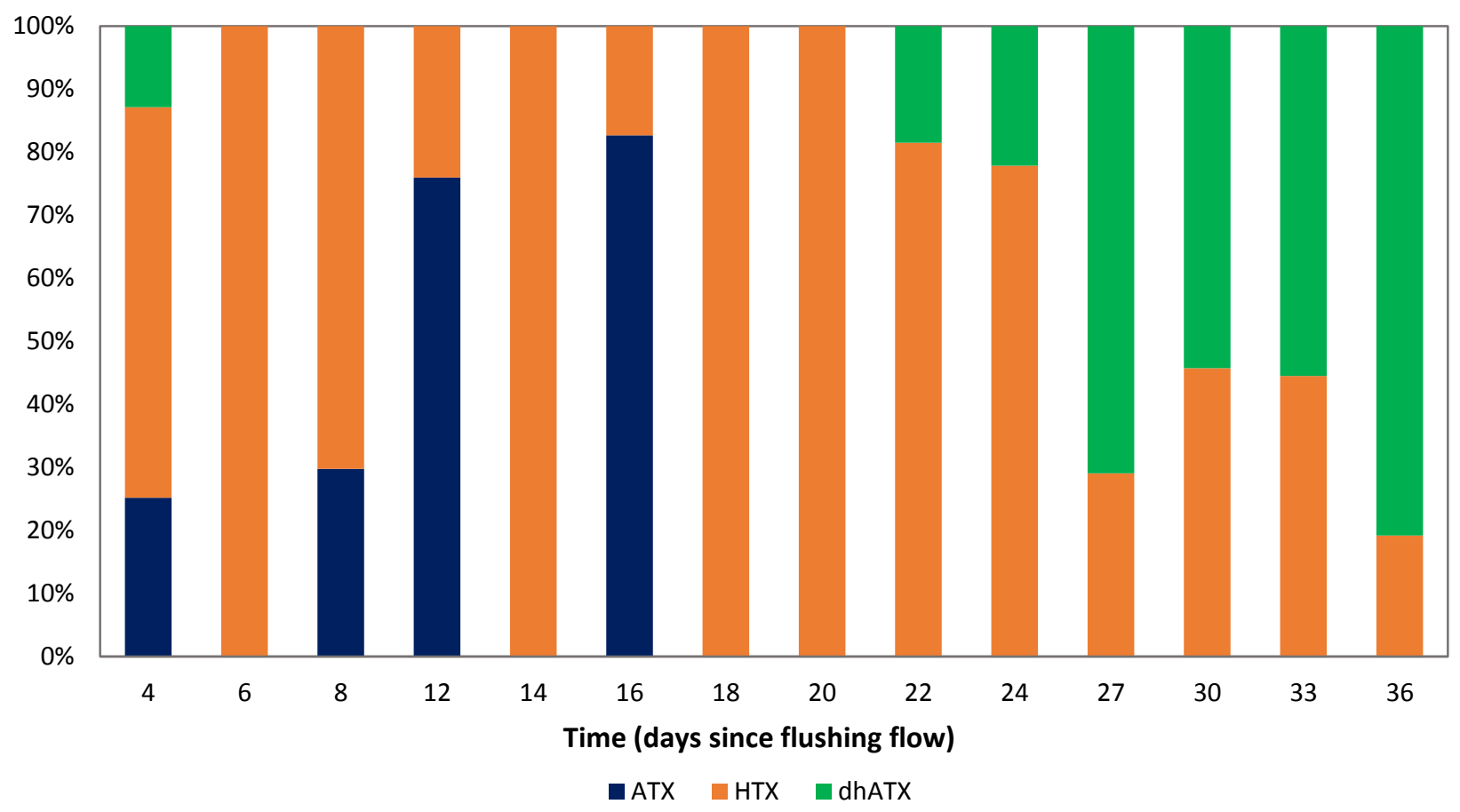

Figure 3.2 Mean proportion of anatoxin variants detected via ultra-performance liquid chromatography-mass spectrometry at each sample point from Site 1 between 9 February and 13 March $(n=3)$. Note dhHTX was not detected in any of the samples.

The highest level of tATXs per cell was found on day 24 ( $\left.208 \mathrm{fg} \mathrm{cell}^{-1}\right)$, which was greater than two-fold of that measured in the preceding days (Figure 3.3). Before this peak, tATXs ranged from 85 to $36 \mathrm{fg} \mathrm{cell}^{-1}$ between day 4 and 20; following the peak, between day 30 and 36, tATXs ranged between 41 and $5 \mathrm{fg}$ cell $^{-1}$. 


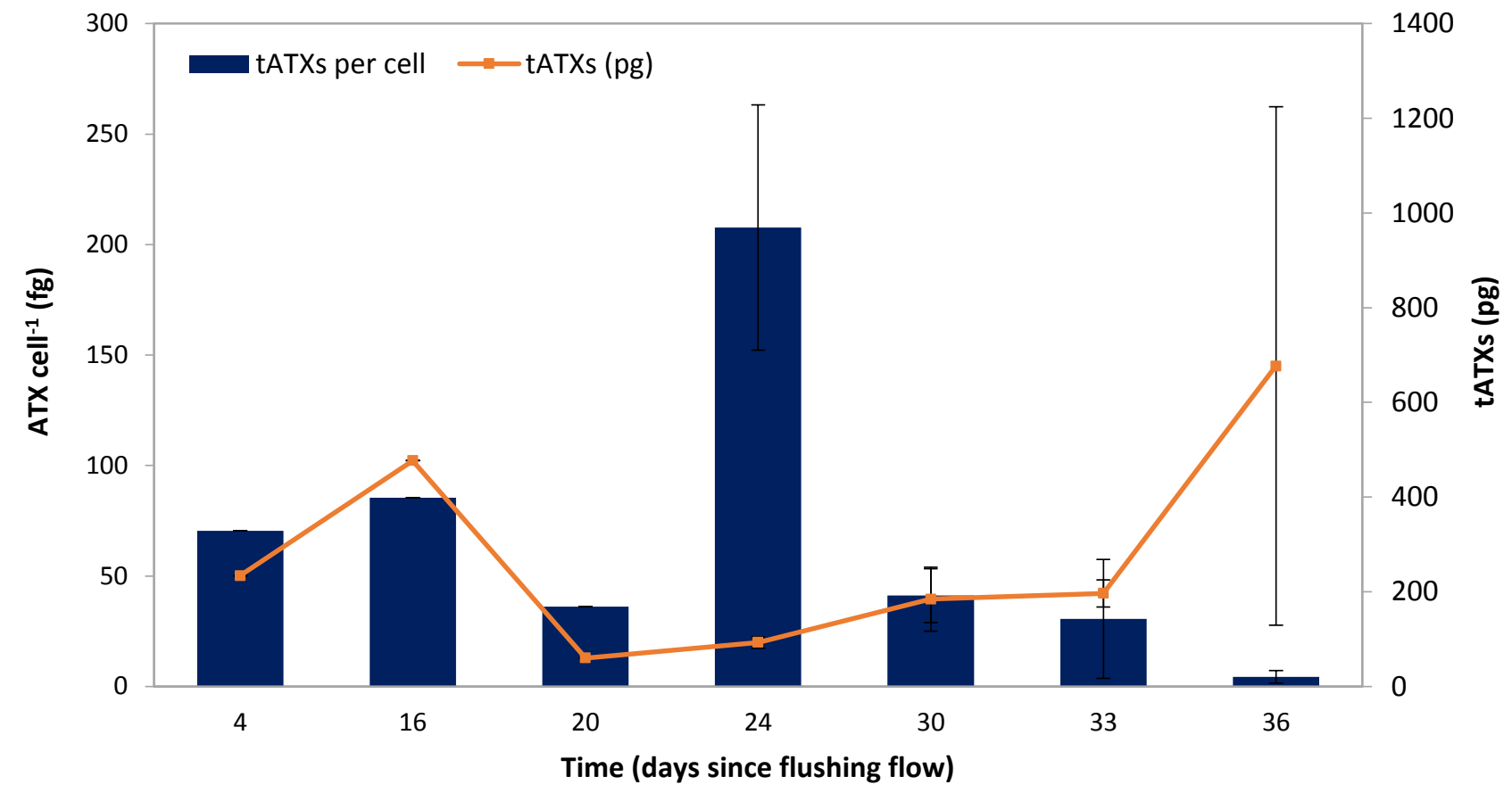

Figure 3.3 Mean total anatoxins (sum of anatoxin-a, homoanatoxin-a, dihydroanatoxin-a; tATXs) per cell (fg) based on number of anaC genes as measured by QPCR analysis and mean tATXs (pg) in the area of rock sampled $\left(255 \mathrm{~mm}^{2}\right)$ based on ultra-performance liquid chromatography-mass spectrometry analysis. Data are from Site 1 between 9 February and 13 March 2013. Values for days 24 to 36 are means $(n=2)$ with error bars showing 1 standard error.

The proportion of toxic to non-toxic cells was greatest at the beginning of the sampling period, with $30 \%$ of all cells positive for the ana-C gene (Figure 3.4). This reduced sharply to $<1 \%$ toxic cells from day 16 until day 36 when this increased slightly to ca. 4\%. The greatest number of toxic cells were observed on day 36, with between 323-664 cells $\mathrm{mm}^{2}$ (Figure 3.4). 


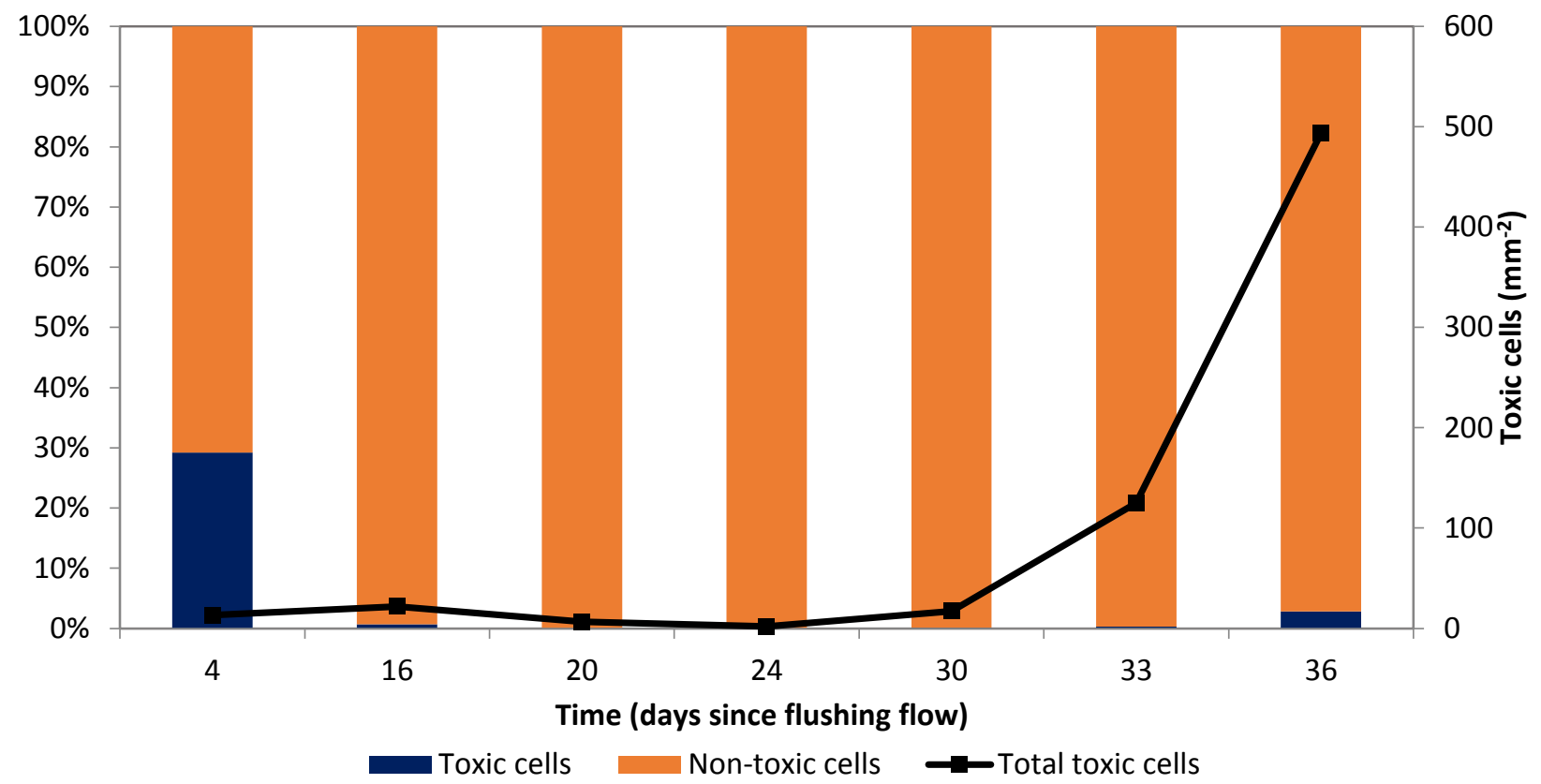

Figure 3.4 Proportion of toxic (dark blue) and non-toxic (orange) cells $\mathrm{mm}^{2}$, and total toxic cells (black line) from individual samples $(\mathrm{n}=1)$ from Site 1, between 9 February and 13 March 2013. Toxic cells were estimated from QPCR analysis and total cells were estimated by microscopy (Chapter 2).

The ANOVA showed a significant difference in tATXs over time $(\mathrm{df}=2,8, F=5.35, p=0.034)$. Total anatoxin per cell was moderate $\left(70-85 \mathrm{fg} \mathrm{cell}^{-1}\right)$ in the early phase (A) of succession and increased three-fold to $208 \mathrm{fg} \mathrm{cell}^{-1}$ in the mid phase (B), but followed a general decreasing trend over time. No significant difference was found between groups A and B or A and C $(p>0.05$; Figure 3.5) but there was a significant difference between group B and C $(p=0.048)$. Mantel's tests showed that changes in ATX variant composition correlated with changes in both the micro$\operatorname{algal}(\mathrm{r}=0.34, p=0.0003)$ and bacterial $(\mathrm{r}=0.35, p=0.0001)$ communities over time. 


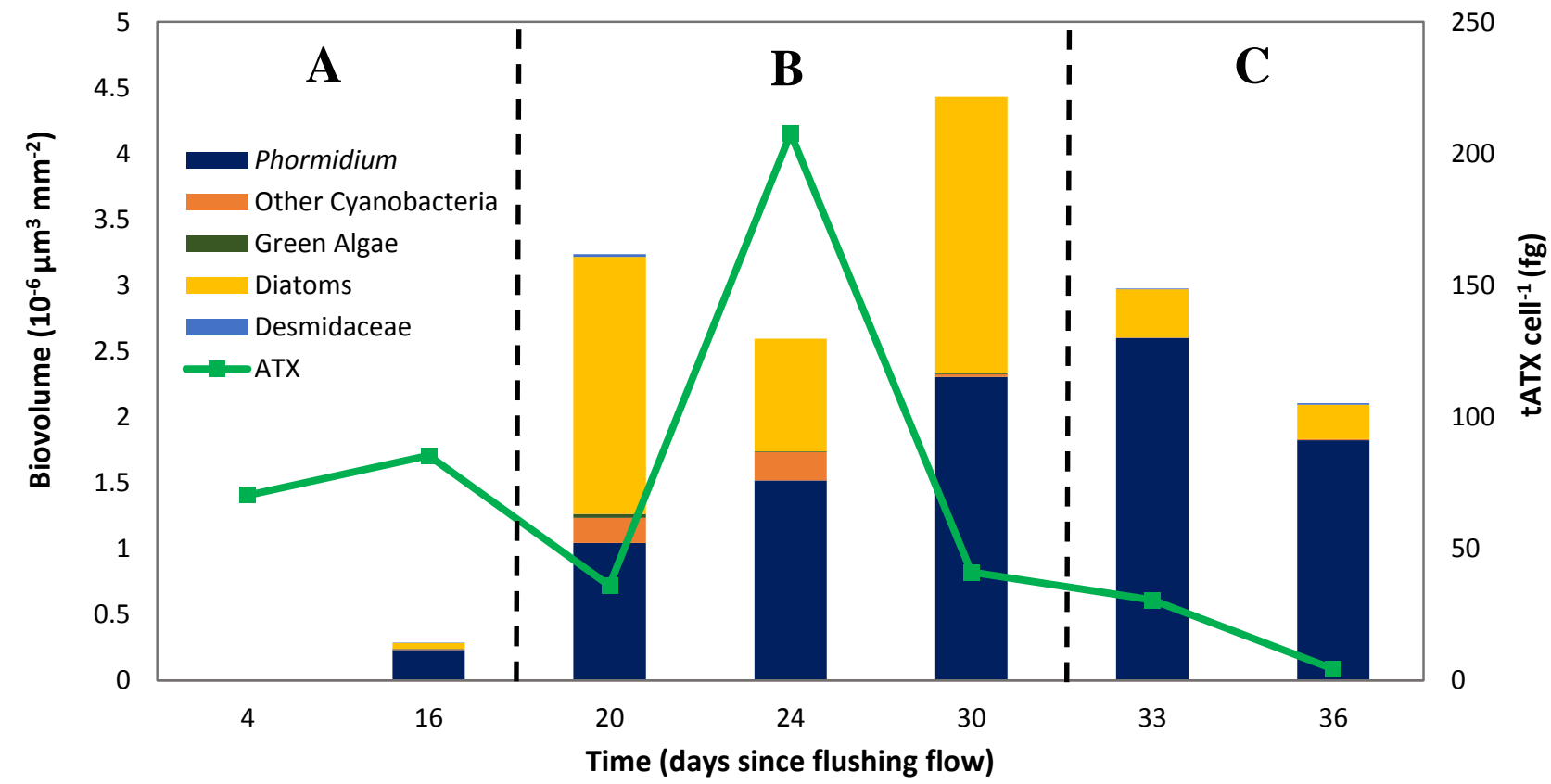

Figure 3.5 Mean biovolumes by taxon $(\mathrm{n}=3)$ over time (estimated from microscope identifications, left axis, Chapter 2), and mean total anatoxins (sum of anatoxin-a, homoanatoxina, dihydroanatoxin-a; tATXs) per cell (fg) based on number of anaC genes as measured by QPCR analysis $(n=1-5$, right axis). Data from Site 1 between 9 February and 13 March 2013. Dashed lines represent partitions between early (A), mid (B) and late (C) phases of micro-algal succession (defined from cluster analysis, Chapter 2).

\subsubsection{Early anatoxin production}

Anatoxins concentrations from Site 1 between 9 February and 13 March, estimated using total cell numbers, showed high tATXs per cell (3-32 $\left.\mathrm{fg} \mathrm{cell}^{-1}\right)$ that were an order of magnitude higher in the first 8 days after the peak flow relative to the rest of the sampling period (Figure 3.6). This prompted further investigation the following season at Site 3 in early summer to confirm these extreme differences in magnitude of early ATX production. 


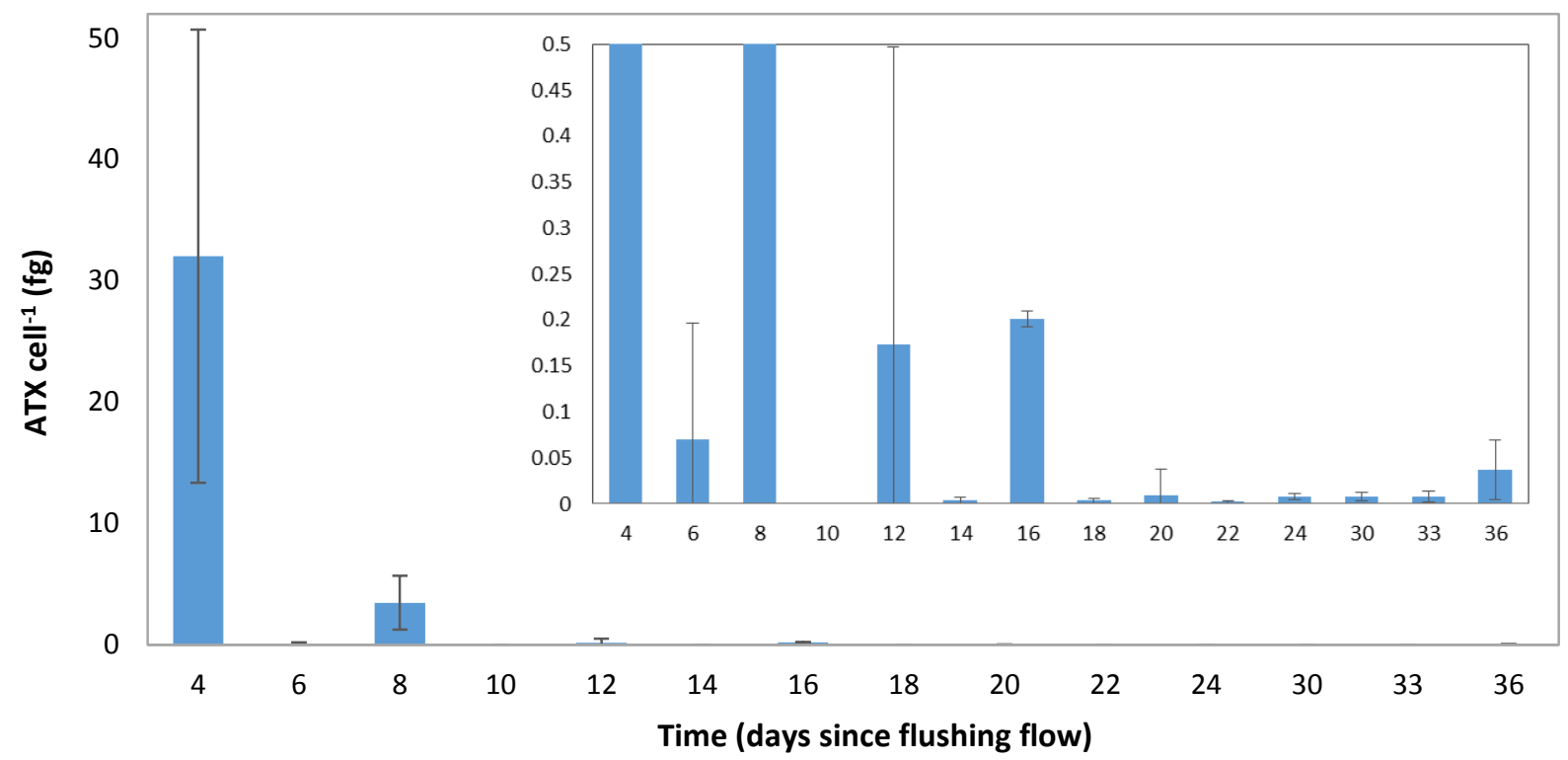

Figure 3.6 Mean total anatoxins (sum of anatoxin-a, homoanatoxin-a, dihydroanatoxin-a; tATXs) per cell estimates from UPLC-MS and total cell numbers from microscopy data (assuming all cells are toxin-producers). Data from Site 1 collected between 9 February and 13 March 2013. Inset shows days that are an order of magnitude lower than days 4 and 8; no anatoxins were detected on day 10, axes units are the same for both graphs. Error bars displaying one standard error $(\mathrm{n}=3)$.

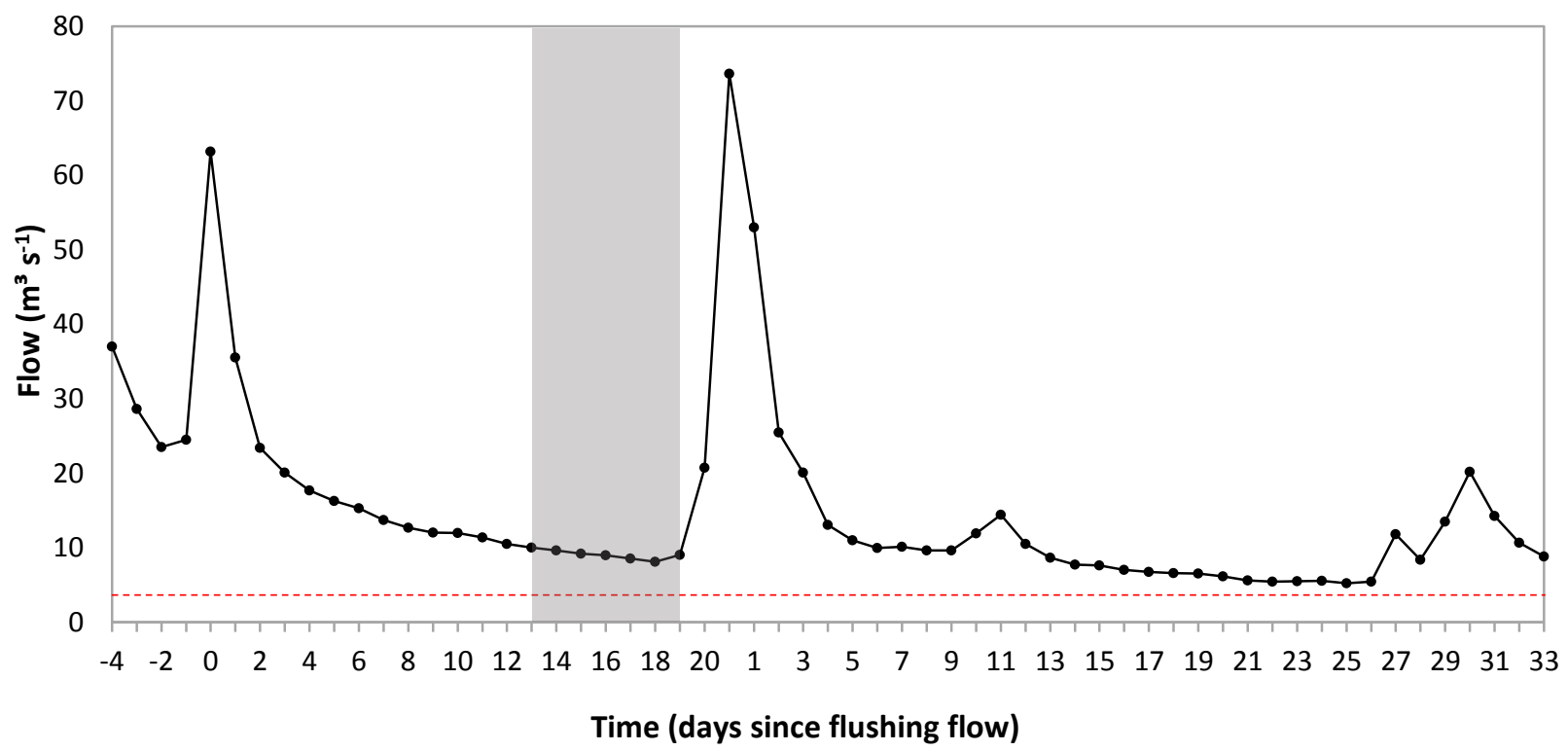

Figure 3.7. Mean daily flow data from 3 November to 31 December 2013, showing the sampling period in early summer (shaded area). Dotted line shows the yearly median flow measured at the Greater Wellington Regional Council gauging site at Taita Gorge (GWRC 3, Figure 2.1, Chapter 2). Day 0 was set at the peak of the flushing flow. 
From this six day sampling period (Figure 3.7) in early summer 2013, anatoxins were only detected in four of the twenty samples after analysis by UPLC-MS (Table 3.3); these were composed entirely of dhATX. Two samples tested positive for the anaC gene via QPCR, one of which also tested positive for anatoxins via UPLC-MS (Table 3.3). Green algae were the main organism observed covering the bottom substrate, with minute amounts of $P$. autumnale biofilm visible on day 19. Hence, no trends in the early production of anatoxins was discernable.

Table 3.3 Total anatoxins (tATXs; pg) detected in individual samples via UPLC-MS, with the presence/absence of anaC gene via QPCR analysis. Data from case study at Site 3 in early summer 2013. ND = not detected.

\begin{tabular}{cccc}
\hline & Rock & UPLC-MS: & QPCR: \\
& & tATXs in sample (pg) & ATX present \\
\hline Day 13 & $1-5$ & ND & - \\
Day 15 & $1-5$ & 16 & - \\
Day 17 & 1 & 12 & - \\
& 2 & 28 & - \\
& 3 & 0 & + \\
& 4 & 0 & + \\
\hline & 5 & 18 & + \\
\hline
\end{tabular}




\subsection{Discussion}

\subsubsection{Anatoxin variability throughout Phormidium biofilm succession}

The ecological function of anatoxins and the factors regulating production remain poorly understood. Some possibilities include nutrient and light stress responses (Harland et al., 2013, Mitrovic et al., 2004). In addition, production of MC toxin can affect the growth and development of surrounding organisms - a phenomenon called allelopathy (Kearns and Hunter, 2000). This type of bio-chemical interaction has never been studied in P. autumnale.

There was an up-regulation of tATX production per cell between day 20 and 24; this coincided with the beginning of rapid $P$. autumnale growth and a large increase in diatom biomass (Figure 3.4), which could indicate an allelopathic response to increased settlement of diatom cells. A similar response was reported in MC-producing Microcystis spp. that reduced dinoflagellate cell densities (Vardi et al., 2002). There was a significant correlation between the community composition and anatoxin variant composition for both micro-algal and bacterial communities, suggesting that changes in community composition may affect the variants being produced or vice versa. It is unclear whether this correlation is a direct response to other biofilm microbes or a consequence of changing bio-chemical conditions associated with the change in microbes throughout succession. The former would suggest an allelopathic role for tATXs. Anatoxin production has been implicated in allelopathic interactions in other cyanobacteria, for example, the planktonic cyanobacteria Anabeana flos-aqua caused paralysis in the motile green alga Chlamydomonas reinhardtii that induced settling of the cells - a means of reducing competition for space and resources in the water column (Kearns and Hunter, 2001).

However, it is unknown whether anatoxins are exported out of the cell in $P$. autumnale. If this were the case, it is much more likely that anatoxins are involved in cell signalling or negative/toxic 
allelopathic activity; while retention of anatoxins within the cells would suggest an intracellular metabolic function. To date, detection of extracellular anatoxins are thought to be a result of cell lysis (Harland et al., 2013) and no exportation pathway has been identified. Production of anatoxins by $P$. autumnale has never been investigated specifically as a cell-cell communication molecule and further investigations of anatoxin regulation in benthic cyanobacteria from in situ field studies are needed.

\subsubsection{Quantitative analysis of anatoxin production}

Studies of previous $P$. autumnale blooms in rivers around New Zealand have demonstrated that the rate of anatoxin production and the proportions of toxic to non-toxic genotypes is highly variable at fine spatial scales (10-1,000 $\mathrm{mm}^{2}$; Wood et al., 2010, Wood et al., 2012b) . Similarly, in this study, samples taken from $255 \mathrm{~mm}^{2}$ areas contained both anatoxin- and non-anatoxinproducing strains (from comparisons of cell counts via QPCR and microscopy). Toxic strains of P. autumnale isolated from New Zealand rivers in two previous studies differed in their responses to varied $\mathrm{N}$ and $\mathrm{P}$ (Heath et al., unpublished), and iron and copper (Harland et al., 2013) concentrations in controlled culture conditions. In Heath et al. (unpublished), tATXs per cell were greatest in the early lag phase (3 to 6 days post-inoculation), while Harland et al. (2013) reported a peak in tATXs in the early exponential growth phase (between 0 and 20 days post-inoculation) for all treatments. Early anatoxin production could indicate a role for anatoxins in biofilm formation, and possibly adhesion to the substrate.

In the current study, tATXs were produced throughout the sampling period (except day 10) at varying concentrations per cell and peaked on day $24\left(208 \mathrm{fg} \mathrm{cell}^{-1}\right)$ during the exponential growth phase, with a general trend of decreasing tATXs over time. There was no statistically significant difference in tATXs per cell between the early- and mid-phase of micro-algal succession, but there 
was a significant difference between the mid- and late-phases. These results are preliminary as there was low replication in the QPCR data; however, studies of anatoxin production in other cyanobacteria (Anabaena and Aphanizomenon species) also report maximum tATX production during the exponential growth phase followed by a decrease in the stationary phase (Osswald et al., 2007).

Unlike the previous studies that were all culture-based, the current study was conducted in situ, and for the first time shows variation in anatoxin production when $P$. autumnale is exposed to natural fluctuations in environmental conditions and biotic influences (e.g., competition, bacterial enzyme activity and grazing). It is possible that anatoxins are produced as a response to colonization/spread of other microbes throughout the biofilm, particularly considering many cyanotoxins are thought to have an allelopathic role (Leflaive and Ten-Hage, 2007). Further in situ studies or multi-species culture studies are needed to identify any acute responses in anatoxin production to other biofilm microbes.

The two culture-based studies (Heath et al., unpublished, Harland et al., 2013) also reported different proportions of anatoxin variants over time. Heath et al. (unpublished) mainly detected dhATX and dhHTX with minute amounts of HTX and no ATX. Conversely, Harland et al. predominantly detected ATX and only occasionally detected dhATX in low concentrations, while HTX and dhHTX were not detected. Unlike those studies, here, ATX and HTX were both produced in the early stages (day 4 to 16) but no ATX was detected thereafter, only HTX was detected on days 18 and 20 and dhATX appeared after day 22. Very little is known of the regulation and functional roles of the various anatoxin congeners. The dihydro-derivatives were thought to be degradation products of ATX and HTX that break down rapidly in sunlight and high $\mathrm{pH}$ (Smith and Lewis, 1987, James et al., 1998) and are less toxic, with a 10-fold decrease in nicotinic receptor 
binding efficiency (Mann et al., 2012). This limited understanding of the tATX variants restricts the interpretation of these results, but suggest further study of the molecular pathways leading to production of these variants, particularly the dihydro-derivatives, is necessary.

Harland et al. (2013) were able to conclusively prove that variations in nutrient levels directly affected anatoxin production, which were most likely indirectly influenced via changes in cell abundances. Likewise, in a concurrent study (reported in Chapter 2), water nutrient levels at Site 1 did not change over time and were therefore considered to be unrelated to anatoxin production. It is possible that biologically-available nutrients within the biofilm matrix can differ to that of the bulk water through changes in dissolved oxygen and $\mathrm{pH}$ (Wood and Young, 2012), however this was not tested in the present study and therefore nutrients cannot be ruled out as an influential factor. Further in situ studies using quantitative molecular methods should focus on changes in nutrient availability within the biofilm matrix to determine the role of nutrients in relation to anatoxin production and regulation.

\subsubsection{Early ATX production case study}

High levels of tATXs per cell in observed early biofilm development in the February-March samples were also observed in the culture-based study of Harland et al. (2013), but because the current study is the first to monitor anatoxin production from un-manipulated $P$. autumnale biofilms in situ, a second sample collection was carried out to confirm this early anatoxin production. Site 3 was selected for this sample collection due to high biofilm coverage observed during previous $P$. autumnale blooms in the Hutt River (Heath et al., 2011, Milne and Watts, 2007). However, during this study there were no $P$. autumnale blooms and green algae was generally dominant. 
Unfortunately, the river flow did not decrease to safe levels for working in $\left(<10 \mathrm{~m} \mathrm{~s}^{-1}\right)$ until 13 days after the peak flow, thus the early colonization phase that was the target of the investigation was potentially missed. However, flows above $12 \mathrm{~m} \mathrm{~s}^{-1}$ are considered high enough to remove biofilms from the substrate and may have prolonged the early colonization phase. The dominance of green algae in the biofilms may have been due to the difference in flow regime, where a longer period of higher flows favoured different micro-algae and led to a different succession of microbes. To date, $P$. autumnale is the only known benthic tATX producer in New Zealand so it is assumed that it was responsible for the anatoxins detected in the November samples.

From this brief study of anatoxin production in early biofilm formation, we were not able to confirm the findings from the first sample collection due to differences in the biofilm community and the flow regime. However, this did test the ability of the UPLC-MS method to detect minute amounts of anatoxins within a large biomass of green algae, while also comparing this method to the QPCR method. The UPLC-MS appeared to be more sensitive to detecting anatoxin production than QPCR, although both are more powerful in synergy - allowing for estimation of the proportion of toxin-producers. 


\section{Chapter 4: General discussion}

The prevalence and intensity of $P$. autumnale-dominated benthic blooms has increased in New Zealand over the last decade (Hamill, 2001, Wood et al., 2007, Heath et al., 2010). This has at least partly became evident due to the numerous dog deaths associated with these blooms, prompting investigation into the factors affecting growth and dominance of this neurotoxin-producing cyanobacteria (Hamill, 2001, Heath et al., 2010, Milne and Watts, 2007, Wood, 2004, Wood et al., 2006, Wood et al., 2007). Other microbes occur within these biofilms (Heath et al., 2010) but until the present study, these had not been characterized and changes in the composition of microbes throughout biofilm formation were unknown. Phormidium autumnale biofilms in New Zealand contain toxic and non-toxic P. autumnale strains (Wood et al., 2010, Wood et al., 2012b), but factors affecting the proportions of each within biofilms have not previously been identified. The knowledge gained in these two areas from this study will help determine how $P$. autumnale dominate these biofilms and whether there are any patterns in toxin production and variation in toxic/non-toxic genotypes associated with biofilm succession.

This thesis has:

1. Characterised the successional development of microalgae in the P. autumnale dominated biofilms of the Hutt River via microscopy.

2. Investigated how bacterial communities vary throughout biofilm succession using ARISA and Next-Generation Sequencing, and inferred potential relationships between $P$. autumnale and other biofilm microbes. 
3. Explored the variation in anatoxin production and anatoxin-producing variants throughout biofilm succession to facilitate an improved understanding of the biological function(s) of anatoxin production.

\subsection{Microbial succession and relationships among biofilm components}

The succession of microbes and their role in benthic bloom formation are poorly understood despite the risks benthic blooms pose to human and animal health (Quiblier et al., 2013). Chapter 2 investigated the succession of micro-algal and bacterial communities within $P$. autumnaledominated biofilms in the Hutt River, Wellington. Three distinct phases of succession were identified for both micro-algae and bacteria, occurring within very similar time periods. These were identified using three separate methods of analysis (morphological identification, ARISA and Illumina ${ }^{\mathrm{TM}}$ sequencing). The environmental parameters measured showed no trends in relation to community composition for either micro-algae or bacteria, suggesting that intrinsic rather than extrinsic factors are more important in determining biofilm composition.

Phormidium autumnale became dominant from day 12 of succession, during the early growth phase, and the exponential growth phase coincided with an influx of diatoms from day 20 that subsided after day 30 - indicating a potential competitive interaction between P. autumnale and diatoms. Microbes often produce secondary metabolites that affect the growth and development

of their competitors, a process called allelopathy (Leflaive et al., 2008); some secondary metabolites are also toxic to other organisms, including mammals (Leflaive and Ten-Hage, 2007). Chapter 3 examined the production of anatoxins by $P$. autumnale throughout biofilm succession and identified a peak in anatoxins per cell on day 24 , followed by a sharp reduction in the late phase. The occurrence of high anatoxin production just four days after the influx of diatoms, 
coupled with a simultaneous reduction in diatoms and anatoxins, provides evidence of an allelopathic role for anatoxins. The functional role of most cyanotoxins is still largely unknown but hypotheses often implicate them as allelopathic or cell-cell signalling molecules (Kearns and Hunter, 2000). Quorum sensing (chemical signalling correlated to cell density) is important in bacterial biofilm formation (Hammer and Bassler, 2003) and this could be another possible function of anatoxins. However, the use of quorum sensing in cyanobacteria is poorly studied and so far only reported in the colony-forming cyanobacteria Gloeothece (Sharif et al., 2008). Further study of anatoxin regulation and transport pathways is necessary to investigate this idea.

Bacterial quorum sensing is possibly involved in the formation of the biofilms in this study, most likely via the Proteobacteria (Miller and Bassler, 2001), of which the Alpha- and Betaproteobacteria were the most abundant. Some bacteria regulate the transcription of genes involved in exopolysaccharide production via quorum sensing (Hammer and Bassler, 2003). The Alphaproteobacteria Sphingomonas produces exopolysaccharides (Azeredo and Oliveira, 2000) and was present throughout succession but was most abundant in early biofilm development, where exopolysaccharides are important in providing a suitable surface for cell attachment. Hence, Sphingomonas may be an essential component in early biofilm formation and provides evidence of quorum sensing in $P$. autumnale-dominated biofilms.

Proteobacteria, including Alpha-, Beta- and Gammaproteobacteria, are often dominant bacterial components of stream biofilms (Manz et al., 1999, Pohlon et al., 2010), as they were in this study. The proportion of bacterial groups changes over time and throughout succession, and is variable in different river systems (Manz et al., 1999). In this study, Alphaproteobacteria were the most dominant group in the early biofilm, while Betaproteobacteria and Flavobacteria were dominant from mid to late succession. Flavobacteria are commonly involved in degradation of biopolymers, 
such as cellulose, chitin, polysaccharides and nucleic acids (Bernardet and Bowman, 2006, Kirchman, 2002), hence their abundance in late succession is probably linked to the break-down of cell contents from lysis, as well as the degradation of the biofilm exopolysaccharide matrix.

High levels of growth and low levels of DRP observed in this study and several other studies of $P$. autumnale blooms in New Zealand (Heath et al., 2011, Wood et al., 2012b, Wood and Young, 2012) indicate that $P$. autumnale is obtaining $P$ from sources other than the overlaying water. Access to additional $\mathrm{P}$ sources via alkaline phosphatase activity in $P$. autumnale and/or other biofilm bacteria is a possible mechanism to explain this (Wood and Young, 2012). Bacteria that produce alkaline phosphatase were present throughout biofilm succession, suggesting that this is an essential process occurring within the biofilms. Whether alkaline phosphatase is the linking factor between the micro-algal and bacterial communities is yet to be determined and should be the focus of further study to determine how $P$. autumnale become dominant in benthic communities.

In addition to a decrease in cellular production of anatoxins, chemical degradation can alter the toxin levels within biofilms and several factors may contribute to the break-down of anatoxin molecules, such as exposure to UV light, increased $\mathrm{pH}$, cell lysis or bacterial bioremediation (Osswald et al., 2007, Afzal et al., 2010, Rapala et al., 1994). It is possible that there was increased shading of toxic cells due to increased microbial biomass in the mid-phase, which prevented the degradation of anatoxins and contributed to the peak in anatoxins found on day 24. Furthermore, the reduction in anatoxin after this point could be due to increased cell lysis as the biofilm matures. Conversely, Sphingomonas was present throughout biofilm succession and some species of this genus have the ability to degrade MC (Azeredo and Oliveira, 2000). All of the known MCdegrading bacteria are Gram-negative Proteobacteria; all dominant bacteria identified in this study 
were Gram-negative and most were of the Alpha- and Betaproteobacteria classes. Hence, it is possible that some biofilm components may degrade anatoxins and further study is needed.

There is a paucity of information on the production and regulation of the different anatoxin dihydro-derivatives (dhATX and dhHTX), which have been suggested as natural break-down products of ATX and HTX (Stevens and Krieger, 1991). In Chapter 3, changes in the proportions of the anatoxin variants aligned with the three phases of microbial succession identified in Chapter 2; showing a loss of ATX and gain of dhATX production as succession progressed. This coupling of anatoxin variants and microbial community composition presents a possibility that one or more of the bacterial components are capable of degrading some or all of the anatoxin variants. Likewise, the coupling with the micro-algal community could indicate differing roles for the different anatoxin variants in response to algal colonisers.

\subsection{Conclusions}

There are three distinct phases of succession occurring for both the micro-algal and bacterial communities and these phases become increasingly similar over time. Phormidium autumnale dominates benthic biofilms in the Hutt River from an early stage in their succession and is able to grow rapidly in the presence of other colonizing microbes. In this study the production of anatoxins was higher in the early-mid phases of biofilm development and may play a role in reducing the negative effects of competing microbes, for example, as an allelopathic response. Bacterial exopolysaccharide and alkaline phosphatase producers were prominent throughout biofilm succession and are likely to be important in assisting attachment to the substrate and maintaining P. autumnale growth. Biopolymer-degrading Flavobacteria were dominant in late succession and likely metabolise algal cellular by-products and contribute to biofilm detachment. A clear pattern 
of microbial succession is described here and linkages between the micro-algal and bacterial communities are evident.

\subsection{Limitations of the study}

Sample sizes in both the community succession analyses and anatoxin analyses were relatively low. This reflects the time-consuming nature of morphological identifications and the step-wise approach used for genetic screening of the bacterial communities. It was necessary to first identify the presence of a pattern in bacterial communities over time via ARISA, which was then followed up by the more detailed (but more expensive) Illumina ${ }^{\mathrm{TM}}$ sequencing method.

The method of analysis used for estimating proportions of toxic and non-toxic cells may have been a limitation, as one sample needed to be preserved for the cell counts and a separate sample used for QPCR analysis. However, there is currently no QPCR assay designed for a single copy gene specific to $P$. autumnale that could be used to estimate total cell numbers via molecular methods such as QPCR. Development of this would enable a more accurate and comparative estimate of intracellular toxins and proportions of toxic to non-toxic cells.

It was not possible to sample the river substrate directly following the flushing flow for safety reasons. Microbes are able to rapidly colonise substrates after clearance and hence some of the very first community changes may have been missed in this study. Although, the microbes may not be present at a detectable level at such an early stage. It may be possible to replicate these conditions in an experimental flume set-up, and this could be an avenue for potential future research.

No effect on substrate cover was identified from the biofilm sampling technique used in this study. It is unlikely that this method affected the succession of microbes temporally or compositionally 
because the biofilm was only just evident two weeks after the flushing flow. Alternatively, other less destructive methods for measuring benthic biomass could be used; for example, the BBE Bentho Torch (Envitech Ltd., Cardiff, UK), which uses the in vivo fluorescence of algal cells to measure benthic algal concentrations in situ. However, the Bentho Torch is limited to cyanobacteria, green algae and diatoms and initial studies show poor relationships between measurements and morphological identifications/biovolumes, especially as biofilms become thicker (I. M. Echenique-Subiabre, pers. comm.).

\subsection{Future directions}

The analysis of the bacterial community identified the presence of several important metabolic functions possibly occurring within the $P$. autumnale-dominate biofilms, including alkaline phosphatase, quorum sensing and degradation of anatoxins. Several of the bacteria identified within the biofilms in this study may interact with $P$. autumnale to facilitate its dominance. Alkaline phosphatase activity was a common feature of the bacteria found throughout biofilm succession, although there were multiple possible producers of alkaline phosphatase present, including cyanobacteria. Further fine-scale investigations of possible phosphatase activity and $\mathrm{pH}$ changes within the biofilm matrix are needed to determine the role of alkaline phosphatase in the dominance of $P$. autumnale. Metatranscriptomics is the study of the actively transcribed ribosomal and messenger RNA within a given community (Gilbert and Hughes, 2011), and this would be useful in identifying the metabolic processes occurring during biofilm succession to determine which microbes are important in the various stages of development.

The use of high through-put sequencing, such as Illumina ${ }^{\mathrm{TM}}$, is relatively recent and is still an expensive option compared to conventional microscopy. Other less costly methods of community characterisation are still effective, including pulse amplitude modulation (PAM) and QPCR 
(refined from methods used here). Pulse amplitude modulation could also be used as a proxy for cell health and to assess photosynthetic efficiency at different stages of succession.

The biofilms analysed in this thesis were those specifically dominated by $P$. autumnale. However, similar analysis of biofilms not dominated by $P$. autumnale, such as those where green algae are dominant, may provide information on the specific conditions that allow this neurotoxic cyanobacteria to proliferate in systems like the Hutt River.

As meteorological systems change in relation to climatic events, it is possible that flow regimes in the Hutt River will also vary (Dore, 2005). Hence, further study of microbial succession in the Hutt River under varied flow regimes could help determine why the occurrence of $P$. autumnale blooms have increased and to predict the occurrence of toxic blooms under future climate change scenarios. 


\section{Reference List}

ABDO, Z., SCHÜETTE, U. M., BENT, S. J., WILLIAMS, C. J., FORNEY, L. J. \& JOYCE, P. 2006. Statistical methods for characterizing diversity of microbial communities by analysis of terminal restriction fragment length polymorphisms of 16S rRNA genes. Environmental Microbiology, 8, 929-938.

AFZAL, A., OPPENLÄNDER, T., BOLTON, J. R. \& EL-DIN, M. G. 2010. Anatoxin-a degradation by Advanced Oxidation Processes: Vacuum-UV at $172 \mathrm{~nm}$, photolysis using medium pressure UV and UV/H2O2. Water Research, 44, 278-286.

ANDERSON, M. J. 2001. A new method for non-parametric multivariate analysis of variance. Austral Ecology, 26, 32-46.

ARÁOZ, R., MOLGÓ, J. \& TANDEAU DE MARSAC, N. 2010. Neurotoxic cyanobacterial toxins. Toxicon, 56, 813-828.

AUGSPURGER, C., KARWAUTZ, C., MUßMANN, M., DAIMS, H. \& BATTIN, T. J. 2010. Drivers of bacterial colonization patterns in stream biofilms. FEMS Microbiology Ecology, 72, 47-57.

AZEREDO, J. \& OLIVEIRA, R. 2000. The role of exopolymers produced by Sphingomonas paucimobilis in biofilm formation and composition. Biofouling, 16, 17-27.

AZEVEDO, S. M. F. O., CARMICHAEL, W. W., JOCHIMSEN, E. M., RINEHART, K. L., LAU, S., SHAW, G. R. \& EAGLESHAM, G. K. 2002. Human intoxication by microcystins during renal dialysis treatment in Caruaru-Brazil. Toxicology, 181, 441-446.

BALlOT, A., KRIENITZ, L., KOTUT, K., WIEGAND, C., METCALF, J. S., CODD, G. A. \& PFLUGMACHER, S. 2004. Cyanobacteria and cyanobacterial toxins in three alkaline Rift Valley lakes of Kenya-Lakes Bogoria, Nakuru and Elmenteita. Journal of Plankton Research, 26, 925 935.

BARRANGUET, C., VEUGER, B., VAN BEUSEKOM, S. A. M., MARVAN, P., SINKE, J. J. \& ADMIRAAL, W. 2005. Divergent composition of algal-bacterial biofilms developing under various external factors. European Journal of Phycology, 40, 1-8.

BEE, S., BRASELL, K. A., HEATH, M. H., WOOD, S. A. \& RYAN, K. G. 2012. Effects of toxic benthic Phormidium on macroinvertebrate communities. New Zealand Freshwater Sciences Society Conference. Dunedin.

BERNARDET, J.-F. \& BOWMAN, J. P. 2006. The genus Flavobacterium. The Prokaryotes. Springer.

BESEMER, K., SINGER, G., LIMBERGER, R., CHLUP, A. K., HOCHEDLINGER, G., HÖDL, I., BARANYI, C. \& BATTIN, T. J. 2007. Biophysical controls on community succession in stream biofilms. Applied and Environmental Microbiology, 73, 4966-4974. 
BIGGS, B. \& KILROY, C. 2000. Stream periphyton monitoring manual, NIWA.

BRIAND, J.-F., JACQUET, S., BERNARD, C. \& HUMBERT, J.-F. 2003. Health hazards for terrestrial vertebrates from toxic cyanobacteria in surface water ecosystems. Veterinary Research, 34, 361377.

CADEL-SIX, S., ITEMAN, I., PEYRAUD-THOMAS, C., MANN, S., PLOUX, O. \& MÉJEAN, A. 2009. Identification of a polyketide synthase coding sequence specific for anatoxin-a-producing Oscillatoria cyanobacteria. Applied and Environmental Microbiology, 75, 4909-4912.

CADEL-SIX, S., PEYRAUD-THOMAS, C., BRIENT, L., DE MARSAC, N. T., RIPPKA, R. \& MEJEAN, A. 2007. Different genotypes of anatoxin-producing cyanobacteria coexist in the Tarn River, France. Applied and Environmental Microbiology, 73, 7605-7614.

CANTER-LUND, H., LUND, J. W. \& FOGG, G. 1995. Freshwater algae: their microscopic world explored, Biopress Bristol.

CAPORASO, J. G., LAUBER, C. L., WALTERS, W. A., BERG-LYONS, D., LOZUPONE, C. A., TURNBAUGH, P. J., FIERER, N. \& KNIGHT, R. 2011. Global patterns of 16S rRNA diversity at a depth of millions of sequences per sample. Proceedings of the National Academy of Sciences, $108,4516-4522$.

CARDENAS, E. \& TIEDJE, J. M. 2008. New tools for discovering and characterizing microbial diversity. Current Opinion in Biotechnology, 19, 544-549.

CARMICHAEL, W. W. 2001. Health Effects of Toxin-Producing Cyanobacteria: "The CyanoHABs". Human and Ecological Risk Assessment: An International Journal, 7, 1393-1407.

CHORUS, I. \& BARTRAM, J. 1999. Toxic cyanobacteria in water: a guide to their public health consequences, monitoring, and management, Taylor \& Francis.

CLARKE, K. \& GORLEY, R. 2006. Primer version 6: user manual/tutorial Primer-E. Plymouth, England.

CLARKE, K. \& WARWICK, R. 2001. Change in Marine Communities: An approach to statistical analysis and interpretation. 2001. PRIMER-E: Plymouth, UK.

COLE, J. R., WANG, Q., FISH, J. A., CHAI, B., MCGARRELL, D. M., SUN, Y., BROWN, C. T., PORRAS-ALFARO, A., KUSKE, C. R. \& TIEDJE, J. M. 2014. Ribosomal Database Project: data and tools for high throughput rRNA analysis. Nucleic Acids Research, 42, D633-D642.

DEGNAN, P. H. \& OCHMAN, H. 2011. Illumina-based analysis of microbial community diversity. The ISME Journal, 6, 183-194.

DOPHEIDE, A., LEAR, G., STOTT, R. \& LEWIS, G. 2011. Preferential Feeding by the Ciliates Chilodonella and Tetrahymena spp. and Effects of These Protozoa on Bacterial Biofilm Structure and Composition. Applied and Environmental Microbiology, 77, 4564-4572. 
DORE, M. H. I. 2005. Climate change and changes in global precipitation patterns: What do we know? Environment International, 31, 1167-1181.

EDWARDS, C., BEATTIE, K. A., SCRIMGEOUR, C. M. \& CODD, G. A. 1992. Identification of anatoxin-A in benthic cyanobacteria (blue-green algae) and in associated dog poisonings at Loch Insh, Scotland. Toxicon, 30, 1165-1175.

ESPELAND, E. \& WETZEL, R. 2001a. Complexation, stabilization, and UV photolysis of extracellular and surface-bound glucosidase and alkaline phosphatase: implications for biofilm microbiota. Microbial Ecology, 42, 572-585.

ESPELAND, E. \& WETZEL, R. 2001b. Effects of photosynthesis on bacterial phosphatase production in biofilms. Microbial Ecology, 42, 328-337.

FALCONER, I. R. 1998. Algal toxins and human health. Quality and Treatment of Drinking Water II. Springer.

FINNERAN, K. T., JOHNSEN, C. V. \& LOVLEY, D. R. 2003. Rhodoferax ferrireducens sp. nov., a psychrotolerant, facultatively anaerobic bacterium that oxidizes acetate with the reduction of Fe(III). International Journal of Systematic and Evolutionary Microbiology, 53, 669-673.

FIORE, M. F., GENUÁRIO, D. B., DA SILVA, C. S. P., SHISHIDO, T. K., MORAES, L. A. B., NETO, R. C. \& SILVA-STENICO, M. E. 2009. Microcystin production by a freshwater spring cyanobacterium of the genus Fischerella. Toxicon, 53, 754-761.

GAGNON, A. \& PICK, F. R. 2012. Effect of nitrogen on cellular production and release of the neurotoxin anatoxin-a in a nitrogen-fixing cyanobacterium. Frontiers in Microbiology, 3.

GAN, N., XIAO, Y., ZHU, L., WU, Z., LIU, J., HU, C. \& SONG, L. 2012. The role of microcystins in maintaining colonies of bloom-forming Microcystis spp. Environmental Microbiology, 14, 730742.

GILBERT, J. A. \& HUGHES, M. 2011. Gene expression profiling: metatranscriptomics. Methods Mol. Biol., 733, 195-205.

GUGGER, M., LENOIR, S., BERGER, C., LEDREUX, A., DRUART, J.-C., HUMBERT, J.-F., GUETTE, C. \& BERNARD, C. 2005. First report in a river in France of the benthic cyanobacterium Phormidium favosum producing anatoxin-a associated with dog neurotoxicosis. Toxicon, 45, 919-928.

HAMILL, K. D. 2001. Toxicity in benthic freshwater cyanobacteria (blue-green algae): First observations in New Zealand. New Zealand Journal of Marine and Freshwater Research, 35.

HAMMER, B. K. \& BASSLER, B. L. 2003. Quorum sensing controls biofilm formation in Vibrio cholerae. Molecular Microbiology, 50, 101-104. 
HARLAND, F. M., WOOD, S. A., MOLTCHANOVA, E., WILLIAMSON, W. M. \& GAW, S. 2013. Phormidium autumnale Growth and Anatoxin-a Production under Iron and Copper Stress. Toxins, $5,2504-2521$.

HAUGLAND, R. A., SIEFRING, S. C., WYMER, L. J., BRENNER, K. P. \& DUFOUR, A. P. 2005. Comparison of Enterococcus measurements in freshwater at two recreational beaches by quantitative polymerase chain reaction and membrane filter culture analysis. Water Research, 39, 559-568.

HEATH, M., WOOD, S. A., BRASELL, K., YOUNG, R. \& RYAN, K. 2013. Development of habitat suitability criteria and in-stream habitat assessment for the benthic cyanobacteria Phormidium. River Research and Applications.

HEATH, M. W., WOOD, S. A. \& RYAN, K. G. 2010. Polyphasic assessment of fresh-water benthic matforming cyanobacteria isolated from New Zealand. FEMS Microbiology Ecology, 73, 95-109.

HEATH, M. W., WOOD, S. A. \& RYAN, K. G. 2011. Spatial and temporal variability in Phormidium mats and associated anatoxin-a and homoanatoxin-a in two New Zealand rivers. Aquatic Microbial Ecology, 64, 69-79.

HILL, G., MITKOWSKI, N., ALDRICH-WOLFE, L., EMELE, L., JURKONIE, D., FICKE, A., MALDONADO-RAMIREZ, S., LYNCH, S. \& NELSON, E. 2000. Methods for assessing the composition and diversity of soil microbial communities. Applied Soil Ecology, 15, 25-36.

HOUSE, W. A. 2003. Geochemical cycling of phosphorus in rivers. Applied Geochemistry, 18, 739-748.

HUANG, C.-T., XU, K. D., MCFETERS, G. A. \& STEWART, P. S. 1998. Spatial patterns of alkaline phosphatase expression within bacterial colonies and biofilms in response to phosphate starvation. Applied and Environmental Microbiology, 64, 1526-1531.

HUDSON, H. 2010. Assessment of potential effects on instream habitat with reduced flows in the Hutt River at Kaitoke. Environmental Management Associates, Chris tchurch. Report, 6, 103.

HURTADO, I., ABOAL, M., ZAFRA, E. \& CAMPILLO, D. 2008. Significance of microcystin production by benthic communities in water treatment systems of arid zones. Water Research, 42, $1245-1253$

IZAGUIRRE, G., JUNGBLUT, A.-D. \& NEILAN, B. A. 2007. Benthic cyanobacteria (Oscillatoriaceae) that produce microcystin-LR, isolated from four reservoirs in southern California. Water Research, 41, 492-498.

JACKSON, C. R. 2003. Changes in community properties during microbial succession. Oikos, 101, 444448.

JAMES, K. J., FUREY, A., SHERLOCK, I. R., STACK, M. A., TWOHIG, M., CAUDWELL, F. B. \& SKULBERG, O. M. 1998. Sensitive determination of anatoxin-a, homoanatoxin-a and their 
degradation products by liquid chromatography with fluorimetric detection. Journal of Chromatography A, 798, 147-157.

JAMES, K. J., SHERLOCK, I. R. \& STACK, M. A. 1997. Anatoxin-a in Irish freshwater and cyanobacteria, determined using a new fluorimetric liquid chromatographic method. Toxicon, 35, 963-971.

JANSSON, M. 1993. Uptake, exchange, and excretion of orthophosphate in phosphate-starved Scenedesmus quadricauda and Pseudomonas K 7. Limnology and Oceanography, 38, 1162-1178.

KEARNS, K. \& HUNTER, M. 2001. Toxin-producing Anabaena flos-aquae induces settling of Chlamydomonas reinhardtii, a competing motile alga. Microbial Ecology, 42, 80-86.

KEARNS, K. D. \& HUNTER, M. D. 2000. Green algal extracellular products regulate antialgal toxin production in a cyanobacterium. Environmental Microbiology, 2, 291-297.

KIRCHMAN, D. L. 2002. The ecology of Cytophaga-Flavobacteria in aquatic environments. FEMS Microbiology Ecology, 39, 91-100.

KRIENITZ, L., BALlOT, A., KOTUT, K., WIEGAND, C., PÜTZ, S., METCALF, J. S., CODD, G. A. \& PFLUGMACHER, S. 2003. Contribution of hot spring cyanobacteria to the mysterious deaths of Lesser Flamingos at Lake Bogoria, Kenya. FEMS Microbiology Ecology, 43, 141-148.

LAJEUNESSE, A., SEGURA, P. A., GÉlinAS, M., HUDON, C., THOMAS, K., QUILLIAM, M. A. \& GAGNON, C. 2012. Detection and confirmation of saxitoxin analogues in freshwater benthic Lyngbya wollei algae collected in the St. Lawrence River (Canada) by liquid chromatographytandem mass spectrometry. Journal of Chromatography A, 1219, 93-103.

LAU, Y. \& LIU, D. 1993. Effect of flow rate on biofilm accumulation in open channels. Water Research, 27, 355-360.

LEAR, G., ANDERSON, M. J., SMITH, J. P., BOXEN, K. \& LEWIS, G. D. 2008. Spatial and temporal heterogeneity of the bacterial communities in stream epilithic biofilms. Fems Microbiology Ecology, 65, 463-473.

LEAR, G., TURNER, S. \& LEWIS, G. 2009. Effect of light regimes on the utilisation of an exogenous carbon source by freshwater biofilm bacterial communities. Aquatic Ecology, 43, 207-220.

LEFLAIVE, J., BOULÊTREAU, S., BUFFAN-DUBAU, E. \& TEN-HAGE, L. 2008. Temporal patterns in epilithic biofilm relation with a putative allelopathic activity. Fundamental and Applied Limnology/Archiv für Hydrobiologie, 173, 121-134.

LEFLAIVE, J. P. \& TEN-HAGE, L. 2007. Algal and cyanobacterial secondary metabolites in freshwaters: a comparison of allelopathic compounds and toxins. Freshwater Biology, 52, 199214. 
LÜRLING, M. 2003. Effects of microcystin-free and microcystin-containing strains of the cyanobacterium Microcystis aeruginosa on growth of the grazer Daphnia magna. Environmental Toxicology, 18, 202-210.

MANN, S., COHEN, M., CHAPUIS-HUGON, F., PICHON, V., MAZMOUZ, R., MÉJEAN, A. \& PLOUX, O. 2012. Synthesis, configuration assignment, and simultaneous quantification by liquid chromatography coupled to tandem mass spectrometry, of dihydroanatoxin-a and dihydrohomoanatoxin-a together with the parent toxins, in axenic cyanobacterial strains and in environmental samples. Toxicon, 60, 1404-1414.

MANTEL, N. 1967. The detection of disease clustering and a generalized regression approach. Cancer Research, 27, 209-220.

MANZ, W., WENDT-POTTHOFF, K., NEU, T., SZEWZYK, U. \& LAWRENCE, J. 1999. Phylogenetic composition, spatial structure, and dynamics of lotic bacterial biofilms investigated by fluorescent in situ hybridization and confocal laser scanning microscopy. Microbial Ecology, 37, 225-237.

MCCORMICK, P. V. \& STEVENSON, R. J. 1991. Mechanisms of Benthic Algal Succession in Lotic Environments. Ecology, 72, 1835-1848.

MCGREGOR, G. 2007. Freshwater cyanoprokaryota of north-eastern Australia: Oscillatoriales, Csiro.

MÉJEAN, A., MAZMOUZ, R., MANN, S., CALTEAU, A., MÉDIGUE, C. \& PLOUX, O. 2010. The genome sequence of the cyanobacterium Oscillatoria sp. PCC 6506 reveals several gene clusters responsible for the biosynthesis of toxins and secondary metabolites. Journal of Bacteriology, 192, 5264-5265.

MEZ, K., HANSELMANN, K. \& PREISIG, H. R. 1998. Environmental conditions in high mountain lakes containing toxic benthic cyanobacteria. Hydrobiologia, 368, 1-15.

MILLER, M. B. \& BASSLER, B. L. 2001. Quorum sensing in bacteria. Annual Reviews in Microbiology, 55, 165-199.

MILNE, J. R. \& WATTS, L. F. 2007. Toxic benthic cyanobacteria proliferations in Wellington's rivers in 2005/06, Greater Wellington Regional Council.

MITROVIC, S. M., PFLUGMACHER, S., JAMES, K. J. \& FUREY, A. 2004. Anatoxin-a elicits an increase in peroxidase and glutathione S-transferase activity in aquatic plants. Aquatic Toxicology, 68, 185-192.

MOHAMED, Z. A., EL-SHAROUNY, H. M. \& ALI, W. S. M. 2006. Microcystin production in benthic mats of cyanobacteria in the Nile River and irrigation canals, Egypt. Toxicon, 47, 584-590.

OSSWALD, J., CARVALHO, A., CLARO, J. \& VASCONCELOS, V. 2009. Effects of cyanobacterial extracts containing anatoxin-a and of pure anatoxin-a on early developmental stages of carp. Ecotoxicology and Environmental Safety, 72, 473-478. 
OSSWALD, J., RELLÁN, S., GAGO, A. \& VASCONCELOS, V. 2007. Toxicology and detection methods of the alkaloid neurotoxin produced by cyanobacteria, anatoxin-a. Environment International, 33, 1070-1089.

POHLON, E., MARXSEN, J. \& KÜSEL, K. 2010. Pioneering bacterial and algal communities and potential extracellular enzyme activities of stream biofilms. FEMS Microbiology Ecology, 71, 364-373.

PRIDMORE, R. D. \& ETHEREDGE, M. K. 1987. Planktonic cyanobacteria in New Zealand inland waters: distribution and population dynamics. New Zealand Journal of Marine and Freshwater Research, 21, 491-502.

PRUESSE, E., QUAST, C., KNITTEL, K., FUCHS, B. M., LUDWIG, W., PEPLIES, J. \& GLÖCKNER, F. O. 2007. SILVA: a comprehensive online resource for quality checked and aligned ribosomal RNA sequence data compatible with ARB. Nucleic Acids Research, 35, 7188-7196.

QUIBLIER, C., WOOD, S., ECHENIQUE-SUBIABRE, I., HEATH, M., VILLENEUVE, A. \& HUMBERT, J.-F. 2013. A review of current knowledge on toxic benthic freshwater cyanobacteria-Ecology, toxin production and risk management. Water Research, 47, 5464-5479.

RANTALA-YLINEN, A., KÄNÄ, S., WANG, H., ROUHIAINEN, L., WAHLSTEN, M., RIZZI, E., BERG, K., GUGGER, M. \& SIVONEN, K. 2011. Anatoxin-a synthetase gene cluster of the cyanobacterium Anabaena sp. strain 37 and molecular methods to detect potential producers. Applied and Environmental Microbiology, 77, 7271-7278.

RAPALA, J., LAHTI, K., SIVONEN, K. \& NIEMELÄ, S. I. 1994. Biodegradability and adsorption on lake sediments of cyanobacterial hepatotoxins and anatoxin-a. Letters in Applied Microbiology, $19,423-428$.

RAPALA, J. \& SIVONEN, K. 1998. Assessment of environmental conditions that favor hepatotoxic and neurotoxic Anabaena spp. strains cultured under light limitation at different temperatures. Microbial Ecology, 36, 181-192.

RAPALA, J., SIVONEN, K., LUUKKAINEN, R. \& NIEMELÄ, S. I. 1993. Anatoxin-a concentration in Anabaena and Aphanizomenon under different environmental conditions and comparison of growth by toxic and non-toxic Anabaena-strains - a laboratory study. Journal of Applied Phycology, 5, 581-591.

RICE, A., HAMILTON, M. \& CAMPER, A. 2000. Apparent surface associated lag time in growth of primary biofilm cells. Microbial Ecology, 40, 8-15.

ROESELERS, G., VAN LOOSDRECHT, M. \& MUYZER, G. 2007. Heterotrophic Pioneers Facilitate Phototrophic Biofilm Development. Microbial Ecology, 54, 578-585. 
ROH, S. W., ABELL, G. C. J., KIM, K.-H., NAM, Y.-D. \& BAE, J.-W. 2010. Comparing microarrays and next-generation sequencing technologies for microbial ecology research. Trends in Biotechnology, 28, 291-299.

ROMAN, A. M. \& SABATER, S. 1999. Effect of primary producers on the heterotrophic metabolism of a stream biofilm. Freshwater Biology, 41, 729-736.

ROMANI, A. \& SABATER, S. 2000. Influence of algal biomass on extracellular enzyme activity in river biofilms. Microbial Ecology, 40, 16-24.

SCHLOSS, P. D., WESTCOTT, S. L., RYABIN, T., HALL, J. R., HARTMANN, M., HOLLISTER, E. B., LESNIEWSKI, R. A., OAKLEY, B. B., PARKS, D. H. \& ROBINSON, C. J. 2009. Introducing mothur: open-source, platform-independent, community-supported software for describing and comparing microbial communities. Applied and Environmental Microbiology, 75, 7537-7541.

SEIFERT, M., MCGREGOR, G., EAGLESHAM, G., WICKRAMASINGHE, W. \& SHAW, G. 2007. First evidence for the production of cylindrospermopsin and deoxy-cylindrospermopsin by the freshwater benthic cyanobacterium, Lyngbya wollei (Farlow ex Gomont) Speziale and Dyck. Harmful Algae, 6, 73-80.

SEKAR, R., NAIR, K., RAO, V. \& VENUGOPALAN, V. 2002. Nutrient dynamics and successional changes in a lentic freshwater biofilm. Freshwater Biology, 47, 1893-1907.

SEVILLA, E., MARTIN-LUNA, B., VELA, L., BES, M. T., FILLAT, M. F. \& PELEATO, M. L. 2008. Iron availability affects mcyD expression and microcystin-LR synthesis in Microcystis aeruginosa PCC7806. Environmental Microbiology, 10, 2476-2483.

SHARIF, D. I., GALLON, J. \& SMITH, C. J. 2008. Quorum sensing in Cyanobacteria: N-octanoylhomoserine lactone release and response, by the epilithic colonial cyanobacterium Gloeothece PCC6909. The ISME Journal, 2, 1171-1182.

SMITH, B. \& WILSON, J. B. 1996. A Consumer's Guide to Evenness Indices. Oikos, 76, 70-82.

SMITH, F. 2012. Investigating Cyanotoxin Production by Benthic Freshwater Cyanobacteria in New Zealand. Unpublished doctoral dissertation University of Canterbury.

SMITH, R. \& LEWIS, D. 1987. A rapid analysis of water for anatoxin a, the unstable toxic alkaloid from Anabaena flos-aquae, the stable non-toxic alkaloids left after bioreduction and a related amine which may be nature's precursor to anatoxin a. Veterinary and Human Toxicology, 29, 153-154.

SØNDERGAARD, M., JENSEN, J. P. \& JEPPESEN, E. 2003. Role of sediment and internal loading of phosphorus in shallow lakes. Hydrobiologia, 506, 135-145.

STEVENS, D. K. \& KRIEGER, R. I. 1991. Stability studies on the cyanobacterial nicotinic alkaloid satoxin-A. Toxicon, 29, 167-179. 
SUN, J. \& LIU, D. 2003. Geometric models for calculating cell biovolume and surface area for phytoplankton. Journal of Plankton Research, 25, 1331-1346.

SURAKKA, A., SIHVONEN, L. M., LEHTIMÄKI, J. M., WAHLSTEN, M., VUORELA, P. \& SIVONEN, K. 2005. Benthic cyanobacteria from the Baltic Sea contain cytotoxic Anabaena, Nodularia, and Nostoc strains and an apoptosis-inducing Phormidium strain. Environmental Toxicology, 20, 285-292.

TEAM, R. D. C. 2010. R: A language and environment for statistical computing. R Foundation for Statistical Computing. Vienna, Austria.

UTERMÖHL, H. 1958. Zur Vervollkommung der quantitativen Phytoplankton Methodik Verhand Internat Verein Theor Angew Limnol 9, 1-38.

VARDI, A., SCHATZ, D., BEERI, K., MOTRO, U., SUKENIK, A., LEVINE, A. \& KAPLAN, A. 2002. Dinoflagellate-cyanobacterium communication may determine the composition of phytoplankton assemblage in a mesotrophic lake. Current Biology, 12, 1767-1772.

VINTEN, A. J. A., ARTZ, R. R. E., THOMAS, N., POTTS, J. M., AVERY, L., LANGAN, S. J., WATSON, H., COOK, Y., TAYLOR, C., ABEL, C., REID, E. \& SINGH, B. K. 2011. Comparison of microbial community assays for the assessment of stream biofilm ecology. Journal of Microbiological Methods, 85, 190-198.

WARD, D. \& CASTENHOLZ, R. 2002. Cyanobacteria in geothermal habitats. The Ecology of Cyanobacteria, 37-59.

WOOD, S. A. 2004. Bloom Forming and Toxic Cyanobacteria in New Zealand Species Diversity and Distribution, Cyanotoxin Production and Accumulation of Microcystins in Selected Freshwater Organisms. PhD, Victoria Univeristy of Wellington.

WOOD, S. A., HEATH, M. W., KUHAJEK, J. \& RYAN, K. G. 2010. Fine-scale spatial variability in anatoxin-a and homoanatoxin-a concentrations in benthic cyanobacterial mats: implication for monitoring and management. Journal of Applied Microbiology, 109, 2011-2018.

WOOD, S. A., HOLLAND, P. T., STIRLING, D. J., BRIGGS, L. R., SPROSEN, J., RUCK, J. G. \& WEAR, R. G. 2006. Survey of cyanotoxins in New Zealand water bodies between 2001 and 2004. New Zealand Journal of Marine and Freshwater Research, 40, 585-597.

WOOD, S. A., KUHAJEK, J. M., DE WINTON, M. \& PHILLIPS, N. R. 2012a. Species composition and cyanotoxin production in periphyton mats from three lakes of varying trophic status. FEMS Microbiology Ecology, 79, 312-326.

WOOD, S. A., RUECKERT, A., COWAN, D. A. \& CARY, S. C. 2008. Sources of edaphic cyanobacterial diversity in the Dry Valleys of Eastern Antarctica. The ISME journal, 2, 308-320. 
WOOD, S. A., SELWOOD, A. I., RUECKERT, A., HOLLAND, P. T., MILNE, J. R., SMITH, K. F., SMITS, B., WATTS, L. F. \& CARY, C. S. 2007. First report of homoanatoxin-a and associated dog neurotoxicosis in New Zealand. Toxicon, 50, 292-301.

WOOD, S. A., SMITH, F. M. J., HEATH, M. W., PALFROY, T., GAW, S., YOUNG, R. G. \& RYAN, K. G. 2012b. Within-Mat Variability in Anatoxin-a and Homoanatoxin-a Production among Benthic Phormidium (Cyanobacteria) Strains. Toxins, 4, 900-912.

WOOD, S. A. \& YOUNG, R. G. 2012. Review of Benthic Cyanobacteria Monitoring Programme 2012. Prepared for Horizon Regional Council.

ŽEGURA, B., ZAJC, I., LAH, T. T. \& FILIPIČ, M. 2008. Patterns of microcystin-LR induced alteration of the expression of genes involved in response to DNA damage and apoptosis. Toxicon, 51, 615623.

ZHANG, J., CHEN, S.-A., ZHENG, J.-W., CAI, S., HANG, B.-J., HE, J. \& LI, S.-P. 2012. Catellibacterium nanjingense sp. nov., a propanil-degrading bacterium isolated from activated sludge, and emended description of the genus Catellibacterium. International Journal of Systematic and Evolutionary Microbiology, 62, 495-499.

ZILLIGES, Y., KEHR, J.-C., MEISSNER, S., ISHIDA, K., MIKKAT, S., HAGEMANN, M., KAPLAN, A., BÖRNER, T. \& DITTMANN, E. 2011. The cyanobacterial hepatotoxin microcystin binds to proteins and increases the fitness of Microcystis under oxidative stress conditions. PloS One, 6, e17615. 


\section{Appendix}

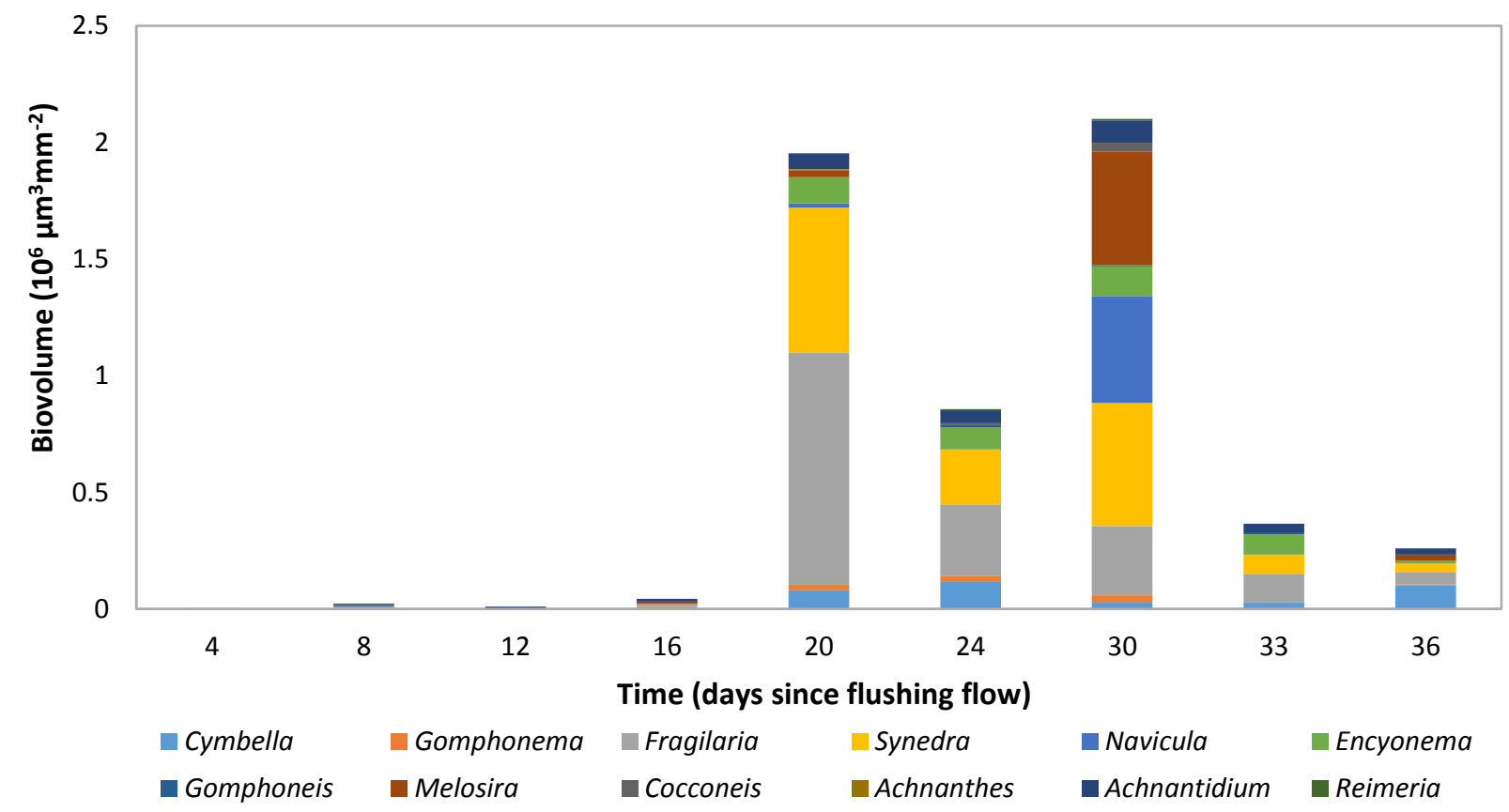

Appendix 1 Proportion of each diatom genus comprising the total biovolume of diatoms from Site 1, sampled between 9 February and 13 March $2013(n=3)$.

Appendix 2 One-Way Analysis of Variance for micro-algal diversity $\left(H^{\prime}\right)$.

\begin{tabular}{ccccccc}
\hline & df & SS & MS & $\boldsymbol{F}$ & Significance & Obs. Power \\
\hline Day & 8 & 0.753 & 0.094 & 2.103 & 0.091 & 0.657 \\
Residual (error) & 18 & 0.805 & 0.045 & & & \\
Total & 27 & 9.293 & & & & \\
\hline
\end{tabular}

Appendix 3 One-Way Analysis of Variance for bacterial (ARISA peaks) diversity $\left(H^{\prime}\right)$.

\begin{tabular}{ccccccc}
\hline & df & SS & MS & $\boldsymbol{F}$ & Significance & Obs. Power \\
\hline Day & 8 & 0.116 & 0.015 & 0.46 & 0.868 & 0.158 \\
Residual (error) & 18 & 0.568 & 0.032 & & & \\
\hline
\end{tabular}


Appendix 4 Samples from Site 1 that were successfully extracted, PCR amplified, purified and sent for MiSeq Illumina ${ }^{\mathrm{TM}}$ sequencing. Results from this analysis were not received in time for inclusion in this thesis.

\begin{tabular}{|c|c|c|c|}
\hline & Rock \# & $\begin{array}{l}\text { DNA volume } \\
\text { amplified } \\
(\mu \mathrm{L})\end{array}$ & $\begin{array}{c}\text { DNA } \\
\text { Concentration } \\
(\mathrm{ng} / \mu \mathrm{L})\end{array}$ \\
\hline \multirow[t]{2}{*}{ D8 } & 3 & 6 & 4.06 \\
\hline & 5 & 6 & 2.82 \\
\hline \multirow[t]{3}{*}{ D12 } & 2 & 3 & 2.78 \\
\hline & 3 & 5 & 4.36 \\
\hline & 5 & 6 & 2.06 \\
\hline \multirow[t]{2}{*}{ D16 } & 2 & 3 & 13.3 \\
\hline & 3 & 3 & 11 \\
\hline \multirow[t]{2}{*}{ D20 } & 2 & 3 & 19.4 \\
\hline & 3 & 6 & 5.3 \\
\hline \multirow[t]{3}{*}{ D24 } & 2 & 3 & 22.8 \\
\hline & 3 & 3 & 15 \\
\hline & 5 & 5 & 10.9 \\
\hline \multirow[t]{3}{*}{ D30 } & 2 & 3 & 6.26 \\
\hline & 3 & 5 & 12.1 \\
\hline & 5 & 5 & 15.5 \\
\hline D33 & 3 & 3 & 18.6 \\
\hline \multirow[t]{2}{*}{ D36 } & 3 & 3 & 26 \\
\hline & 5 & 2 & 17.2 \\
\hline
\end{tabular}


Appendix 5 Summary of average $(\mathrm{n}=3)$ micro-algal biovolumes $\left(\mu \mathrm{m}^{3} \mathrm{~mm}^{2}\right.$; unshaded rows) and cell concentrations $\left(\mathrm{cells}^{2} \mathrm{~mm}^{2}\right.$; shaded rows) for each taxon; sampled from Site 1 between 9 February and 13 March 2013.

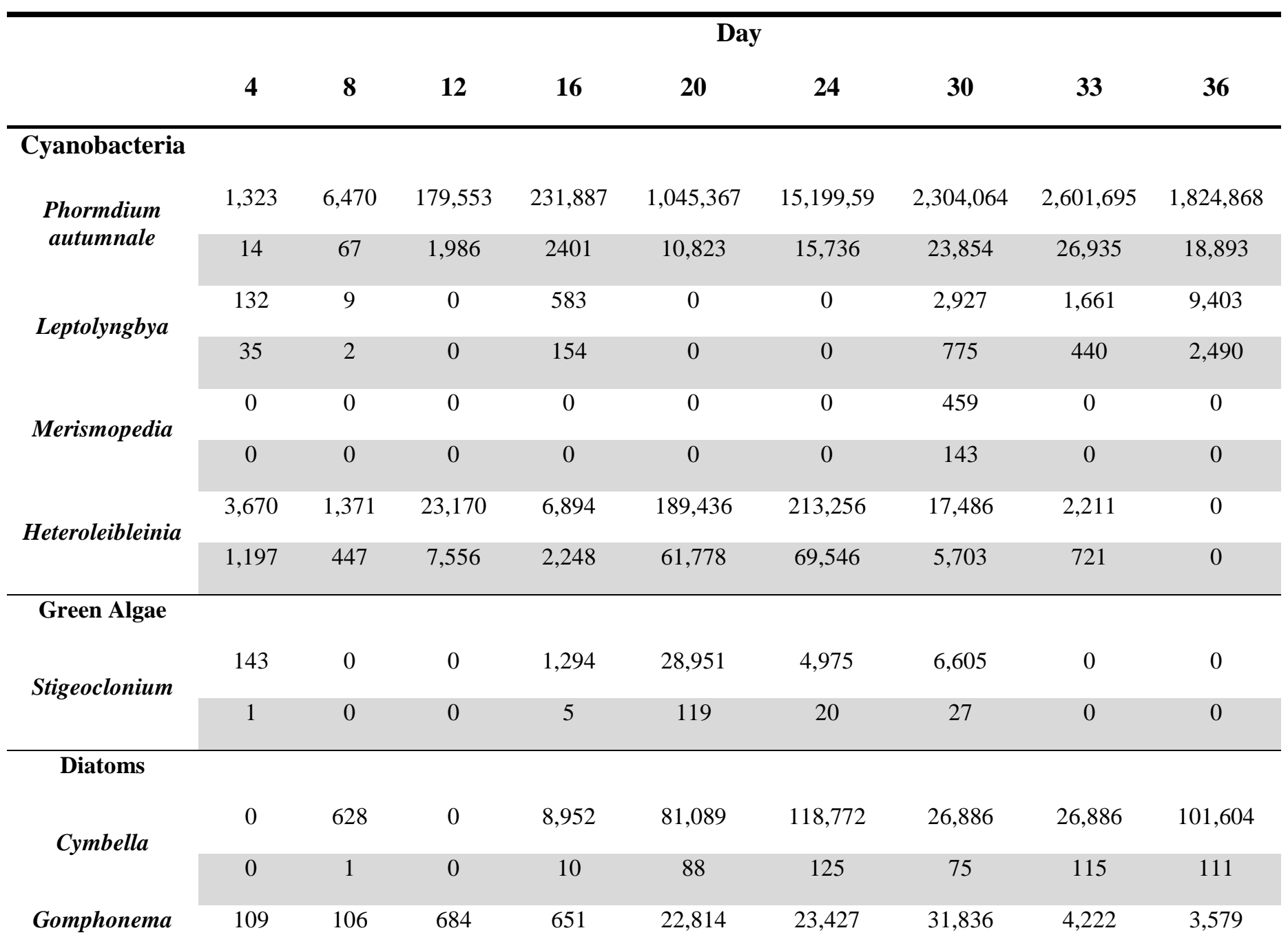




\begin{tabular}{|c|c|c|c|c|c|c|c|c|c|}
\hline & 2 & 2 & 14 & 13 & 460 & 473 & 642 & 85 & 72 \\
\hline \multirow{2}{*}{ Fragilaria } & 217 & 2,190 & 2,377 & 10,994 & 993,812 & 303,369 & 296,207 & 119,778 & 50,757 \\
\hline & 0 & 4 & 4 & 20 & 1,792 & 547 & 534 & 216 & 92 \\
\hline \multirow{2}{*}{ Synedra } & 0 & 5,822 & 0 & 0 & 622,838 & 238,504 & 528,754 & 82,794 & 39,045 \\
\hline & 0 & 1 & 0 & 0 & 78 & 30 & 66 & 10 & 5 \\
\hline \multirow{2}{*}{ Navicula } & 497 & 9,769 & 0 & 0 & 17,898 & 0 & 456,588 & 0 & 0 \\
\hline & 0 & 3 & 0 & 0 & 5 & 0 & 135 & 0 & 0 \\
\hline \multirow{2}{*}{ Encyonema } & 0 & 182 & 331 & 993 & 113,112 & 94,628 & 128,994 & 86,378 & 10,852 \\
\hline & 0 & 0 & 0 & 1 & 151 & 126 & 172 & 115 & 14 \\
\hline \multirow{2}{*}{ Gomphoneis } & 0 & 108 & 0 & 0 & 0 & 9,786 & 4,619 & 4,994 & 0 \\
\hline & 0 & 0 & 0 & 0 & 0 & 20 & 9 & 10 & 0 \\
\hline \multirow{2}{*}{ Melosira } & 0 & 1,369 & 0 & 10,838 & 28,202 & 0 & 487,062 & 0 & 27,538 \\
\hline & 0 & 0 & 0 & 2 & 5 & 0 & 86 & 0 & 5 \\
\hline \multirow{2}{*}{ Cocconeis } & 641 & 423 & 1,078 & 0 & 4,362 & 8,775 & 37,561 & 0 & 0 \\
\hline & 1 & 0 & 1 & 0 & 5 & 10 & 43 & 0 & 0 \\
\hline \multirow{2}{*}{ Achnanthes } & 0 & 284 & 0 & 340 & 2,886 & 0 & 0 & 0 & 0 \\
\hline & 0 & 1 & 0 & 1 & 5 & 0 & 0 & 0 & 0 \\
\hline \multirow{2}{*}{ Achnantidium } & 1,147 & 1,979 & 6,430 & 11,695 & 66,670 & 54,153 & 95,861 & 40,561 & 26,008 \\
\hline & 5 & 8 & 26 & 48 & 273 & 222 & 393 & 166 & 107 \\
\hline \multirow{2}{*}{ Reimeria } & 0 & 247 & 0 & 0 & 0 & 5,250 & 6,588 & 0 & 0 \\
\hline & 0 & 1 & 0 & 0 & 0 & 15 & 19 & 0 & 0 \\
\hline
\end{tabular}




\begin{tabular}{cccccccccc}
\hline Desmidaceae & & & & & & & & \\
Clostarium & 0 & 0 & 0 & 0 & 6,428 & 0 & 0 & 0 & 0 \\
& 0 & 0 & 0 & 0 & 100 & 0 & 0 & 0 & 0 \\
Cosmarium & 0 & 0 & 0 & 123 & 12,704 & 0 & 0 & 6,950 & 11,280 \\
& 0 & 0 & 0 & 1 & 65 & 0 & 0 & 36 & 58 \\
\hline
\end{tabular}

